University of San Diego

Digital USD

2003

\title{
"You are with Someone Who is a Fighter": Constructing a Model of Transformation which Can Occur in Surviving Breast Cancer
}

Helen Hays Eckmann EdD

University of San Diego

Follow this and additional works at: https://digital.sandiego.edu/dissertations

Part of the Leadership Studies Commons

\section{Digital USD Citation}

Eckmann, Helen Hays EdD, "'You are with Someone Who is a Fighter": Constructing a Model of Transformation which Can Occur in Surviving Breast Cancer" (2003). Dissertations. 707.

https://digital.sandiego.edu/dissertations/707

This Dissertation: Open Access is brought to you for free and open access by the Theses and Dissertations at Digital USD. It has been accepted for inclusion in Dissertations by an authorized administrator of Digital USD. For more information, please contact digital@sandiego.edu. 


\title{
"YOU ARE WITH SOMEONE WHO IS A FIGHTER": \\ CONSTRUCTING A MODEL OF TRANSFORMATION \\ WHICH CAN OCCUR IN SURVIVING \\ BREAST CANCER
}

\author{
A Dissertation \\ Presented to the \\ Faculty of \\ University of San Diego \\ In Partial Fulfillment \\ of the Requirements for the Degree \\ Doctor of Education \\ in \\ Organizational Leadership
}

by

Helen Hays Eckmann

Spring, 2003 
(C) 2003

by

Helen Hays Eckmann

Reproduced with permission of the copyright owner. Further reproduction prohibited without permission. 


\section{ACKNOWLEDGEMENTS}

First, I acknowledge my husband, Jim, who has encouraged me and taught me about leadership, courage, ethics and the value of hard work by the way he lives and the way he loves me.

Thank you to my chair, Dr. Kathleen Collins, for encouraging me to write both what I know and what I think. Thanks also to Dr. Bob Donmoyer, and to his wife, June, for their incredible talent, support, enthusiasm, guidance and joy concerning this work. I also thank Dr. Dan Miller and Dr. Fred Galloway for encouraging me through the sensitive nature of this work.

Thank you also to Dr. Ruth Behar for her assistance and suggestions on the methodology section of this work.

I thank the women who love me and have helped me through this work: Billie Sue Holt, Alana Nicastro, Leigh Wren Salem and Shelly Marks Valdez.

I thank my daughters and daughters-in-law who have helped me to become even more aware of the beauty of being a woman: Laura Eckmann, Laura Hays Galloway, Sharla Hays and Kara Eckmann Powell. I thank my grandchildren, Hannah Hastings, Hali and Emma Galloway, Nathan and Krista Powell and those children who are to follow.

I thank the women of this study who demonstrate the ways that crisis can reveal character. Their stories bring honesty and courage to other survivors and to myself. Lastly, I thank God that I am alive. 


\section{TABLE OF CONTENTS}

PAGE

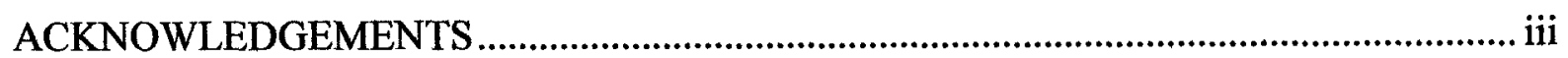

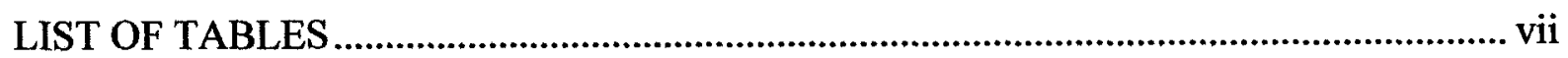

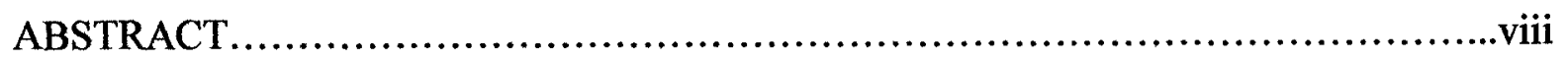

CHAPTER

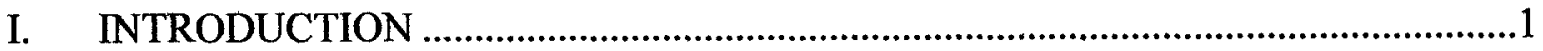

Overview...............................................................

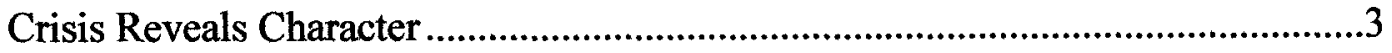

Leadership, Transformation and Storytelling .................................................9

Implications for the Current Work.................................................................10

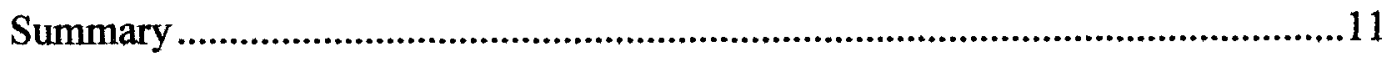

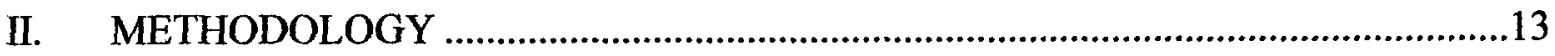

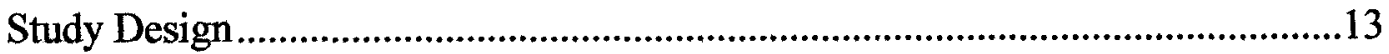

Participants................................................................ 18

Interview Procedures...................................................21

Data Analysis......................................................24

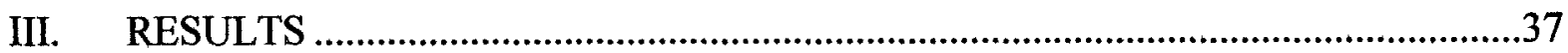

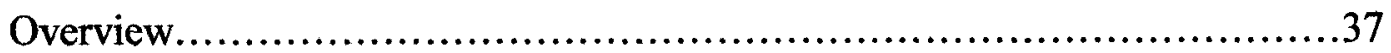

Theme One- Surprise/Suspense...................................... 37

Theme Two - Study............................................. 38

Theme Three - Separation..............................................38

Theme Four - Surrender/Reflection..................................... 39 


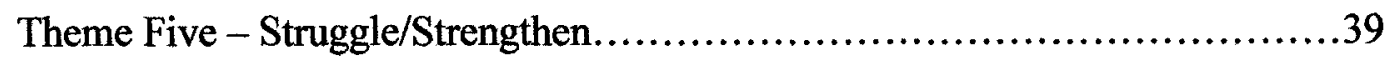

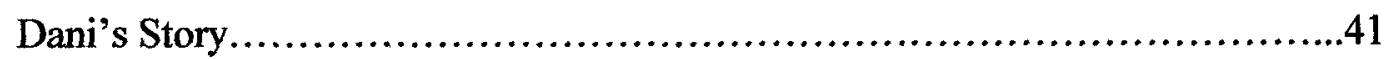

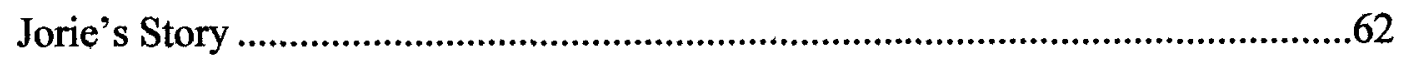

Arlene's Story ……………...................................................................................74

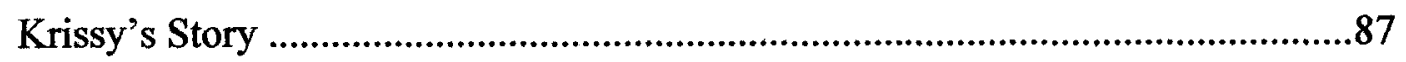

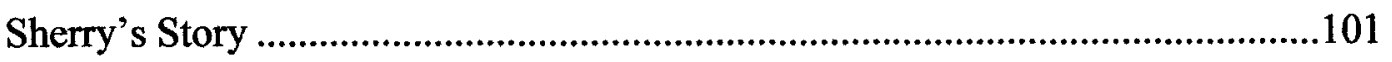

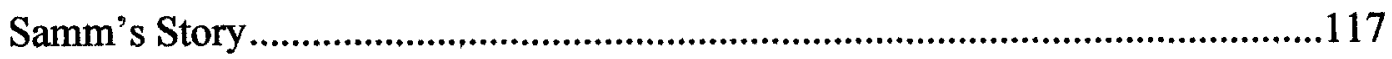

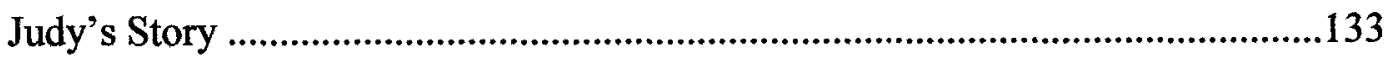

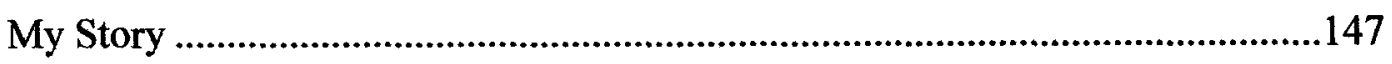

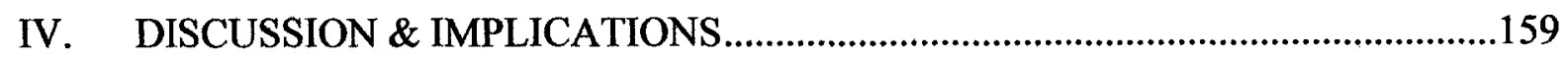

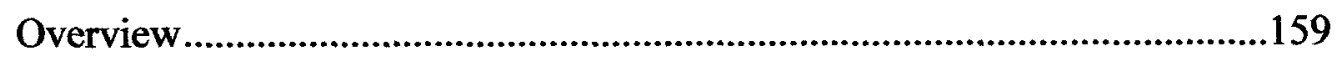

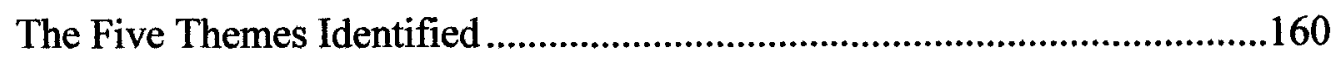

The Five Themes Became Stages ......................................................................163

The Five Stages Become the Sophia Model .....................................................163

Details of Stage One-This can't be happening to me.".................................168

Details of Stage Two- “I want to get smarter than cancer."............................170

Details of Stage Three_-"I felt that I had just lost my old life." .....................171

Details of Stage Four - “You have to accept your body all over again."......174

Details of Stage Five_-"You are with someone who is a fighter." .................175

Reactions from the Women of this Study to the Five Themes and to the

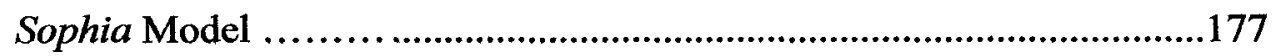

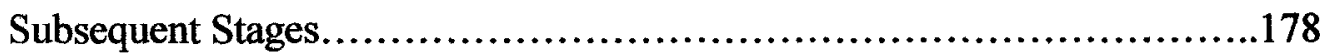

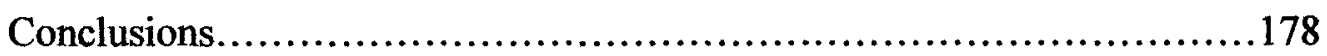

Explanation of Tables/Appendices .......................................182 


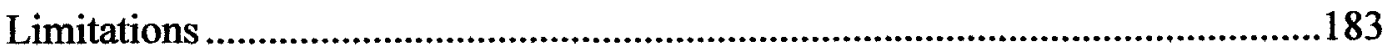

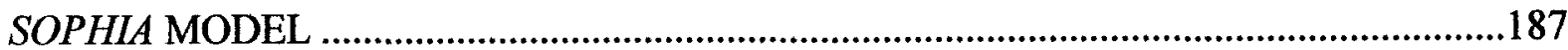

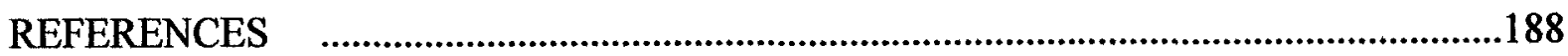

APPENDICES

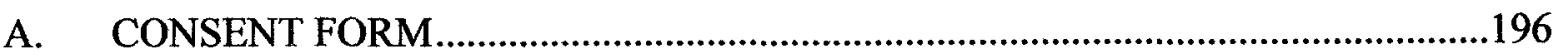

B. LETTER TO PARTICIPANTS 1) To verify transcript.................................................198

C. LETTER TO PARTICIPANTS 2) To verify themes/model ..........................................200

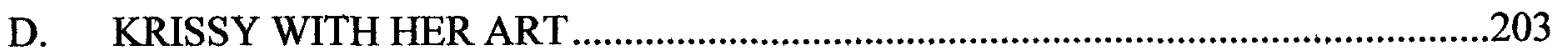

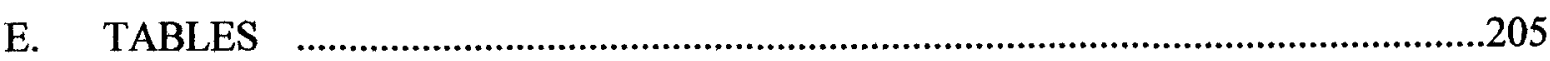

Table 1 - Ages and Dates ..............................................................................206

Table 2 - Family Factors ..................................................................................207

Table 3 - Methods of Diagnosis .......................................................................208

Table 4 - Methods of Treatment................................................................209

Table 5 - Other Factors.............................................................................210

F. ADVICE FROM THE WOMEN OF THIS STUDY ..............................................211

To Newly Diagnosed Women..........................................................................212

To Someone who loves a Newly Diagnosed Woman.......................................213

To Those who work with a Newly Diagnosed Woman....................................214

To the Doctors who Treat Women With Breast Cancer ..................................215 


\section{LIST OF TABLES}

TABLE

PAGE

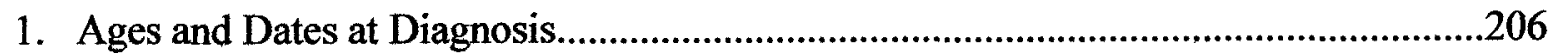

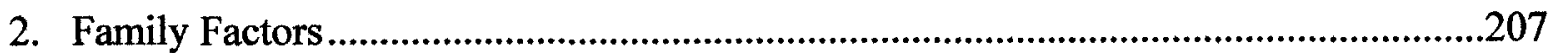

3. Methods of Diagnosis/Node Involvement ...............................................................208

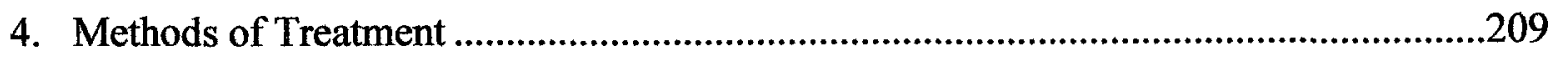

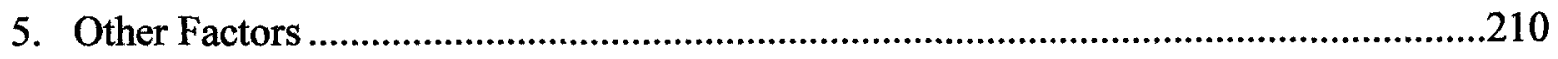




\section{ABSTRACT \\ "You Are With Someone Who Is a Fighter"}

The American Cancer Society estimated a quarter of a million women would be diagnosed with breast cancer in 2002 . For each of those, another ten women are living with or have survived this disease. At diagnosis, most women view their futures with dread. As with other extreme traumas, the diagnosis of breast cancer can bring profound transformation (Jackson, 1983; LeShan, 1994; O'Brien, 1995). In this study, seven survivors of breast cancer articulate their journeys through this disease and detail how they were able construct transformed lives. The women described how they turned tragedy into triumph.

Individual interviews were conducted and were subjected to both narrative analysis (the analysis of their individual stories) and to analysis of narrative (a cross-story analysis) as described by Polkinghorne $(1991,1995)$. In the narrative analysis the details of each woman's journey are presented as individual stories to demonstrate the decisions and events that led to transformation. In the analysis of narratives, those stories were coded and group themes identified. This second stage of analysis revealed that a systematic transformation process was present in each narrative. Using autoethnography (Ellis \& Bochner, 2000; Gravel, 1995) the story of the author (a three-time breast cancer survivor) was incorporated into the analysis and themes. A model is presented with five stages of transformation evident across all the narratives.

This study will bring hope to women who have been diagnosed with breast cancer and to those who love, know, or work with them. This work also brings practical insight into the process of transformation. This perspective on transformation can be used to assist individuals and organizations to view crisis as a possible starting point for transformation. 


\section{CHAPTER I}

\section{INTRODUCTION}

"I Am Scared. I Am Scared to Death."

Overview

Dr. Susan Love, ${ }^{1}$ (1995) M.D., MBA, and former director of the U.C.L.A. Breast

Center, has stated "One in nine women will develop breast cancer in her lifetime" (p. 167). Joyce Wadler ${ }^{2}$ (1992) also commented that the women diagnosed, and their stories of death or survival, can be found in every corner of our society, and that the "story" of breast cancer diagnosis is the story of

many women, young and old, gay and straight, poor and well to do, black and white. It is a story of a forty-four year-old career woman in New York and of a married woman of thirty-five with young kids, living in the Midwest. It is the story of an elderly widow and a young lesbian. This disease strikes all kinds of women indiscriminately and too often kills them. (Wadler, 1992, p. 167)

The American Cancer Society (2001) estimates that breast cancer incidence is growing at approximately $3 \%$ a year. This rate of incidence and growth makes breast cancer an epidemic (Pert, 1997). According to the American Cancer Society (2001), approximately 175,000 women in 1999 and 182,800 women in 2000 were diagnosed with breast cancer.

\footnotetext{
${ }^{1}$ Dr. Love is currently an adjunct professor of surgery at U.C.L.A. Medical Center. She was appointed by President Clinton to the National Cancer Advisory Board in 1998. Her book, Dr. Susan Love's Breast Book, is a leading work on the disease.

${ }^{2}$ Joyce Walder is an author and a New York Times columnist; her story is a personal narrative about surviving breast cancer.
} 
Based upon those statistics and survival rates, there are over two million women in the United States who are currently surviving this disease (California Cancer Registry, 2002).

Presently, there is no cure for this disease. For a number of reasons, including improvements in screening and treatment, diagnosed women are enjoying longer life expectancies each year. In the $1940 \mathrm{~s}$, for instance, only $72 \%$ of breast cancer patients survived for more than five years after diagnosis. Women diagnosed in 2002 have a $96 \%$ chance of surviving five years, and $71 \%$ will survive for ten years or more (American Cancer Society, 2002). Breast cancer mortality rates are now 20 percent lower than they were 25 years ago (California Cancer Registry, 2002). Thus, more women are surviving and are living longer after being diagnosed with breast cancer.

Yet statistics only reveal part of the problem. They do not reveal the dread and fear with which many women, starting at very young ages, view this disease. Statistics also do not reveal the stories of triumph and transformation that many women have experienced in the process of surviving this disease, nor do they offer the lessons and transformed lives that many survivors have experienced. This study explores what can be learned from the stories of breast cancer survivors who have consciously responded to the disease by transforming their lives.

This study was designed to give voice to the stories that statistics don't tell. The purpose of this work was to learn from and to air the stories of seven ${ }^{3}$ women who have not only survived this disease but also transformed their lives in response to their illness. The stories offer those who follow them a guide for their journeys. The goal of this work was to highlight the lives, voices and stories of women whose lives unexpectedly changed for the

\footnotetext{
${ }^{3}$ Seven women were interviewed for this study; the addition of my story makes eight.
} 
better after surviving this disease. Each woman described a unique and surprising journey that included a transformation within themselves or in their homes, or in their work, and in some cases, their communities.

This study was informed by two bodies of literature: (a) texts that identify where and when crisis can reveal character, and (b) research texts that link storytelling to transformation, and result in increased leadership. Both of these literatures will now be discussed.

Crisis Reveals Character

There is a significant body of literature based on the transformational experience that can result from crisis. This literature came from individual experiences (Hagberg, 1994; Remen, 1996; Sacks, 1970; Wadler, 1992) and from medical science (Hirshberg \& Barasch, 1995; LeShan, 1994). It shows how, after surviving a crisis, individuals can find their lives more meaningful (Montada, 1992; Moran, 1987). For example, after conducting a research project with several thousand cancer patients over a thirty-five year period, LeShan (1994) found evidence that some individuals who survive cancer consider themselves as having more insight, power and direction after recovery. The story of one of LeShan's research subjects, Karen, is told in detail as an example:

Karen had been raised in a family in which there was a very great stress on the fact that a "good" person takes care of other people and puts his or her own needs second. Karen had always loved to draw. More than anything else she wanted to be a commercial artist. Her family, however, did not view this as an occupation that contributed to the good of humanity, and it was therefore unacceptable. Karen therefore studied school administration in college and 
went into this field. As she put it, "Art is everything for me so I gave it up to take care of others. To do what I should." When I [Le Shan] questioned her further on this, she said, "I was always taught that I must do the things I should do rather than what I want to do."

She was successful in her chosen career and rose fairly rapidly in the school system. She brought high intelligence and a high energy level to her work and is one of those people who probably would have been successful in anything to which she applied herself, no matter what her personal likes and dislikes were about the field.

In her early thirties she developed a rapidly growing breast cancer with metastases to the lymph nodes. She brought a large briefcase of papers from her office and planned to take care of them in the hospital while recuperating from a mastectomy.

The day before surgery was scheduled, Karen suddenly felt a great freedom. It was, she said, as if a tremendous load had been suddenly lifted from her shoulders. She felt, "I have cancer. Therefore I can now do what I want. I don't have to take care of these papers. I can draw again."

During her recuperation, she spent most of her time with sketchpad and pencils instead of the professional papers in her briefcase. The results of the mastectomy were excellent. No further symptoms were seen for seven years, after which a small node appeared on the scar tissue. A biopsy was inconclusive and further surgery was advised. Karen decided instead on a wait-and-watch policy. She started to pay even more attention to her needs as 
a person and as an artist. She took up working with watercolors, something she had wanted to do for a long time but "had just never gotten around to it." After three months the node disappeared and no further symptoms were noted in the following ten years. She says her life is full and rich "and there is always so much more to learn how to do." (LeShan, 1994, pp. 120-121)

Karen's story highlights how the crisis of being diagnosed with breast cancer can help someone to reevaluate her life. This reevaluation caused Karen to decide to construct her life in a way that more closely resembled her own desires rather than those she felt were imposed by her family. The diagnosis of cancer provided Karen with the opportunity to reset her life priorities. After diagnosis Karen gained a perspective that offered a new direction for her work and for her life. She gave up a stressful job and began to fulfill her lifelong desire to paint. Karen transformed her life.

Another example of how crisis can reveal character is found in Frankl's (1984) Man's search for meaning. Frankl tells the poignant story of what he learned as a result of his incarceration in a concentration camp at Auschwitz:

Most important, however, is the third avenue to the meaning of life. Even the helpless victim of a hopeless situation, facing a fate he cannot change, may rise above himself, may grow beyond himself, and by so doing change himself. He may turn personal tragedy into a triumph. (p. 170)

Frankl described his life in a German prison camp as an awakening to the knowledge that each day might be his last. He daily faced starvation and was at the mercy of merciless prison guards. He was unable to control his external world but he was able to control his thoughts. In the midst of this unthinkable deprivation and crisis, Frankl discovered that he 
could transform his life by purposefully crafting his thought life. After accepting that he could not control his captors' behaviors, he purposefully created an interior world that was rich, deep, full of meaning, and filled with beautiful memories of his former life with his wife. Frankl described the contrast of the world provided by his captors and the interior world he constructed for himself:

For hours I stood hacking at the icy ground. The guard passed by, insulting me, and once again I communed with my beloved. More and more I felt that she was present, that she was with me; I had the feeling that I was able to touch her, able to stretch out my hand and grasp hers. The feeling was very strong: she was there (emphasis his). Then at that very moment a bird flew down silently and perched just in front of a heap of soil, which I had dug up from the ditch, and looked steadily at me. (p. 89)

Frankl explained this process, "The way in which a man accepts his fate and all the suffering it entails, the way in which he takes up his cross, gives him ample opportunity even under the most difficult circumstances - to add a deeper meaning to his life" (p. 88). Frankl had very little that he could control in his world.

Like Karen and Frankl, the women of this study found themselves confronted by a series of events over which, at first, they thought they had little or no control. The women in the current study, like Frankl, described the ways in which they took control of their lives in the midst of a crisis. The women described the ways they found new and deeper meaning for their lives and turned what first appeared to be tragedy into a triumph.

An assumption of this study is that a crisis can lead to a series of decisions and events that can lead to a transformed life. Women's studies literature contains examples of women 
transforming themselves into more powerful selves after surviving a crisis (Dietrich \& Shabad, 1989; Jackson, 1983; Lather \& Smithies, 1997). Gilligan (1982), for example, described how a crisis affected some of the women in her study:

"Crisis reveals character" says one of the women as she searches for the problem within herself. That crisis also creates character is the essence of a developmental approach. The changes described in women's thinking about responsibility and relationship suggests that the capacity for responsibility and care evolves through a coherent sequence of feelings and thoughts. As the events of women's lives and of history intersect with their feelings and thoughts, a concern with individual survival comes to be branded as "selfish" and to be counter-imposed to the "responsibility" of a life lived in relationships. And in turn, responsibility becomes, in its conventional interpretation, confused with a responsiveness to others that impedes recognition of self. (p. 126)

Gilligan explained that some women's capacity for self-responsibility evolved through surviving a crisis. She described how the events of a woman's life could connect her more closely with a desire to survive, and to survive with an increased capacity for a meaningful life.

Similarly, Hagberg (1994) in her book, Real Power, explained, "Women's lives, in general, are not predictable, awakened by crises and shocks, not by gradually evolving development" (p. 189). She continued: 
When women decide what they want out of life, they then begin to take themselves more seriously and to invest in themselves. They realize that there are a wider variety of possibilities for them. (p. 189)

Hagberg further stated that crisis could lead to a transformation that would reveal character. "This can only come out of an intense and honest inner conversation in which life's priorities are set" (p. 99). She described this inner conversation:

What are my real strengths, weaknesses, interests, and values? What do I really want out of life and work? How can I be respected and competent and still be true to myself? It involves finding out who you are rather than who you thought you should be in order to get ahead or prove yourself. It is more authentic and successful in the long run. (p. 193)

The stories of the women of this study highlighted the progression of realizations for greater possibilities that accompanied surviving this disease (Hirshberg \& Barasch, 1995; LeShan, 1994). After diagnosis the women described how they considered new possibilities for their lives. Some took leadership positions for the first time (Bridges, 1980; Bruner, 1986; Jaworski, 1998). After diagnosis the women of this study extended and invested themselves in deeper and more meaningful ways, including their work, families, or communities. Three of the women in this study ventured into national politics. These new ways of investing in themselves were unimagined before the diagnosis and survival of breast cancer. This study demonstrated that some women for the first time in their lives were awakened and energized into exciting and new leadership opportunities by the awakening provided by the survival of breast cancer. 
Leadership, Transformation and Storytelling

There is a connection among leadership, transformation and the telling of stories. One of the seminal texts on leadership written by Burns (1978) is titled simply Leadership. Burns, an historian, naturally gravitated to the stories of great men to explain the emerging field of leadership. Burns said, "The study of leadership in general will be advanced by looking at leaders in particular. The development of certain leaders or rulers is described not in order to 'solve' leadership problems or necessarily to predict what kind of leader a person might become, but to raise questions inherent in the complexity of leadership process" ( $p$. 27).

A recent example of combining leadership and transformation studies with the genre of storytelling is found in the Harvard Business Review, Collingwood (2001). Collingwood described leadership theory by telling the stories of 17 leaders (three of them women), and showed the linkage between stories, leadership and transformation. Collingwood used stories to explain how these leaders accomplished transformation in their organizations. Numerous authors in the field of leadership have used stories to illustrate these principles in the field (see, e.g., Bennis, 1996; Collins, 2001; Collins \& Porras, 1994; Gardner; 1990; Mink, 1993; Northouse, 2001; O'Toole, 1995).

O'Toole (1995) in Leading Change: Overcoming the ideology of comfort and the tyranny of custom, explained his theory of values-based leadership (integrity, trust and respect for followers) using the stories of the four American Presidents whose likenesses are carved on Mount Rushmore: Presidents Washington, Lincoln, Roosevelt and Jefferson. He referred to these men as "Rushmoreans." $O$ 'Toole then chose four modern day "Corporate Rushmoreans" and stated: 
If I were a sculptor, I'd chisel a Mount Rushmore frieze of corporate leaders. Choosing the quartet to portray would be harder than choosing American's four greatest presidents, so I'd make the task easier for myself by arbitrarily limiting the candidates to living CEO's of large, publicly held corporations. (p. 41)

He continued his explanation of his theory of values based leadership by telling the stories of four well-known CEO's: Herman Miller's Max De Pree, Corning's James Houghton, Motorola's Robert Galvin, and Scandinavian Airline's Jan Carlzon (p. 41). O'Toole used their stories to explain how they incorporated integrity, trust and respect for followers as they transformed their organizations. He illustrated the link between leadership, transformation and the telling of stories.

\section{Implications for the Current Work}

The focus of this study was to explore the development of transformation in the lives of seven breast cancer survivors through analysis of the stories they told of their survival. For the purposes of this work "transformation" will be defined as the improvement in an activity, expression or component of a participant's life. The women of this study described new and powerful ways in which they demonstrated leadership in their lives, families, communities or work.

A preliminary study on this topic was completed using the stories of two women who self identified as having a transformed life after surviving breast cancer. For the current work, their two stories were added to five additional breast cancer survivor's stories. One of the two women from the preliminary study described her work prior to breast cancer as "high-level administration." At the time of the interview she happily described herself as an 
"entrepreneur." After breast cancer she redefined her life, quit her job and started her own successful business. Each of the women of this study distinguished between her former life (i.e., pre-diagnosis) and her current life and described having risen above their former views of themselves. As one of the women said, she learned "Girls kick ass."

This topic was chosen with special care because I, too, am a breast cancer survivor. I knew that I had entered a different world after surviving this disease. I knew that I was transformed. My story of surviving breast cancer is told last. As can be seen from the stories, no two are the same yet common themes were identified. Although each of the women of this study experienced an unwanted journey through diagnosis and treatment of breast cancer, the transformation each woman experienced was unique.

Summary

The purpose of the current study was to look at the connections among crisis and leadership and transformation. There is a rich tradition of literature that identifies that crisis can reveal character (Frankl, 1984; Gilligan, 1982, Hagberg, 1994). Further, there is a tradition in the literature on leadership, transformation and use of storytelling as a learning tool (Bennis, 1996; Collins, 2001, Collins \& Porras, 1994; Gardner, 1990, Mink, 1993; Northouse, 2001; O'Toole, 1995). The stories of seven women who self-identified as having transformed lives as the result of surviving breast cancer was added to my own and together provided the landscape for exploring the connection among crisis, transformation and leadership.

This study will benefit women who have been or will be diagnosed with this disease as well as those who love, live or work with them. The women of this study described how they began to take their lives differently and began to exercise new or different leadership 
after this disease. The women, though each had remarkably different lives at the time of diagnosis, described broad themes of experience and transformation as they progressed through to recovery. After analysis, these themes became a staged model for transformation following the crisis of diagnosis of breast cancer.

Two layers of analysis were performed on the data (Polkinghorne, 1991; 1995). The first layer of analysis is the arrangement of the data into individual stories (narrative analysis). The second level of analysis (analysis of narratives) concluded themes that emerged from the women's stories, including my own. The discussion and implications section (Chapter IV) demonstrates a model that was developed using five themes that emerged from the data. The description of the methodology used in the analysis of the data follows. 


\section{CHAPTER II \\ METHODOLOGY}

"There Is Nothing Out There That Tells the Good Stories of Us Survivors"

\section{Study Design}

This study was designed to give voice to the experiences of seven women who selfidentified as constructing a transformed self through the survival of breast cancer and to explore what could be learned from their stories. The objectives of the study were: (a) to obtain their life story narratives and thereby document their journeys through breast cancer; (b) to add my own story of survival of breast cancer to theirs; (c) to integrate their narratives with my own, adding my reflections on both their stories and my own; and (d) to look for broad themes that would further understanding of how a crisis such as breast cancer can, at least sometimes, help to build a new (and the assumption in this work is) and better life.

The study is based on the solid academic grounding using personal voice in research. This research was based upon the voices of the seven women interviewed as well as my own. Using a personal voice is a form of research and is often essential in studying experience. The tradition of inclusion of voice in research has emerged more fully as women have become researchers and the subjects of research (Abu-Lughod, 1993; Berkin \& Horowitz, 1998; Broughton \& Anderson, 1997; Lather, 1991; Lather \& Smithies, 1997; Luria, 1968; Wagner-Martin, 1994). In the past, stories were most often told about men.

The differences between biographies of men and biographies of women have been described frequently in the past twenty-five years of theoretical attention to the genre, Men's lives are usually focused outward, and the important 
"facts" of their existences are external and public. (Wagner-Martin, 1994, p. 67)

... . Telling a woman's life however, is less formulaic. For one thing, most women's lives are a tightly woven mesh of public and private events. The primary definition of a woman's selfhood is likely to be this combined publicprivate identity. (Wagner-Martin, 1994, pp. 5-6)

The experience of personal voice in this research was considered in the tradition of Behar (1996) and Gilligan (1982), both from the field of anthropology and of Polkinghorne $(1991 ; 1995)$ and Dietrich and Shabad $(1989)$ from the field of psychology. ${ }^{4}$ The findings were reported in story form and as much as possible made use of the women's own words to tell their stories. Their words explain both their public and private lives as follows:

Early feminist theorists of the autobiography carved out a space for critical discussion of women's self-representation by celebrating the non-autonomous, other-directed, and communal female selves they encountered in a range of ignominiously neglected works. This strategy has the effect of bringing existing autobiographical criticism, which sought out and found, in a mutually reinforcing chain, attributes such as individually, coherence, and selfconsciousness. (Broughton \& Anderson, 1997, p. 97)

Women tell their stories "conveyed in their own words whenever possible rather than through commentary by the men around them" (Berkin \& Horowitz, 1998, p. 3). The women's stories in this study displayed their thinking and conscious processes as they journeyed through this disease. This work relates directly to a topic highly visible in the

\footnotetext{
${ }^{4}$ Gilligan also writes in the field of psychology.
} 
media, a topic championed by women from every corner of our society. One can rarely turn on the television or pick up a magazine without finding a reference to breast cancer.

As an example of this visibility, the topic of breast cancer is included in the Handbook of Qualitative Research (2000). Chapter 23, by Miller and Crabtree (2000), is titled: "Clinical Research" and begins, "We are closer to Eden. The war against breast cancer advances and the local and national media stage another heroic celebration of the latest miracle. A drug prevents breast cancer" (p. 607). In this chapter the story of Camille is told: Meanwhile, amid a Middle Atlantic landscape of small farms, crowded urban streets, and rigid walls of private property, Camille joins the clan of onebreasted women (Williams, 1991). She is confused and worried. Poor, frightened, and 50, she knows the breast cancer is spreading. Her life, composed of memories, children, career, lovers, and anticipated hopes, appears shredded; she fears no one is listening. (p. 607)

Miller and Crabtree (2000) continue:

This is the clinical research space we have witnessed - many conversations behind walls, but increased suffering, confusion, and searching in the clinical world despite technological "advances." The public discontent and the missing evidence are the hope upon which this chapter builds. We imagine a clinical research space where Camille, her doctors, the biomedical products industry and the researchers meet and seek transformation. (p. 608)

Thus, breast cancer is being fought on many fronts, form the more "clinical" efforts described above by Miller and Crabtree to the personal. This study emphasizes the latter and 
was designed to offer a venue for the positive stories, the stories of women who found themselves transformed by the experience of surviving breast cancer.

The topic covered in this research is personal both to me and to millions of women and to those who work with or love them. The women of this study often found themselves making "the personal - political." These stories will provide useful descriptions for an event that at first can appear to be devastating and can result in a transformed life.

This study was conducted using oral life story interviews. Goodson (1998) defines life stories as those that "comprise the person's account of his/her life (most often delivered orally) at a particular point in time" (p. 11).

As I considered how to tell the stories of these women, especially in light of my own experiences with this disease, I determined that the constraining models of doctoral dissertations that are often used seemed not to leave space for the deeper meaning and complexities of these women's experiences. I wanted to provide a venue for women to detail how they turned tragedy into triumph. I wanted through those stories to offer faith, hope and practical information to those who are yet to be diagnosed with this disease. I chose a methodology that would restore the human subject at the center-the suffering, afflicted, fighting human subject - we must deepen a case history to a narrative or tale; only then do we have a "who" as well as a "what," a real person, a patient, in relation to a disease - in relation to the physical. (as cited in Collins, in press, p. xxxix)

\footnotetext{
${ }^{5}$ This phrase first took hold in the women's movement of the in 1960's and typifies how women began to turn personal issues into political ones. Breast cancer is an example of a personal issue that women have politicized.
} 
A preliminary study of two women was conducted in April, 2001. The preliminary study was conducted with approval from the University of San Diego Committee on the Protection of Human Subjects. This study revealed some of the underlying complexities of surviving this disease, such as occasionally dealing with misogynistic doctors and with the confusion breast cancer patients can face their doctors advise them of conflicting clinical trial results.

Additionally, the preliminary study provided an indication that each woman had a unique experience surviving this disease. There were similarities and, at the same time, there were stark differences among their stories of survival. For example, the two women had very different experiences in the discovery of breast cancer. Judy, who had been married to Charles for over a quarter of a century, had been feeling pain in her breast long before diagnosis, while Jorie was completely surprised to find a lump on her honeymoon. Continuing, they had polarized reactions to coping with breast cancer in at least two major areas: (a) the use of alternative medicine (Judy actively going out of the United States for treatment while Jorie "ate a few more vegetables"); and (b) Judy viewed the Race for the Cure as an "insult," while Jorie was inspired and "moved to tears" by it. Judy and Jorie, however, did have agreement in three major categories: (a) their husbands had been major contributors to their survival of breast cancer; (b) loss of hair in chemotherapy was a "very small part" of the overall scheme, even though before the hair loss they had assumed it would have a terrible impact; and (c) they had carefully planned ways to reduce the stress in their lives following their diagnosis. As to this latter point, both women quit high stress jobs and, at the time of the interviews, worked primarily out of their homes. 
The preliminary study paved the way for my increased sensitivity in the subsequent interviews. As I reviewed the transcripts from the preliminary study in preparation for the larger study, I was reminded to keep the women's experiences central to the work and to focus on the actual words of their experiences. Thus, direct quotes of the participants are used as a core of their stories.

Interestingly, even though I did not intentionally set out to make it so, the seven women presented a wide range of ages at diagnosis. The youngest woman was diagnosed at 29 , and the eldest, Arlene, was originally diagnosed at 36 , and was diagnosed (for the second time) at age 60 . This wide age range at diagnosis gave the study a broader view for analysis.

\section{Participants}

Selection criteria. There were three qualifications used to select the participants in this study: (a) The participant must be female; (b) she must be a breast cancer survivor; ${ }^{6}$ and (c) she must self-identify, or explain experiences that qualify as having had a transformational experience as a result of surviving breast cancer.

"Qualitative inquiry typically focuses in depth on relatively small, even single cases (n-1), selected purposely" (Patton, 1998, p. 165). Merriam (1998) explained that in using purposeful sampling the researcher will "discover, understand and gain insight and therefore must select a sample from which the most can be learned" (p. 61). This study was not designed to get an average opinion or to pinpoint the typical experience of a woman surviving breast cancer (Donmoyer, 1990), but to gather "information-rich cases from which one can learn about issues of central importance to the purpose of the research" (Merriam, 1998, p. 61).

\footnotetext{
${ }^{6}$ For purposes of this work, "survivor" is an individual who has been diagnosed with breast cancer, treated for breast cancer and who is still alive.
} 
The purposeful sampling employed also triggered "snowball" or "chain" sampling (Patton, 1997). As I contacted women whom I knew were breast cancer survivors I asked them if they could identify other women they knew who met the above requirements for participation in this study. The women interviewed were selected from women that I knew and from these referrals.

Participant identification. The following is a description of how each of the women in this study came to become part of this work. The first two women, Jorie and Judy, were participants of the preliminary study.

For the past five or six years, I had seen Jorie working out at a local gym. After a while we began to talk. One day she told me that she was going in for a breast cancer screen and that she was a survivor. I told her I was also a survivor. Later, I mentioned to her my study and she agreed to be a participant.

A fellow doctoral student contacted her friend, Judy, and asked her if she would be interested in talking to me about my research. With Judy's permission, I was given her telephone number. I contacted her, explained the study and she agreed to participate.

After receiving approval from The Committee for the Protection of Human Subjects for the larger study, the other five participants were obtained as follows:

In 1994, while I was in recovery from my first diagnosis of breast cancer, one of my doctors seemed very pleased with the emotional and moral support I was getting from my husband, Jim. My doctor casually said that my husband should write a book on the subject for husbands of breast cancer patients. Jim worked on the book for about four months and eventually decided to self-publish. He found out more about women's health in general and 
located Ruth Jacobowitz, ${ }^{7}$ who had written best sellers on women's health issues, such as menopause. Jim met several times with Ruth and she wrote the forward to his book, Breast Cancer: Strategies for Husbands to Support Their Wives (Eckmann, 1995).

Dani was in charge of the Survivors Network, which is a support group for breast cancer patients she founded. Jim and I met with Dani in 1995 to see if she could help us distribute his book. For the past three years, at Dani's request, Jim has given away about 3,000 books at local breast cancer events. At one event where I was assisting Jim in distributing his book, Dani told the audience her story. I was amazed at her humor and the severity of her illness, and how young she was when she was diagnosed. When I began obtaining participants for this study, I asked Dani if she would be included. She quickly agreed.

In May of 2002, Jim was contacted again to donate books to the grand opening of a park that is dedicated to cancer survivors. The park is located across from the San Diego International Airport. When I delivered the books I asked the coordinator of this event if she knew of other women whom she thought might want to be a part of a study highlighting stories of women who had survived breast cancer and felt they had been transformed.

The coordinator immediately told me about Arlene and Rosalie. When I contacted Arlene, she immediately offered to be a part of the study. When I called Rosalie she asked me to e-mail her a description of the study. I did so, and she soon advised that she did not qualify but she would forward my descriptive e-mail to eight women whom she knew were survivors. With e-mail they could respond to me in anonymity. Within a few days, I heard

\footnotetext{
${ }^{7} \mathrm{Jacobowitz}$ is an author of books designed to assist women through mid-life health issues such as menopause and osteoporosis.
} 
from Samantha and Sherry, who responded to Rosalie's e-mail and volunteered to be a part of this research.

I have had over ten friends and acquaintances that I know of who have been diagnosed with breast cancer, including Krissy. From the beginning of this work I wanted Krissy to be a part of this study. As soon as I received approval from the Committee for the Protection of Human Subjects I sought her out. When I contacted her, she said that she was willing to be a part of the study. I asked her what she was doing differently now than before her diagnosis. Krissy thought a minute and said, "You don't mean art, do you?" She went on to explain that she began working as a commercial artist after surviving breast cancer. She told me she had started drawing as part of her recovery. I asked her to tell me no more until we met and I could get it all on tape. We set up an interview at my home and she brought some of her artwork (see Appendix D for a photograph of Krissy with an example of her art).

In selecting women for the study I did not focus on any particulars such as the length of time elapsed after diagnosis their past or current career experiences, or the like. It had been my observation in the many women that I had talked to in a non-scientific and general way that many were eager to tell their stories about surviving breast cancer.

\section{Interview Procedures}

Prior to each interview, I contacted each woman by telephone and explained the purpose of this research. Each of the women selected was not just willing but excited to be interviewed and, after initial contact, immediately set a date for interview. Each woman was asked for one hour of uninterrupted time, and two of the women, Samm and Krissy, felt that they would be interrupted at their work or home and asked if my home was available. Arlene 
said that she would be interrupted at her work, but offered to take off time from work and to meet me at her home.

All of the women in the study were given the option of using a pseudonym. However, when I mentioned at the beginning of the interviews the attempts I was going through to keep the transcriptions, interview notes, tape recordings, memos, drafts, and field notes confidential, all but one emphasized her desire that I use her actual name in the study. Each appeared eager to have her story included in this work

The women were given a copy of the consent form and my telephone number and email address at the conclusion of the interview. Although I offered each of them assistance in the form of meeting with a Marriage and Family Counselor (who had a mastectomy) none of the women chose to call her. I offered this assistance so that if any of the women had a negative experience before, during or after telling her story to me, they would have a professional to contact. However, each of the women, in her own way, said it felt good to tell their whole story and not have to reduce the story, as Samm said, into a "three minute sound bite."

The study was based on one conversational interview with each participant and was built around emerging, open-ended questions (Patton, 1997). The first question, "Tell me about your experience surviving breast cancer," was used as a grand tour question, and was followed by a series of probing questions. Each interview opened with a grand tour question, which was followed by probing questions. It is important to note that during the interviews the themes were never mentioned. For example, none of the women in the study were asked, "Did you find yourself feeling separated?' or "What did you do to study the disease?" 
Instead, the interviews were open-ended and each brought forth the topics, occurrences and events that were uniquely important and of interest to her.

Each interview lasted from one hour to one and one-half hours. The interviews were audiotaped with the consent of the participants. Additionally, within twenty-four hours of each interview I typed up field notes that listed among other things, my thoughts of our session and details of how the women appeared to me in the setting. For example, when Krissy described her experience with chemotherapy, I noticed that she drew into herself, making her body actually take up less room on the couch. She looked younger to me, "Like a first grade schoolgirl being overwhelmed" (Eckmann, field notes, "Krissy"). As another example, the field notes included information about the interview with Dani. There was a Shiva sitting on her desk in her office. This large four foot wooden statue represented to me "that it had been carved into just like Dani and I" (Eckmann, field notes, "Dani"). I thought that Dani, the Shiva and I had a lot in common - we had all been carved into and we had all been transformed.

These women gave voice to their external struggles (with doctors, treatments, insensitive friends and family). At the same time they gave voice to their internal struggles (fears of dying, disfigurement and loss of joy). The women often spoke of surprising themselves by finding peace in the midst of struggles. Their stories are full of their insights, power, and courage (Kotter, 1998; Parker, 1996; Quinn 1996).

Each woman was given the opportunity to review the transcript of her interview. I sent each woman a copy of her transcript with a self-addressed stamped envelope to make any additions or corrections. Three of the women stated they would rather receive their transcript by e-mail attachments. In all cases I explained that the women (a) would be given 
the opportunity to read any of the transcriptions from our interview; (b) would be allowed, at any time, to retrieve all of the data from our interview; and (c) had the absolute right to decline the use of the interview for this study.

I transcribed each interview within two to five days of the interview. As I transcribed, I inserted comments that described hand movements, breathing patterns and nonverbal communication as I had observed them. I wrote what I remembered, including sounds I heard during the conversations, such as sighs, laughter, and body movements. I included those sounds in the transcripts and field notes.

The seven women in this study were asked to describe specifically how they constructed a transformed life through surviving breast cancer and how they perceived those experiences of transformation. To explain the sensitive nature of their stories I drew heavily on "intimate ethnography," which is a connection between a subject and the researcher (Barnes, 1997; Behar, 1996; Lerum, 2001; Sherif, 2001).

\section{Data Analysis}

The stories of recovery from breast cancer by the participants in this study were compared to my own story of recovery. My transformational experiences occurred gradually with ever-increasing power. I gained momentum at the successful completion of each medical treatment while at the same time matriculating through college and graduate school. In looking for transformational experiences in each participant in the study, therefore, I was patient with the data. I observed these women during the interviews and paid careful attention not just to what they said, but how they said it. As I personally transcribed each of their stories, I remembered more details that I would include in the notes of the transcripts. I then read and reread the transcripts and the field notes from each woman at least eight times. 
After continued connection and analysis (Glesne, 1999; Locke \& Spirduso, 2002; McDougal 1989; Wolcott, 1990) of all the data, meanings began to "bubble" up. As Polkinghorne noted at an invited address in Montreal, Canada, "Things we didn't understand at the time can bubble with meaning later" (as cited in Collins, in press, p. xlvi).

Eventually, coding was commenced on the transcripts. The procedure for coding is well described in the social science research literature (e.g., Glesne, 1999; Patton, 1997; Rubin \& Rubin, 1995; Spradley, 1979). These authors suggest coding by use of the process in which the researcher moves back and forth repeatedly through all of the interviews until one obtains a set of codes that is useful for characterizing the data. As I followed this process and went back and forth numerous times through each woman's transcript, I became aware of concepts, phrases and even words that were common. These commonalities led to the realization that the women were in their own way describing at a higher level a shared experience. At first these broad concepts seemed so simple (like being surprised at being diagnosed with breast cancer) that I did not understand their value or significance. It was as if these concepts were hidden in plain sight in each of the women's stories. As I continued to evaluate the transcripts and studied the stories of the women using these broad codes five points of connection emerged. These points of connection were later identified as themes that were evident in each of the women's stories. The themes were later identified as stages. The stages became the Sophia model. This process will be described below (and in the Discussions and Implications Chapter).

As Denzin (1989) stated, “A personally committed ethnographer is presumed and not the morally neutral observer" (p. 274). Davies (1999) commented: 
I have emphasized throughout the unavoidable and essentially desirable reflexivity of such research. This reflexivity is to be found at all levels, from the reactions of the informants to the presence of an ethnographer ...

It is present in all stages of the research, from selection of the topic through fieldwork to analysis and writing up. And it is to be found in all kinds of research methods, whether the open research design of participant observation or the more structured techniques of social surveys or network analysis. I argue that it is possible to make comprehensive and positive use of this reflexivity. (p. 229)

Further, as a fellow survivor of breast cancer, I brought to the interviews an "insider's" advantage (Sherif, 2001). "The case of partial insiders who have background ties to the cultures being studied provides a certain insight into the dynamics that can occur in the research process" (p. 438). The women I interviewed understood that I shared firsthand in the extensive challenges breast cancer presents, though each treated this information in her own way. For example, Sherry began her interview by asking about my experience with breast cancer. Judy asked me to turn off the recorder at the end of the interview and asked about my experience with this disease. Still, two of the women never alluded to my journey through this disease, yet two of the women did occasionally say, "You know what it's like," as they discussed a particular treatment.

In our conversations I often responded to the women by asking them to give me more details of their experiences. Being an insider gave me the advantage as to what to watch for as well as what to listen for. For example, when they spoke of chemotherapy I knew to ask, "What type?" I was careful to watch how they touched their chests as they spoke. Such 
sensitivity and this type of detail came from my own newly acquired habit, after ten surgeries, of resting my hand on my chest as I speak of breast cancer. I watched which breast they laid their hand upon and that gesture was a signal for me to observe which breast was her affected breast. I listened carefully to hear if any of the women felt sorry for themselves at the time of the interview. I knew to ask how others might have hurt them by telling them stories of other women who had died of breast cancer, since that had been such a haunting experience for me.

At the same time I attempted to look at the experience as a stranger and tried to make as few assumptions as possible. As the women discussed their experiences with surgery or chemotherapy I would ask probing questions to have them fill in details. I asked, if they did not state, what the hospital looked like, what the size of the room was, and if they were scared or surprisingly calm. I often asked who provided support for them at that time. These questions from an "outsider" status provided powerful details. For instance, as the result of directly asking Judy who was with her at her last chemotherapy appointment, I found out that she had gone alone, and that she cried and feared dying. And as a result of an "insider" question I found out that Krissy had chemotherapy in a place called "the chemo lounge" with over a dozen matching recliners. I remember thinking that the words "chemo" and "lounge" didn't fit together well.

As an insider I was able to focus on the words of those who were being interviewed and at the same time I was able to look for their deeper meanings. As an example, I noticed that when Samm spoke of choosing the mastectomy over a lumpectomy, she sat up straight in the chair with a "don't look back gaze" (Eckmann, field notes, Samm). Samm also lifted up her right arm at a 90-degree angle like a crossing guard. I didn't ask Samm what the look and 
her hand movement meant. However, as an insider, and since I've had a double mastectomy, I know that when I speak to someone about the choice I made to have both of my breasts removed I do not want anyone second guessing me. As an insider I assume Samm didn't either.

Because I am familiar with the pattern that is usually used in the treatment of breast cancer (surgery, radiation, chemotherapy), I was able to focus my questions on feelings and reactions rather than on the details of treatment progression. Being an insider offered the participants and me a way (as Judy said in her interview) "to cut through to the chase." We all experienced instant rapport because of our shared mutual experience with breast cancer. We also shared a mutual admiration for our fierce resolves to live and to live well.

My story of survival and transformation is included in this work. Autoethnography was used to decipher my own experience of breast cancer. Autoethnography is a means by which the researcher exposes a vulnerable self that will reflect on the narratives of others with an insider's knowledge and understanding. Behar (1996) explains the genre of autoethnography, the use of a personal voice in a body of work, thusly:

The charge that all the variants of vulnerable writing that have blossomed in the last two decades are self-serving and superficial, full of unnecessary guilt or excessive bravado, stems from an unwillingness to even consider the possibility that a personal voice, if creatively used, can lead the reader, not into miniature bubbles of navel-gazing, but into the enormous sea of serious social issues. (p. 14)

Ellis and Bochner (2000) described autoethnography as follows: 
Autoethnography is an autobiographical genre of writing and research that displays multiple layers of consciousness, connection of the personal to the cultural. Back and forth autoethnographers gaze, first through an ethnographic wide-angle lens, focusing outward on social and cultural aspects of their personal experience then, they look inward, exposing a vulnerable self that is moved by and may move through, refract, and resist cultural interpretations. As they zoom backward and forward, inward and outward, distinctions between the personal and cultural become blurred, sometimes beyond distinct recognition. Usually written in first-person voice, autoethnographic texts appear in a variety of forms - short stories, poetry, fiction, novels, photographic essays, personal essays, journals fragmented and layered writing, and social science prose. In these texts, concrete action, dialogue, emotion, embodiment, spirituality, and self-consciousness are features, appearing as relational and institutional stories affected by history, social structure, and culture, which themselves are dialectically revealed through action, feeling, thought and language. (p. 739)

My story along with the stories of the other participants in this work brings validity to this work because

it evokes in readers a feeling that the experience described is lifelike, believable and possible. You might also judge validity by whether it helps readers communicate with others different from themselves, or offers a way to improve the lives of participants and readers (Ellis \& Bochner, 2000, p. 751). 
My experiences with surviving breast cancer are told in a section entitled, "My Story." In addition, occasionally I inserted (a) my perceptions and observations as the women told their stories, or (b) comments concerning their experiences. The first level of observation I refer to as Participant Observation, much like a witness to an event. The second level of observation I refer to as Author Observation, wherein I related my own experience in conducting this research as a woman, as an ethnographer, and as a fellow breast cancer survivor. This second level is italicized in this study.

Examples of Participant Observation and of Author Observation are located in “Krissy's Story.” An example of Participant Observation is: "Krissy spoke almost in a whisper and uncharacteristically, slowly." In this first level of observation I described my perception of her speaking and compared my observation of her normal speaking pattern to the one she used in the telling of that part of her story. An example of the second level of observation, Author Observation, is found a few pages later:

At that moment Krissy and I joined in laughter that is beyond the level of our relationship. We had not spent four hours together in the past four years, and yet we were laughing like best friends. We both knew that having cancer had separated us from others, and we both had received from others more awe and wonder than we deserved.

Having had the same experience as the speaker often prompted this second level of observation, Author Observation. I did this to distinguish between what I saw or perceived I saw, from what I felt and experienced as the interviews progressed.

Reliability was obtained in this study by involving the women in the review of: (a) their respective transcripts of the interviews, (b) the themes, and (c) the resulting five-stage 
model. The women were asked to revise, amend or delete text from the transcripts, and they were encouraged to comment on ways the themes and model met or did not meet their experiences.

Ellis \& Bochner (2002) noted that, Since we create our personal narratives from a situated location, trying to make our present, imagined future and remembered past cohere, there's no such thing as orthodox reliability in autoethnographic research. However, we can do reliability checks. When other people are involved you might take your work back to them and give them a chance to comment, add materials, change their minds, and offer their interpretations. (p. 751)

In the end, none of the women chose to edit the transcripts. In addition, none of the women objected to the themes that had been identified or the model I had developed. The women did however, express unique, individual reactions to the themes and the model. Their specific reactions are offered in Discussions and Implications, Chapter IV.

Once collected and recorded, the stories were analyzed using a methodology provided by Polkinghorne $(1991 ; 1995)$, namely, the narrative analysis and the analysis of narrative. The narrative analysis was used to tell the individual stories of breast cancer survivors. Their stories were examined before diagnosis, to diagnosis, through treatment, and into the survival stage of this disease. Next, through analysis of narratives, the compilation of these stories (Lincoln \& Guba, 1985) was reviewed for broad themes. These methods are described next.

Narrative Analysis. Narrative analysis is descriptive, and I relied on the person being interviewed to use her "own narrative as a tool for constructing, ordering and expressing meaning to her life" (Collins, 1999). Polkinghorne (1988) asserted, "the basic figuration 
process that produces the human experience of one's own life and action and the lives and actions of others is the narrative" (p. 159). To perform the narrative analysis, I read the transcripts and field notes and wrote a story highlighting the experiences of surviving breast cancer for each of the women. I included the thoughts, events and insights described by them.

I attempted to catch the essence of each woman's story, and added enough description to help the reader get a picture of the setting and of each woman. I read the stories I had written and checked them against the transcripts and field notes. I carefully looked to be sure that I had used the women's words as much as possible. I rechecked to be sure that I had not left out any important parts of their story and, for each woman's story there were no fewer than five rewrites.

Polkinghorne (1995) noted that in narrative analysis data is gathered through the relating of life events that are integrated by the researcher to "configure the data elements into a story that unites and gives meaning to the data as contributors to a goal or purpose" (p. 13). Sykes (1998) listed the steps necessary to perform this analysis:

1. Specify the outcome or denouement to which the story will lead.

2. Arrange the data elements chronologically.

3. Identify which data elements are contributors to the identified outcome

4. Construct a plot outline.

5. Fill in the outline with detail from data elements.

6. Adjust outline, where necessary, to better fit the data.

7. Collect additional data, where necessary, to fill in "gaps." (p. 77)

To implement Sykes' steps for analysis, I first determined that I wanted to highlight the experiences of each woman as she described her journey through surviving this disease, 
with an eye for her description of transformation. Next, I arranged the data in order of her experience with breast cancer, from before being diagnosed, through diagnosis, during treatment, through recovery, and onto survival. Third, I identified which information would be the best contributors to explaining her journey. Fourth, I constructed a plot outline. This was just a simple one-page handwritten outline of each woman's experiences. Next, I adjusted the outline and added information that was pertinent to her story while deleting information that was redundant or not relevant to the major points of her story. Lastly, I collected data that would fill in the gaps, such as the medical data outlined below.

The stories of the women often referenced medical experiences; accordingly, medical references were added to triangulate the data. American Cancer Society, American Medical Association, Komen Foundation and the California Cancer Registry websites were used as current sources for uniform definitions and explanations of traditional medical information. Alternative medicine was also a part of this study since two of the women, plus me, discussed alternative medicine in their interviews. Several resources were used to provide context and definitions for the women's experiences with alternative medicine (Chopra, 1997; Diamond \& Cowden, 1997; Hirshberg \& Barasch, 1995; LeShan, 1994; Pert, 1997).

Each interview was coded with an eye to the emergent themes and epiphanies within the story of each woman's life. These themes offered an "emplotted narrative" which reflected "order and meaningfulness that is not apparent in the data themselves" (Polkinghorne, 1995, p. 16). Denzin (1989) described the need for the researcher to look for "essentially problematic moments in the lives of individuals" (p. 129). Breast cancer treatment and recovery offered a plethora of opportunities for finding epiphanies. 
Analysis of Narratives. After studying the individual transcripts and the field notes the data began to speak to broader themes. The stories of these women began to reflect a larger picture, a broader scope that connected to transformation literature (Jackson, 1983; LeShan, 1994; O’Brien, 1995).

The analysis of narratives drew on a variety of data, including "actions, events, and happenings" (Polkinghorne, 1995). The purpose of the analysis of narratives was to "explain through narrative why something happened" (Polkinghorne, 1988, p. 161). Thus, when the narrative analysis was completed on the data from the vantage point of all of the narratives, themes began to emerge (Lincoln \& Guba, 1985).

I analyzed each woman's experience on its own and as it related to the other women of the story and to my own experience. With analysis of the narratives it became evident that each of the women had experienced a similar progression of experiences from diagnosis through survival. Five themes, which are presented in detail below and also in "Discussion and Implications" (Chapter IV), became apparent:

1. Surprise/Suspense. Each of the women was understandably surprised by the diagnosis and held in suspense while awaiting the results. The degree to which each was surprised, however, differed. Krissy had been cautiously optimistic but "looking over her shoulder" for cancer due to her family history. Judy was surprised by the diagnosis but had been experiencing pain in her breast, so had been cautious and concerned. Dani, Jorie, Samm, Sherry and Arlene said that the diagnosis of cancer came to them unexpectedly.

2. Study. The methods and levels of study were unique to each woman. Dani eventually undertook research into clinical trials to optimize chances of survival. 
Sherry described buying and reading every book on breast cancer at a local bookstore. Samm consulted her neighbor, an oncologist.

3. Separation. The women often described various kinds of drastic separation despite simultaneously feeling an understandable newfound closeness with others. This unique separation they described included separation from (a) their former images of themselves, (b) parts of their bodies, (c) people who either left them or people from whom they had to distance themselves.

4. Surrender/Reflection. The women described the sometimes very long process of surrendering. This included surrendering to treatments and finding themselves reflecting upon what they valued in life. The women were not giving up, like surrendering to an enemy, but accepting the necessary treatments for survival. The women described how, during treatment, they often reflected on how they would live the rest of their lives differently than before.

5. Struggle/Strengthen. The women described being awakened and energized by the experience of surviving breast cancer. They told of finding a new courage with new skills, to reinvent their lives.

Once the five themes were identified, I considered the most effective way to group and display the data. As much as possible the women's own words were used to tell their stories. Usually "block quotes" were utilized for quotations 40 words or longer. However, a few times "block quotes" were used for shorter statements which, because of their importance to the story, required additional emphasis.

How to present the women's stories, and in what order, plus how to incorporate my own personal experience was the final decision I had to make in presenting this study. In the 
end, I decided to tell the seven individual stories as they related to each of the five themes. I also decided, after considering many options, to tell the women's stories in ascending order of age at first diagnosis of cancer. Dani was diagnosed at 29, Jorie at 36, Arlene at 36 , Krissy at 40 , Sherry at 42 , Samm at 46 and Judy at 52 . Thus, Dani's story is told first, with the others following in sequence as listed here. I decided to tell my story last through the five themes. 


\section{CHAPTER III}

\section{RESULTS}

\section{"Just Grab the Time You Have Now and Do Whatever You Can Do"}

\section{Overview}

This section presents the stories of the participants', and my own, journeys through breast cancer to recovery. The stories are presented in ascending order of age at first diagnosis (although mine is told last). Each woman describes her fears as well as her victories over those fears.

Each story begins with an introduction, and is then divided into five themes that emerged from the analysis of narratives. A final section, entitled Reflections, follows each woman's story. The reflection section includes my connection to the women and their stories of survival and transformation. I sought to use "forms of research that fully acknowledge and utilize subjective experience as an intrinsic part of research" (Davies, 1999, p. 5).

\section{Theme One-Surprise/Suspense}

Each of the women communicated they were unprepared for the experience of finding themselves with breast cancer. Four of the women learned of their breast cancer after a discovery of a lump; the other three women (plus me) were diagnosed as a result of having a mammogram. ${ }^{8}$

\footnotetext{
${ }^{8} \mathrm{~A}$ mammogram is an X-Ray of the breast. Mammograms are done with a special type of $\mathrm{X}$-ray machine used only for this purpose. A mammogram can show a developing breast tumor before it is large enough to be felt by a woman or even by a highly skilled health care professional. Screening mammography is used to help find breast cancer early in women without any symptoms. Diagnostic mammography helps the doctor learn more about breast masses or the cause of other breast symptoms. Website of the American Cancer Society, http://www.cancer.org/docroot/gry/gry_0.asp?txtSearch=-mammography\&dictionary=\&btnGo.x=10\&btnGo.y= 5.
} 
"Suspense" refers to the time between finding a lump (or an anomaly on a mammogram) and receiving a definitive diagnosis. That time is like standing on thin ice. In the interviews, most of the women spoke of this period with whispers of disbelief, even though years and years had passed since the events. Except for Dani, each experienced a brief amount of time (ranging from two hours to two weeks) in the Surprise/Suspense stage. Some of the women's doctors appeared to rush to obtain diagnostic results, while other doctors took more time. In the Surprise/Suspense theme the women described how they were shocked and scared, and found themselves dreading their futures.

\section{Theme Two-Study}

Most of the women communicated that, after experiencing the shock and surprise of diagnosis, they sought to gather as much comprehensive information about breast cancer as possible, as quickly as they could. Each of the women exemplified this theme (and the other themes as well) in a unique way. Some sought information in books, others by called other survivors, and some found attending support groups gave them the information they craved. The women often said that before they began to study breast cancer they felt they might die, and that after studying the disease they were more hopeful they would survive. This period was a pivotal stage for each of the women as, through information gathering and study, the women began to take charge of their experience. The seeds of transformation had started to germinate.

\section{Theme Three-Separation}

Each of the participants communicated that she experienced separation on at least one of three levels. First, many of the women spoke of feeling separated from the rest of the world and from their former lives. They voiced how the diagnosis of cancer made them feel 
as if they were viewing their lives from a different vantage point, one that was apart from who they were previous to the diagnosis.

Second, many spoke of being separated from parts of their bodies through surgeries. Four of the women had had mastectomies (a complete removal of the breast), and three of the women had had lumpectomies (removal of cancerous tissue only).

Third, separations sometimes occurred from others. Dani's fiancé left her. Some of the women devised ways to protect themselves from comments of friends and acquaintances. Theme Four-Surrender/Reflection

"Surrender" as used here means to yield oneself to an influence, act or emotion. Each of the women surrendered to the treatments for the disease, and to pain and loss. Each began to reflect seriously on and gain insight into her future life. The women stopped thinking about what they did not have, e.g., perfect health, and started reflecting on what they did have, such as the hope of survival.

The women were pensive in this phase of their storytelling, and were often quiet and appeared to be peaceful. Often their hands lay still in their laps. According to Hagberg's (1995) model, these women were gaining experiences at the time of the events, and "finding their own way of doing things, of continuity within themselves. Everyone chooses a different way to do this and experiences varying levels of crisis along the way" (p. 95).

\section{Theme Five-Struggle/Strengthen}

All of the women reported experiencing a newfound power and strength that contributed not only to their survivals but also to their transformations. They spoke of doing things unimagined before cancer, including undertaking a new endeavor, or doing activities engaged in before in new ways or with a new awareness. 
The women found themselves taking more risks and having a renewed commitment to make their lives count. They did not feel sorry for themselves-in fact, quite the opposite, in this fifth stage, the women "knew what their life's purpose was and seemed to be able to wed this to their lifestyle and their work. From deep inside they had naturally evolved what had always been waiting to be recognized" (Hagberg, 1995, p. 115). While relating this part of their experiences, they smiled more (I had the sense this was not to me but to themselves.) as they described their accomplishments during and after breast cancer. They talked about how the battle against cancer had given them new tools to be able to tackle life. 
Dani's Story-Introduction

Dani was diagnosed with breast cancer at 29 and was 42 at the time of the interview. She began and ended her story about breast cancer with laughter. She was like a large fire that cast a bright flame. At some points Dani seemed like a stand-up comic for breast cancer.

We met for the interview in her office. I arrived before her, was shown to her office, and took that time to observe her artifacts. On her neat desk was a four-foot wooden carved Shiva god. ${ }^{9}$ While I waited I looked through her books and found that she and I gravitated toward much of the same material.

When Dani arrived she was all a-flutter, all apologies. She was wearing a long white jacket that looked like a doctor's coat and a bright red scarf that her hands would catch and send into flight during her animated conversation. She works at an oncologist's office in San Marcos, California. All of the staff, even the doctors at this large office, treated Dani as if she was their Shiva, a necessary and valued part of their team.

The Shiva god was between us during the interview, looking over my left shoulder and her right. My view of Dani during the one and a half-hour interview was with the Shiva overlooking Dani, a tropical garden in the background.

The following text quotes Dani extensively, I use paraphrase for the following three purposes: (a) to provide information, (b) to make the presentation more succinct, and/or (c) to clarify transitions.

\section{Surprise/Suspense.}

Dani began telling her story this way: "When I was 20, playing on the women's varsity basketball team at San Diego State, I felt a lump on the upper outer quadrant on my

\footnotetext{
${ }^{9}$ Hindu god of destruction and reproduction.
} 
right breast. [Dani said that it was a tiny little bump about the size of a BB] I went to student health and I said, 'What is this?"' She said the woman in student health told her to "take it seriously." Dani, six feet tall, strong and athletic, did not take it seriously and did not followup.

Seven years later, when she was 27 , Dani became engaged to "a millionaire, a multimillionaire" who was a couple of years older than she was and "one of the first computer guys, millionaires." About that time, she pointed out to her gynecologist the same BB-sized lump. He "thought it was significant enough to get a mammogram." Based upon the results of the mammogram her gynecologist sent her to a surgeon "that same day."

The surgeon "took one feel of it and pronounced, 'Look, you are too young, you have no family history, don't worry about it."' Dani said she felt "relieved," but the tiny lump kept haunting her:

And progressively over the next several months I went back to my gynecologist. He called up the surgeon, and the surgeon said, "Don't worry about it." So then I went again and again, a total of eight visits with physicians, seeing that surgeon three times.

Dani said part of the reason that she was pushing for a test of this little lump was that her fiancé and she "were planning a trip around the world so we weren't going to have access to a doctor." Dani said she wanted a biopsy, but she "was a little bit intimidated by this physician." To convince her doctor of the need for a biopsy, Dani mentioned to the doctor that she had just seen a TV report on

"The Phil Donahue Show" about needle aspiration ${ }^{10}$ and ... they said, "It is

${ }^{10}$ A type of needle biopsy. Removal of fluid from a cyst or cells from a tumor. In this procedure, a needle is used to reach the cyst or tumor, and with suction, draw up (aspirate) samples for examination under a 
not very painful and you can find out about a lot about what it is." So I said that to the surgeon, and he makes a face and said to me, "Well, Dani, you are so young; you are 29 years old."

As Dani described the doctor making a face, she threw her arms up in the air, her red scarf flying like a signal the bulls were about to enter her life. As she spoke the doctor's words, she used a condescending voice. She was uncharacteristically deadpan and serious about the mistreatment she got from this doctor and, like a good storyteller, she played all the parts and transformed her voice into the voices of all the characters. The voice she used for herself was that of a little girl: and tentative, weak and wavering. The voice she used for the doctor was strong, arrogant, know-it-all and bombastic.

Dani kept apologizing to the doctor and was almost begging for the needle aspiration. Using her version of the booming, condescending doctor's voice she said, “All right, all right, look, just to make you happy, I'll do it." As she said this, she acted out pulling a needle out of her desk drawer and hurriedly sticking it into her right breast.

Dani continued, "He sticks a needle in it, and it is solid and his face falls. And he pulls out an aspirate and throws it in the trash can." At this point in our interview I leaned forward; I could not believe what I was hearing. She quoted the doctor:

"Well, it is solid mass and it needs to come out, but don't worry there is no way you have cancer, it is just a fibroma." ${ }^{11}$ When he threw it away like that after all of this time, I started worrying about it and I felt I had been dismissed, kind of like a hypochondriac.

microscope. If the needle is thin, the procedure is called a fine needle aspiration or FNA. Website of the American Cancer Society, http:/www.cancer.org/docroot/GRY/GRY_0.asp?dictionary=\&pagKey $=\mathbf{N}$ ${ }^{11}$ A benign tumor. 
Dani went to another surgeon for a second opinion. The second doctor, like Dani, could not believe that the first doctor had thrown away the specimen. The second doctor said, "He could have found out what the nature of it was by that [aspirate]."

Dani sought to schedule surgery to remove the tiny lump. The second doctor was going on a trip and wanted to do the surgery in a clinic. The only way to get the lump removed sooner than later was to use the original doctor, even though Dani knew "he didn't take me seriously." However, she went back to her first surgeon.

The surgery was scheduled in a little hospital near her family's home. Before the surgery, Dani kept thinking to herself: "You know this is not in my realm of possibility. I've got this fairy tale world ... and I'm going around the world on a trip. No one in my family has ever had cancer."12

At this point in the interview, Dani began to sit up straighter in her chair; she appeared larger and to take up more space. She described this part in another voice, a stronger voice. Using this strong voice she recalled telling herself, "Whatever this is, you can handle it."

With this newfound resolve, Dani went into surgery. She explained that the doctor was going to be able to tell he while she was on the operating table whether or not she had cancer. The doctor later told Dani that he "knew, it was obvious what it was," and he knew he didn't get it all.

As soon as I came out from the anesthesia and I woke up and my whole family was there-my fiancé, my family and all the kids and everything. I knew something was wrong; he told me and he was shook up about it. He said

\footnotetext{
${ }^{12}$ Dani's mother had seven sisters and none of them had been diagnosed with breast cancer.
} 
it wasn't much bigger than his thumbnail, but he told me to go to an oncologist to find out what to do next.

Dani carefully mouthed the next words without a trace of humor in her voice: "So I was shocked to have cancer. I was blown away. I just felt completely let down by the medical profession. I couldn't believe that I'd been pursuing this, and that had happened." Study

Dani explained her growing concern over her health and the medical care she had received.

I was angry and thinking whom can I trust? How can I figure this out? I was responsible and I was going to the doctor. How could this have happened? And how could this have happened to me? So I went and got eight separate opinions I was so freaked out. . . I had to figure out what I as going to do. I just didn't know enough about it. I just needed to keep teaching myself.

The pathology ${ }^{13}$ report concerning the specimen showed it was "a high grade tumor. It was the fastest dividing tumor; it was the most aggressive tumor." She needed to act quickly. Dani described herself before diagnosis as the type of patient that would say, "Oh, that's OK, all right. Oh, I feel silly coming in." After diagnosis, she became someone who actively pursued doctors and researchers to obtain the best and latest information on breast cancer. At one point she found herself "calling up the person in charge of a national study on breast cancer." She described her evolution: "So I came from trusting these physicians, to

\footnotetext{
${ }^{13} \mathrm{~A}$ "pathologist" is a doctor who specializes in diagnosis and classification of diseases by laboratory tests such as examination of tissue and cells under a microscope. The pathologist determines whether a tumor is benign or cancerous and, if cancerous, the exact cell type and grade. "Pathology" is all the procedures, conditions or results of a particular disease. Website of the American Cancer Society, http://www.cancer.org/docroot/GRY/GRY_0.asp?dictionary=\&pagKey=P.
} 
really sitting down and making them tell me everything they knew. I learned to question them." She found that she was going to have to find the answers herself.

\section{Separation}

Dani started CMF chemotherapy ${ }^{14}$ right away, and at the same time she felt that she needed to keep the relationship with her fiancé vibrant. To that end, eight weeks after surgery, they planned a trip to Guatemala in between Dani's chemotherapy sessions. She "didn't want her fiancé to think she was a dud." She was concerned because he had the world by the tail, and he was attracted to me because I was always fun. We'd walk into a cocktail party - no matter what, I was the center of attention and fun. Everything was always easy.

As they were "sitting on the runway" she touched her right breast (the same side) and "all of a sudden way up high on my pectoral muscle, I felt a lump, as we are taking off on the plane." As she said this, she reached for her right breast and her mouth registered pain and shock, as she relived that moment. They continued the trip but in the middle of their trip she said her hair started falling out. "I had really long hair down my backside, and my hair starts falling out in clumps." Dani described her approach at that time: "I'm just trying to be cool about it. . . But I started thinking, "What am I doing?"”

Dani concluded she had "failed" her chemotherapy and her lumpectomy. She explained, "Failing chemotherapy, [meant] having a tumor grow while under chemotherapy." They returned from the trip and Dani was facing "all of this." She said her relationship with her fiancé was beginning to unravel. She recalled a meeting with a doctor with her fiancé in the room:

\footnotetext{
${ }^{14}$ A mixture of Methotrexate, Fluorouracil, and Cyclophosphamide, powerful drugs with significant side effects. Website of Cancernet, http://www.cancernet.co.uk/chemotherapy.htm.
} 
I started projecting myself out and starting to figure out that skill, I guess that was it. Even though I've got this millionaire fiancé next to me, who is Mr. Everything and Everybody, written up in Fortune Magazine and everything, in a sense that didn't matter to me. .... I have to find things to do me good-that really matter for me.

Dani believed, accurately, she would be going back into the hospital for extensive treatments, "or worse." She recalled:

I'm thinking, "I don't know, and he's not hanging in there." I can't even imagine feeling like I'm attractive to him, much less anybody else. But this was kind of made worse by being young. You are totally ripped out of a normal life, and I suddenly felt like I was 90 years old.

Her fiancé decided to leave her after she was no longer "the perfect babe." But he, it was just not the life he was thinking he was going to have. We're going to go off and get married and do all of this fun stuff and you know. So anyway. . . he just started to withdraw. You know, it blew me away because here is a guy that is negotiating with IBM for millions of dollars and everything but he just can't handle-can't do it.

And where is the fiancé? He is kind of, you know, coming in and out and everything. And I remember my, I found out later, my mom, who is Southern Belle sweet, you know. I think they said that he came over for lunch when I' $m$ in the middle of the worst part of it and my mom is just talking to him and she had made him lunch and he is sitting in the family room eating lunch at the table. And he is saying “T, you know, we haven't been able to 
talk about this but, you know, Dani hasn't told anybody this, but I think we are kind of falling out of love, so I don't think we are going to be getting married and I'm thinking about moving back to San Francisco." And my mom turns around and says to him. "You know"-I can't believe my mom did this, but says-'I think lunch time is over but I got to tell you right now, if you're ever walking down the street and you get shot in the back don't turn around because you will know it was me."

\section{Surrender/Reflection}

Dani thought her "doctors were very nice, but [the cancer] has just defied gravity." She was willing to surrender to any treatment necessary to live and needed to find the right doctor to help her. "Just what they said could not possibly happen, did. Man, I've got to figure this out." Dani said she learned "that the only one I can rely on is me." She needed to take charge of her treatment and recovery. Dani's taking charge would lead her to surrendering to horrific treatments and ultimately to reflecting or what her life had been and was to become.

Dani decided to find a "national expert." She wanted the best, "I was going to go to Sloan-Kettering ${ }^{15}$ or M.D. Anderson ${ }^{16}$ in Houston." ${ }^{17}$ She said, "By the time I got an appointment (at M.D. Anderson) my tumor had grown so much it was inoperable. The lumpectomy had failed and I was headed for a mastectomy. I had so much cancer in my breast." She was referred to a "very sharp guy." He wasn't a senior guy, but he was very, very sharp. Dr. Jaborie was an Iraqi/Lebanese man with a thick accent." Dr. Jaborie

\footnotetext{
${ }^{15}$ Memorial Sloan-Kettering Cancer Center, New York, New York. (http:// www.mskcc.org)

${ }^{16}$ The University of Texas M.D. Anderson Cancer Center, Houston, Texas (http://www.mdanderson.org)

17 "Study" efforts often continue throughout treatment and recovery.
} 
assembled a group of 30 doctors to physically examine her, and he brought Dani into the lab to explain her tumor to her while it was under a microscope. Dani said she thought to herself, "He may be a little funky with that accent and all, but this is something different than anybody else has done." In Dr. Jaborie's opinion, Dani needed “the highest walking dose they had ever given anyone of Adriamycin, and they were going to do two cycles to try to see if they could get a response," i.e., to get the cancer to shrink.

Another doctor (Doctor X) at M. D. Anderson, senior to Dr. Jaborie, told Dani she did not need Adriamycin but needed to have a bone marrow transplant. ${ }^{18}$ She recalled him telling her, "This is probably going to be your best chance at living, and you have a very aggressive cancer." Dani had to sue her insurance company to get this $\$ 200,000$ procedure covered. But she still had three major reservations about bone marrow transplantation. One concern was that this procedure would have required confinement in a small room, about seven feet by seven feet, for six weeks. No one would be permitted to touch her during that time, and food and supplies would be imported through a "clean-room type" window. Another concern was that this procedure was new and untested. Her most important concern was that early statistics showed that " 10 to $15 \%$ " of those who went through bone marrow transplantation died from the treatment itself, not the disease.

\footnotetext{
${ }^{18} \mathrm{~A}$ complex and sometimes risky treatment that may be used when cancer is advance or has recurred, or as the main treatment in some types of leukemia or lymphoma. A portion of the patient's or donor's bone marrow is withdrawn, cleansed, treated and stored. The patient is given high doses of chemotherapy to kill the cancer cells. The drugs also destroy the remaining bone marrow, thus robbing the body of its natural ability to fight infection. The cleansed marrow is given by transfusion (transplanted) to rescue the patient's immune defenses. The best place to have a bone marrow transplant is at a comprehensive cancer center or other facility that has the technical skill and experience to perform it safely. Website of the American Cancer Society, http://www.cancer.org/docroot/gry/gry_0.asp?txtSearch+bone+marrow+transplant\&dictionary=\&btnGo.x=10\& btnGo.y $=10$.
} 
Dani decided that she wanted both of her doctors in one room at the same time to discuss her treatment options in front of her. She wanted Dr. Jaborie to debate with Doctor X. Dr. Jaborie agreed; she said Doctor X balked at her taking that type of control. Dani said:

So I called the clinic and they said he was too busy, the bone marrow guy. And I said, "Look I'm going to have to make a very serious decision. You are talking about the transplant and the mortality rate on that is $15 \%$, and I'm only 29 years old and I have to make this decision."

Doctor X stated, "Listen, my dear, you have very little hope; it is April and you have very little hope of living until Christmas." Most people would crumble at that pronouncement, but Dani had learned to struggle for the care she needed.

I had tears coming down, but I still had my voice, "I've got to make this happen." So I said, "Look doctor, for God's sake, look. This is important, just give me five minutes of your time with the two of you in the room, because I've got to sort this out."

The doctors met and Dani watched them disagree on her care. She listened carefully to their arguments.

They are arguing about mortality and how long I'm going to live, and I had forced it. It was a serious disagreement between the two of them. I remember sitting there, and I felt like, maybe it is how you feel if you are going to faint. Everything was in slow motion. I was listening so hard because I wanted to hear both sides. I wanted to hear their rationale for both sides. I just kept feeling, listening. I kept visualizing the home movies where they have the dinosaurs, and you are the one person, the human tribe girl and waiting for 
one of those dinosaurs to step on you. And I remember thinking, "I don't like feeling this small." And as they were still talking I remember thinking to myself, "Goddamn it, all that any of us has is right now." And I remember distinctly sitting in the room and thinking, "You are going to make up your mind, and whatever it is it is going to be good for you because you-you-are the only one who can really know what is right for you. And as far as what they said and you're thinking you are not going to live very long, we are all going to walk out of this room at the end of this conversation. And they are all going to have to cross the street and who knows, one of these guys could get run over by a truck and I could out live them."

After a short time of reflection, Dani decided to go with Dr. Jaborie for the high doses of chemotherapy and not undergo a bone marrow transplant. "Here is the top guy in the world, from one of the top [cancer] centers giving her "his professional opinion and [I] said, 'No, thanks." Dani separated herself from the medical wisdom of Dr. X and decided to be strong and make the decision that was right for her. She said, "Never knowing it before, never feeling I had anything I had to be strong enough for in my life.... This was a tough one."

At the same time, Dani surrendered to an arduous course of chemotherapy, described below. She described another aspect of surrender, namely, surrendering to uncertainty, in these words:

I really wanted to talk to somebody who learned how to live with this uncertainty. Someone who had learned how to live with their life redefined, someone who had redefined their life. So I would just talk to a lot of different 
people. And every time I talked to a cancer survivor who had been through it, I would take that experience; I would think about what skills they had used. And just how to, and I started to learn how to be, how to metamorphose from being the woman, the girl that when you walked in the room and people would go, "Oh, God, she really has had a bad deal and she is very serious, she is not out of the woods" kind of thing.

\section{Struggle/Strengthen}

Dani described her misery caused by the high does of chemotherapy that Dr. Jaborie administered, this way:

I did four more courses. They kept stepping up the dose of Adriamycin, which almost killed me. It almost killed me. I was in the [hospital] for 19 days. I can't even tell you. I am somewhere around 6 feet tall and I was down to 120 pounds, and I had such a severe reaction, these fevers, that I was just hallucinating all the time and I was on morphine and I couldn't swallow or eat anything. ... I had 14 blood transfusions because my bone marrow was so suppressed. My parents were considering having a priest come give me the last rites.

At this point in the interview Dani and I were both crying from the emotional impact. She took a deep breath, leaned back in her chair and blew air out of her mouth as if through a straw. She was quiet for a second. She then said, "I can't believe I'm getting upset about this, I don't normally give the whole story. "I whispered to her, gesturing with both of my hands open, shoulder high as if to say, "No, No, this is very, very important." I noticed that 
we were both slumped in our chairs. Maybe we didn't want to take up too much space, as though afraid of the disease. The agony in the room was palpable.

She went on, "So it was really, you know, pretty intense." Then she stopped. We were both quiet again. My intuition told me that leaving this part of her story half told would not please her. After about 15 seconds, I quietly said, "So at this point you are very, very sick." Dani resumed after another short silence:

I'm so sick, I am so sick. I remember I can only define "sick feeling” that I'm so at the edge of existence that I remember the clock in my room and I had these severe fevers that spiked up to 105 or 106 and I remember looking at the clock on the wall. For two days they were trying to knock me out of this high fever. And I remember being in so much pain. It was just ridiculous how much pain I was in.

At this point, Dani began to sit up straighter and I mirrored her strength and began to sit taller, too. She took a deep breath in then let it out, then another, and slowly with a dirgelike cadence continued:

And I remember looking back at the clock and it was like an hour and a half. You know I couldn't believe five minutes could last so long. But that is how, it was a pivotal several days when I just did that continually, just say, "All right, you did that, now just get past this next five minutes."

Dani underwent two years of treatments. When they were completed she still had things to deal with:

I don't have a breast. I don't know how long I'm going to live. I have a lot of very close wonderful friends, but people [formerly] were thinking, "I just 
can't relate to Dani. She is about to marry a millionaire." So here was this life, this wild life, and then, not too much time later, my whole life walked out the door.

Dani went on, "Yes, and I'm left, and I'm thinking, 'How do I start from here?'" She then said that she was "starting from scratch, not only from scratch but from the minus column because of what I didn't have. I was trying to think of what I wanted to do for the rest of my life."

Dani faced depression. Before her own experience of depression, when others came to her feeling depressed she would say, "Well, just shake it off, just shake it off!" Dani learned that depression is "deep and dark. I felt like I was at the bottom of a funnel, of a big tornado. I just could not see any light anywhere, anywhere." But she thought, "I can't be on antidepressants, I can't be a nut."

Dani went to Dr. Jaborie after all of the treatments were completed to discuss her future and her fears. She told me what he said, "You know, Dani, I think, knowing you, the only thing you would regret if it came back is, if you spent that time not really living and pursuing something that meant something to you."

She took Dr. Jaborie's advice. She said, “He was exactly right. So I just started pursuing things I wanted to do. So I just started, I had some sales and I had some business before I started all of this."

She also came to some realizations about herself and her life:

I realized that my definition of who I'd be is different than who I was before I went through this experience. It really was about me, it wasn't about anybody else's scale about what was good or a successful life or a happy life. And 
maybe it meant that I'd never find someone that I could trust or fall in love with.

Dani decided to "redefine" her life. She started going to support groups but did not resonate with the other members, who were typically decades older than she was. "But when you are young, you feel like you are in a special group." Dani then decided to start her own support group in Orange and San Diego Counties. "It was called the Walking Fish Society." She said, "I'm a walking fish—I'm not like everybody else." She described this effort: At the end of my treatment I started going to a support group. I actually went to the Wellness Community in Los Angeles, there wasn't one here. And it was, you know, very helpful, in retrospect, but when I was going through it, you know, I was 29,30 years old and everyone in the group was 30 years older than the young ones. You know, they were grandmothers and I learned a lot from them but I wanted to, I wanted to talk to young people. Because I could share, they were saying they were upset that they couldn't go to their grandkids' graduations, and I'm thinking, you know, when you are going through it at the time, it is all the things that matter to me, and I've since come to realize it is the absolute value of whatever losses you have. And whether you are old or young, or whatever, it is all the same. But when you are young you feel like you are in a special group. So I started a support group in San Diego, and one in Orange County and it was young; it was called the "Walking Fish Society." It was after this idea that people were cancer survivors and you can, people can live through cancer and society does not recognize it. It is like we say "walking fish" that it is like this funky analogy. 
We had this little pin and I thought that is me, I'm a walking fish, I'm not like everybody else. So we did this. And I was, so I just started gravitating. I just started to just really decide to enjoy life and to have fun and I started, it really became an entire pursuit for me because I started looking for resources and going to groups and talking to people.

Dani started the "Walking Fish" to help others and herself deal with trying to create a new life this side of cancer. For instance, when Dani found people whispering behind her back about how sick she had been she knew people were "not being mean, but just being people. They kept asking, 'Oh, Dani how are you really doing?'" Dani then said she didn't want others to walk on eggshells around her nor did she want pity. "It is fun to be pitied for about a weekend, but after that it is just, terrible, horrible," she added.

Dani and I laughed at the truth of her last statement. Pity feels like a straightjacket. Being around people who pity us makes us start thinking we are pitiful, small and helpless. We both have had lots of people whisper about our medical condition behind our backs, and we hate being pitied. We both like feeling strong, capable and large. We laughed the laugh of drunken cowboys on holiday about how much we both hate being pitiful. We don't want people whispering behind our backs and we don't want to be pitied. We both learned from cancer how much we want to be strong and how much we want to laugh and enjoy our lives. We cried in our laughter, and we were both sitting tall in our chairs. Dani handed me the Kleenex box. Our laughter had chased the whispers and pity away, and the air in the room felt fresh and new.

Dani said she wondered at that time how she was going to help others to stop feeling sorry for her. She asked herself, "How am I going to attack that problem?" She decided: 
When I walk in a room I'm going to make people feel comfortable with my cancer. I'm going to make jokes. If I let people know that l'm comfortable with it they will become comfortable with it. So I became this ridiculous comedy routine. I would think of a new repertoire of some way to make people laugh. Like, “Oh I've heard that somebody said these Mexican plates have lead in them and that causes cancer." And I'd say something like, "Don't worry about that, I had a whole set of them, there is no problem, eat up, eat up!"

With this, Dani, threw her hands in the air, and the red scarf went flying again. She was waving victory now. We laughed loudly, enjoying this moment.

After all her surgeries and treatments, Dani needed to get a job because she was about "\$70,000 in debt from medical care and related travel expenses." Her need for money and her desire to help others survive cancer gave her a strong desire to find just the right job. She counted her strengths. "I'm a sales babe, and I'm an entrepreneur." She laughed at this point and added: "I needed to find the thing I wanted to get out of bed for." She saw an ad in the newspaper at a medical center as the director of patient care. She was hired for the job and began expanding her job description the day she started work there. She interviewed doctors and patients, visited surgeries and went everywhere in the hospital trying to figure out ways to have the medical center be more "patient friendly." She became "a lunatic and wanted to know how [she] could participate in curing cancer and making the patient's experience different." Additionally, she started more support groups in San Diego for cancer survivors, 
"Thrivers Network" and, "Cancer Survivorship: San Diego!"19 Dani said, "[I] began to build myself from a place."

After tackling the professional side of her life, Dani decided it was time to take on the most difficult side, her personal life, and her dating life:

I had this black cloud thing behind me: “This girl does have another breast but she probably doesn't have a future and probably can't have kids and she probably can't-- [Dani's hands flew up in the air but no words were spoken]. She doesn't seem like a bargain to me, and she is in big time debt."

At the same time she had doubts, she had a hard won strength and decisiveness about who she was and what she wanted. 'I'm not going to waste my time on anybody who doesn't value who I am." But even with her decisiveness and determination, she was pensive during the interview as she noted, "I'm not going to fit into the mold of the perfect babe anymore. I'm going to be somebody that is going to be an unusual story - I'm a walking fish, I'm something different."

Dani then spoke of a former friend who had always admired her from afar. He took her to dinner one night, told her that he really loved her and offered to marry her. Dani considered his proposal, but knew that she didn't love him. She knew marrying him would be "taking the easy way out." Then she said, "I remembered going home and thinking, if this is the last year of my life, I don't want to spend it with him." She knew that this experience "told her about her life." She learned that she wasn't going to "freak out about it, if I meet somebody or not."

\footnotetext{
${ }^{19}$ Dani was featured in The San Diego Union Tribune on Sunday November 3, 2002. Her story was told in brief in Peter Rowe's column entitled, "Chemicals, breast cancer: a strong link?"
} 
She began dating and had "the most wild experiences dating, because it was really liberating actually." She said that men were "prescreened" by her experience. She spoke of a university professor and a "little Italian guy" to whom her brother introduced her. The professor was the first man "to love me for who I am, the new me."

She and the Italian man each taught the other an important lesson:

Him discovering a different way to think about a woman and me thinking, "Not only can I date again but I can have the most passionate relationship I'd ever had in my entire life, this wild hanging-from-the-chandelier business and everything."

Dani came to the conclusion, "You know, I'm not missing anything. I'm probably gaining something out of this whole experience because these are new experiences that I thought would never be possible."

Five years ago, Dani met the man who was to become her husband. After one dinner, "I thought I would probably marry him, and he thought the same thing." He loves and supports her through her "14 hours-a-day" involvement in cancer recovery processes. As a married woman she thinks of the implications breast cancer has had on all women:

For me, having breast cancer was a very feminist experience. For me, it was learning about what is valuable. It was about being stripped of it all and finding out what mattered. I was building back and thinking, I don't care what society says, or what anybody else thinks about what it's like to be a woman. I am me.

If I hadn't had this experience I would have married the rich fiancé, I would have become an unhappy housewife without identity. I would have 
earned nothing on my own. My husband now, we are committed to the breast cancer cause. We didn't live together for three years when we were married so I could complete the local commitments I had made to the cause. Today my husband loves me for who I am and that is really very liberating, and a wonderful thing. I know that I could not have found what is valuable within myself without my experience of surviving breast cancer.

Dani knew herself well enough to be able to evaluate the woman she would have become if she had married the multi-millionaire. She compared a possible future as being defined (by herself and by others) as the wife of a rich man, with being married to a man who supports her work and her passions.

Dani's work includes being the only person on the UCSD Institute Review Board without a medical degree. She spent ten years coordinating a park, which opened in April, 2002, to celebrate cancer survivors. [The park is located across the street from the San Diego International Airport.] Additionally she is on the Regional Cancer Institute and the TobaccoTax Initiative, which will fund "a hotline so that people can find out the latest clinical trials."

Dani's final comments:

If I left this earth I would say I know that I left something that mattered. That I knew was important. What is important is not about anybody else. It is a very selfish thing. I feel I've contributed something and know I have changed things. If I came along again, [reoccurrence] it would really make my world, my experience, different. 
Reflections on Dani's transformation

Dani's transformation is both personal and professional. Her personal transformation came as she decided that she was going to make each day count. She decided that she could not determine how long her life was going to be, but she could decide how many times a day she was glad to be alive. Dani's laughter helped me to laugh with her and to let cancer know that it could have our breasts, but not our joy. Dani's professional transformation has come as the result of aligning herself with organizations that can provide funding for breast cancer research. She coordinates local, state and national campaigns to "find the cure" for breast cancer. Before breast cancer, Dani defined herself as the "fiancé of a millionaire." Dani now defines herself in terms of the projects like the Cancer Survivor's Park in San Diego and gaining funding for a national registry where all newly diagnosed women are able to secure the data from the most recent breast cancer research trials. Dani had a lot more to offer the world than being a woman who hangs on the arm of a multimillionaire. 
Jorie's Story-Introduction

Jorie was diagnosed with breast cancer at 36 . She was 41 at the time of the interview. When I met Jorie for our interview she had her dark chin-length hair pulled back into a tiny ponytail at the nape of her neck. She wore jeans overalls, a white long-sleeved shirt and a royal blue vest; young women's attire. The royal blue in the fleece vest accentuated the navy blue of her eyes. She was fit, tanned, and had just enough meat on her bones to look strong but not fragile. She had a runner's body. We met at her home in Southern California, in April, on a perfect, warm spring day. I was surprised that she had on three layers of clothing. I wondered if she, on some level, had consciously or unconsciously worn extra protection for herself, considering the subject matter we were about to cover.

Jorie's home is a single level tract home surrounded by two-story homes. Her home looked lived in, not messy but inviting. Jorie and the house made me feel like my feet would be welcome on the couch. Jorie introduced me to her twelve-year old-daughter who soon disappeared into the rear of the house. I immediately became alarmed because I could hear that a carpenter was doing some loud hammering for a remodeling project back there.

I asked Jorie if we could reschedule the interview because the carpenter's hammering would make the 8 to 10 hours of transcription efforts miserable. She took control, walked to the back of the house, interrupted "Vinnie" and told him to take a break. I heard her say we needed "an hour of silence."

She walked back to the dining room, told me to set up and we began the interview. The effective yet kind manner in which she took charge with Vinnie gave me a glimpse of the woman I was about to interview. She was matter-of-fact with Vinnie and not at all rude or unkind. She found the "sweet spot" between over-bearing and begging. She knows how to 
ask for what she wants, and it appeared to me she is all right with not getting her way all of the time.

At the beginning of the interview Jorie neatly summarized the professional transformation she has seen as the result of her struggle with breast cancer:

I am not working. I was working full time at a pretty stressful job. I was commuting about an hour and a half a day. And yes, my stress level has gone way down. I quit my full time job in August; it will be two years in August. Now I work for a very low-pressure company. I work for my brother, three days a week, about four to five hours a day. So it is really nice.

The following text quotes Jorie extensively, I use paraphrase for the following three purposes: (a) to provide information, (b) to make the presentation more succinct, and/or (c) to clarify transitions.

\section{Surprise/Suspense}

On February 3, 1996, Jorie married. She and her new husband were spending a week in Hawaii celebrating their new marriage when the unthinkable occurred: "I discovered a lump in my right breast on my honeymoon." Jorie was then 36 years old.

Jorie's physician "wasn't suspicious about the lump. He thought it 'felt like a fibroid cyst., ${ }^{20}$ Jorie commented, "I was about to have my cycle." (Some women's breasts are more "lumpy" just before and during their cycles). Therefore, neither Jorie or her doctor were especially alarmed.

In fact, she felt that finding the lump on her honeymoon had something to do with the fact that sometimes "Men are pigs." She said this comment in an explosion of laughter.

\footnotetext{
${ }^{20}$ A fluid filled mass that is usually benign. The fluid can be removed for analysis. Website of the American Cancer Society, http://www.cancer.org/docroot/GRY/GRY_0.asp?dictionary=\&pagKey=C.
} 
Using both her strong hands, she slapped the glass-topped dining room table with force as she said this. We both laughed. I waited. She began talking again with a slower cadence of speech and her mood and her eyes darkened. She went from light-hearted to dead calm. She explained that she found the lump right after finding out there were two strippers at her husband's bachelor party. Jorie was very clear that the stress she felt over the strippers had something to do with her finding the lump:

Yes, I have never understood, I just will never understand it. Well, anyway, I caught wind that there were not only one, but two, at my husband's bachelor's party. He has a lot of friends, and they all came; a couple even came from Europe. So I find out that there is this occurrence at the party and I was hurt, incredibly saddened by it. It just stressed me out. I was really, really hurt; I was bummed out. And I never felt this lump before that.

They scheduled Jorie's first mammogram a few days later on Valentine's Day, 1996.

She recalled:

So everything happened very quickly. When the films were developed from the mammograms, nothing appeared on the right breast, which was the suspicious side. However, the technician noticed calcification deposits ${ }^{21}$ on my left side. I thought that was odd.

The technician predicted two things: Jorie would need to come back for additional magnification mammograms $s^{22}$ and "nine times out of ten this type of thing is nothing." The technician had only the first part right

\footnotetext{
${ }^{21}$ In each of my own mammograms, tiny white dots, which we hoped were calcifications (non-cancerous calcium deposits), were cancerous. Cancerous and non-cancerous "dots" often look the same on mammograms.

${ }^{22}$ Magnification mammograms are $\mathrm{X}$-rays of the breast that magnify a specific location of the breast that is under suspicion.
} 
After looking at the magnification mammograms the doctor was suspicious and performed a lumpectomy on the left breast. Jorie said she remained "very suspicious about my right side; however, everyone's focus was on the left breast." The resulting lumpectomy on the left breast showed "ductile carcinoma in situ," which meant that it was cancer, but the cancer was contained in a sack. Jorie was given the option of having radiation, "or I could choose to have nothing, or I could choose to have a mastectomy."

Jorie then took what looked like a very deep breath and slowly but succinctly revealed her past experiences with cancer. I had no idea what was coming:

I had Hodgkin's' disease ${ }^{23}$ when I was 16 , and I had thyroid cancer when I was 29. And because of my history, it is like playing Russian roulette, so I opted to have a lumpectomy $y^{24}$ and follow-up treatment for what would be approximately seven weeks of radiation. ${ }^{25}$

I worked to keep my composure. I knew that this woman had successfully faced difficult health battles and didn't need or want my sympathy or tears. I struggled to stay steady with the news of her previous cancers. She did not need me to get weak. I breathed deeply. Jorie continued with her story, while I was thunderstruck that this strong, capable woman has faced three major medical complications with such a matter-of-fact way of

\footnotetext{
${ }^{23}$ An often-curable type of cancer that affects the lymphatic system. Named for the doctor who first identified it. Website of the American Cancer Society, http://www.cancer.org/docroot/GRY/GRY_0.asp?dictionary=\&pagKey=H.

${ }^{24}$ Surgery to remove the breast tumor and a small amount of surrounding normal tissue. Website of the American Cancer Society, http://www.cancer.org/docroot/GRY/GRY_0.asp?dictionary=\&pagKey=L.

${ }^{25}$ Radiation therapy: treatment with high-energy rays (such as $\mathrm{x}$-rays) to kill or shrink cancer cells. The radiation may come from outside of the body (external radiation) or from radioactive materials placed directly in the tumor (internal or implant radiation). Radiation therapy may be used to reduce the size of a cancer before surgery, to destroy any remaining cancer cells after surgery, or, in some cases, as the main treatment, Website of the American Cancer Society, http://www.cancer.org/docroot/GRY/GRY_0.asp?dictionary=\&pagKey=R.
} 
dealing with a young life that has been laced with cancer. She sat tall in her chair as she told this story. She looked in my eyes, but not piercingly. She breathed in a consistent and rhythmic pattern. Jorie was about to explain how she found out that she was about to battle with cancer for the third time.

At that moment she pointed to a golden retriever who had been sitting at my feet. She introduced me to Chemo and said that the dog was a present from her husband just before she started treatment. This dog, and my own golden retriever at home, were content to just sit at our feet and do what they could to make our days better.

When she finished the seven weeks of radiation she said, "My oncologist was still very suspicious of the lump on the right side, and wanted to have a needle aspiration." The aspiration came back negative. ${ }^{26}$ As Jorie related the results of the needle aspiration during our interview, she took another breath, and by the tentative way that she whispered "negative" I knew she was about to tell me of yet another wave of cancer.

I had a follow-up mammogram six months after the last date of my radiation, and lo and behold, the lump appeared on the mammogram. So I had to start treatments all over again. I went for the lumpectomy. I was kind of very optimistic because my first treatment experience for the left side, was very inconvenient and a nuisance, going to radiation five days a week for six weeks. But I got through it fine and it wasn't painful; it was just kind of a nuisance.

\footnotetext{
${ }^{26}$ A negative biopsy means that the specimen(s) shows no cancer.
} 
But when I found out, when the results came back from this second lumpectomy the treatment was going to have to be different. The results showed it was positive, and it wasn't "in situ."

This time Jorie had a strong possibility of having stage II cancer, or metastasized cancer. ${ }^{27}$ The lumpectomy was an "outpatient thing" and the moment she woke up from the anesthesia the surgeon was standing over her bed and told her that her options were either a mastectomy ${ }^{28}$ or a lumpectomy. Having just gotten married, I wasn't ready to make that drastic of a decision [mastectomy]. That was my personal thing. So they went in and took a bigger mass, another [larger] lumpectomy and [did] the lymph node removal. They took out 14 [lymph nodes] and it [cancer] had spread to three or four. Which was just on the verge of whether I should be treated with chemotherapy or just radiation. So after that I did have 12 weeks of chemotherapy ${ }^{29}$ followed by another seven weeks of radiation.

\footnotetext{
${ }^{27}$ The spread of cancer cells to distant areas of the body by way of the lymph system or bloodstream. Stage II cancer or metastasized is cancer that has spread to another area of the body. Website of the American Cancer Society, http://www.cancer.org/docroot/GRY/GRY_0.asp?dictionary=\&pagKey=M.

28

Surgery to remove all or part of the breast and sometimes other tissue. Modified radical mastectomy removes the breast, skin, nipple, areola, and most of the auxiliary lymph nodes on the same side, leaving the chest muscles intact. Partial, or segmental, mastectomy removes less than the whole breast, taking only part of the breast in which the cancer occurs and a margin of healthy breast tissue surrounding the tumor. Prophylactic mastectomy is a mastectomy done before any evidence of cancer can be found, for the purpose of preventing cancer. Quadrantectomy is a partial mastectomy in which the quarter of the breast that contains a tumor is removed. Simple mastectomy or total mastectomy removes only the breast and areola. Website of the American Cancer Society, http://www.cancer.org/docroot/GRY/GRY_0.asp?dictionary=\&pagKey=M.

${ }^{29}$ Treatment with drugs to destroy cancer cells. Chemotherapy is often used with surgery or radiation to treat cancer when the cancer has spread, when it has come back (recurred), or when there is a strong chance that it could recur. Website of the American Cancer Society, $\mathrm{http}: / / \mathrm{www}$. cancer.org/docroot/GRY/GRY_0.asp?dictionary=\&pagKey=C.
} 
Even though this was Jorie's fourth time being diagnosed with cancer, it was the first time she was to have chemotherapy. She found herself getting more and more anxious as the day drew near. She then recalled the time, a few days before she started chemotherapy: I remember the Sunday before my chemo was to begin on a Tuesday. I was fretting all day. I was just a mess of emotions. Of course, the anticipation is always worse. Sunday morning, a beautiful warm day, and I was sitting on the edge of the couch. You know when you are fretting about something, just sitting on the edge? And my husband is reading the paper and he looked over at me and said, "Honey, what's wrong?" And I said, "I am scared to death. I am scared to death." And he took my hand and he said, "Come on, let's go wash the cars."

Car washing was not her idea of what she needed at the time, but his suggestion did get "my body moving." Jorie found herself comforted by being outside in the warm air and doing something with her husband. In fact, she found that "was a stepping-stone and a real point of growth for our [their] relationship."

Study

Jorie found her husband also provided all the help she needed as she navigated through learning about and choosing treatment for breast cancer. She and her husband studied her treatment options together. The choices were overwhelming. "It is just too much information." She leaned on her husband to be her second set of ears at each of the doctor appointments. "My husband is a very bright individual; he is a sponge when it comes to learning anything." 
He came to every single appointment with me. You know when you are talking to your surgeon, when you are talking to your oncologist, when you are talking to your radiation oncologist. when you are talking to the technicians, it is just like too much information. He came to my local needle biopsy; he came to every consultation I had. He was just there with me all of the time. It made the information a lot easier to digest.

\section{Separation}

Jorie spoke of feeling of separation from those who have not been diagnosed with a terminal disease, during the time of her diagnosis and up to the present. As an example, of this experience, she told about how a distant family friend who had been recently diagnosed with cancer had called her. Jorie became aware of the instantaneous bond she felt when she with this man who had just been diagnosed with cancer:

Knowing what I'd been through he was on the phone with me immediately. And this is a grown guy, very macho, a body builder, and everything, and he was in tears on the telephone with me. It made me feel, well, so sad, but it made me feel so good that he called me and just poured out his heart to me, that he wanted to hear my voice and wanted to talk to me about what he was facing and what he was going to face.

Jorie said she instantly felt close to this man and that they were somehow on the same team. Jorie was delighted to share intimate information with this man, something unthinkable before he was diagnosed with cancer.

With the wisdom of a journeyman cancer survivor she knew, however, that his experience with cancer was going to be different than hers. This was true not just because he 
was a man, or because he had a different type of cancer, but because people who have been through this experience know that we are all separate and different, and in Jorie's words, "everybody's situation is unique."

Occasionally Jorie feels a separation from her friends and others, especially when they find out that she has survived cancer. She mentioned how they treat her differently in that they think of her as somehow super-human. Sometimes she feels uncomfortable receiving praise for just doing what she had to do to recover. She appreciates the admiration and at the same time she feels separated by the admiration since she is only following doctors' order.

Jorie spoke of how sometimes being thought of as separate from others can give us an advantages as well. She said, "They have an admiration for what I've been through, how it has affected me, and how I've handled it. With that in mind I would imagine that they might see me as a leader."

She stated her husband credits her as having phenomenal qualities, and she said he thinks "I am a rock."

And I skip off to these appointments like all is fine, because I can't worry about it, I can't lose sleep over it. I go in hopes that every time I leave the office it is with a good, clean bill of health. And I think that he [Jorie's husband] is impressed with the amount of strength that I show coming and going to those appointments.

Jorie did not take her health for granted, however. Starting from when she was 16 , when she was first diagnosed with cancer, she has considered each day a "gift," an attitude that separates her from most people. 
With my experience with cancer, I have-I think I've grown up really, really quickly. I try not to take life for granted because it really is too short. And when you have a life-threatening moment or moments such as I have, you have to put life into a different perspective.

Surviving cancer had taught Jorie to view herself differently. At the same time, others view her differently. She explained that surviving cancer has "created an admiration" for herself. She then looked at me directly and asked me, "Don't you admire yourself for having been through and gone through and dealt with the daily grind of this situation?" I responded, "Yes, I'm real proud of myself." I actually answered before I thought about my words. I was surprised at the depth of my own strength of voice and conviction in the answer.

\section{Surrender/Reflection}

Jorie's "surrender" in her breast cancer journey was connected to her altered physical appearance. The surgeries forced her to surrender part of her body to stay alive. She reflected on that surrendering of her body and dealt with the complexity of loss and survival in a matter-of-fact way.

It is a disfigurement. You almost have to accept your body all over again. When I look at myself in the mirror I think well, at least I'm here.

In reflecting on her experience of surviving breast cancer, Jorie said, "I get very emotional. I don't know why we had to go through this. Everything always happens for a reason and God never gives us anything that we can't handle." In a whisper she said, "We should definitely celebrate our lives." 


\section{Struggle/Strengthen}

Through the process of surviving breast cancer Jorie gained a new appreciation for and connection to women. She has learned through breast cancer that "I think that there are things that women certainly can't share with a man. That it is easier to talk with women." She got quiet, then with a burst of laughter continued, "Girls kick ass."

Her face brightened as she began to tell of participating with thousands of other women in the Komen Race for the Cure and how this yearly event to support breast cancer research helps her to appreciate life more.

When they had the ladies choir, then they let the doves fly, I got so emotional I didn't think I was going to be able to run. I was so touched and so in awe of all of us. Of us. And I wasn't looking around and I was looking straight at the stage, and I wasn't looking anywhere else. because I was literally blubbering. My lip was going, "bub-bub-bubb." You know, if I look at anybody I'm just going to lose it entirely. The tears are streaming down. It wasn't a sad feeling; it was a feeling of life and of camaraderie. We were all leaders that day.

In a good-mother like, sing-song voice she continued:

It is a terrific day to celebrate; it is nice to be around all these women. When you look at all of these women, you think, "Wow! There is a ton of women here who are going through it. Have been through it-that are battling it and surviving."

She continued, "I see some of the most beautiful women at that event. And we should celebrate life and not take things for granted. Live on!" 
A whimsical smile appeared and I thought she was done. In a straightforward way, she ended the interview. She smiled and simply said, "So that was my experience." Reflections on Jorie 's transformation

At the very least, Jorie's transformation was work related. Jorie was working at a full time job with a long commute at the time of diagnosis. At the time of the interview, she worked for her brother and out of her home and on a irregular basis. Jorie keeps her body, home and life streamlined. Her life means too much to her, this side of cancer, to spend it on the road trying to impress strangers. She now wants to love her husband, her daughter and her dog Chemo. 
Arlene's Story-Introduction

Arlene was first diagnosed in 1976 with breast cancer when she was just 36 years old. She said she thought then she "was going to die within three days." She was diagnosed with breast cancer on the other breast in 1990 when she was 50 years old. Each time she had a mastectomy. She was 62 at the time of the interview. Thus, she is a 26 -year survivor of breast cancer.

Arlene was born in Costa Rica 62 years ago. From the day of her diagnosis until now she has been a loyal, fearless and tireless champion for women diagnosed with this disease. She moved to the United States when she was 18 years old "to go to school and to work." She met her husband, Bob, in Los Angeles in 1965, and they married in 1966; their children are now 34 and 31 and they have three grandchildren.

Arlene speaks with a faint accent that was hard for me to place. As I listened to her, it seemed that she sometimes used a clipped cadence of speech that to me was more reminiscent of a Chinese heritage than a Spanish one. She sat squarely in her chair and had a matriarchal air about her. Her big, devoted, golden retriever dog with a white face stayed within about ten feet of us during the entire interview. Arlene is smart and she is in charge. She spoke quickly, and even though my own battle with this disease has covered a decade I found myself learning about breast cancer from her.

Arlene's brown eyes are lighter than the color of coffee and more of a golden brown, just like mine. She wore a t-shirt and a pair of slacks. We sat outside on the patio of her home overlooking a small valley in Southern California. We both wore sunglasses, and when she had a particularly important point to make, she would use her right hand to lower her 
sunglasses to look me straight in the eye. I wore a coat and a long-sleeved shirt, while she was comfortable in just a thin short-sleeved shirt. Arlene is what I would call "robust" or sturdy in build.

She lives in a particularly peaceful setting; birds chirped and sang just a few feet from where we sat on her patio. Her office must be a very different sort of place, because when we first talked on the telephone to set up our appointment, she told me, "Oh, if we meet at my office we will be constantly interrupted. The only place we can have quiet is at my home." She was right. I had asked for one hour of uninterrupted time for our interview. At exactly one hour from the time I arrived, the telephone rang. She spoke too softly on the telephone for me to understand any of her words, but when she came back to signal the interview was over and to say good-by to me, she told me it was her husband checking up on her.

The following text quotes Arlene extensively, I use paraphrase for the following three purposes: (a) to provide information, (b) to make the presentation more succinct, and/or (c) to clarify transitions.

Surprise/Suspense

Arlene was initially diagnosed with breast cancer nearly three decades ago when she was only 36 years old. She stated:

I didn't know the first thing about breast cancer in 1976. I thought I was going to die within three days. I tried to educate myself about the disease. I didn't have any options. I entered a clinical trial where I had radiation first and a mastectomy second.

Arlene's life changed almost immediately when she was diagnosed. In her quartercentury journey through breast cancer she has had opportunities to "meet very interesting 
women." Her ability to speak Spanish and her understanding of differences in cultures has

been useful in the battle against this disease. She explained, "I quit my job and decided to do volunteer work. I worked with a physiologist who had gotten a grant to interview Spanishspeaking women about breast cancer."

Her experience with breast cancer unfortunately began anew 14 years later in 1990 . "I definitely knew that there was something wrong in my other breast." She got a mammogram and "they saw something" and suggested a needle localization procedure. ${ }^{30}$ When she came out of surgery, her husband gave her the news:

It was all over my breast. It was a spider web type of cancer and I didn't have an option for a lumpectomy. So I had another mastectomy, and I had a great oncologist who gave me chemotherapy the same day. She had Adriamycin ${ }^{31}$ chemotherapy for six weeks. ${ }^{32}$ And she spoke softly as she explained her doctor "would put me to sleep." As she said this, her left hand in slow motion acted out putting a needle into her right forearm. Interestingly, she maintained my gaze while

\footnotetext{
${ }^{30}$ There are two types of localization procedures. "Needle Localization" is a procedure used to guide a surgical breast biopsy when the lump is hard to locate or when there are areas that look suspicious on the $\mathrm{x}$-ray but there is not a distinct lump. A thin needle is placed into the breast. X-rays are taken and used to guide the needle to the suspicious area. The surgeon then uses the path of the needle as a guide to locate the abnormal area to be removed. "Wire localization" is a method used during a surgical breast biopsy when the lump is hard to find or when there is an area that looks suspicious on the $\mathrm{x}$-ray. A thin, hollow needle is placed into the breast and $\mathrm{x}$ rays are taken to guide the needle to the area in question. A fine wire is inserted through the center of the needle. A small hook at the end of the wire keeps it in place. The hollow needle is then removed, and the surgeon uses the path of the wire as a guide to find the abnormal area to be removed. Website of the American Cancer Society, http://www.cancer.org/docroot/GRY/GRY_0.asp?dictionary=\&pagKey=N; and http://www.cancer.org/docroot/GRY/GRY_0.asp?dictionary=\&pagKey=W.

${ }^{31}$ Adriamycin (Doxorubicin) is an active medicine against many cancers, and is one of the older chemotherapy drugs, having been in use for decades. Adriamycin is a clear, orange-red colored powder or liquid, which is administered intravenously only. Website of Tirgan Oncology Associates, http://www.tirgan.com/adria/htm.

${ }^{32}$ Chemotherapy is often administered over several weeks or even months.
} 
making this gesture. I could almost see the bright red color of Adriamycin going into her veins. Ifelt a chill.

The doctors were undecided if she should have radiation on this breast or not since she didn't have "clear margins." 33 Arlene wanted radiation. But she was concerned as to whether the radiologists had been careful in 1976 when she had radiation on the other breast. Once a portion of a body is radiated, it can never be radiated again. Her doctors were concerned "the radiation in 1976 was not like the radiation in 1990, so they were afraid of [over] spray." If in 1976 there had inadvertently been some over spray of radiation onto this breast, the results could have been disastrous for Arlene.

In retrospect the decision to have radiation turned out not to be a good one. "If I had known then what I know now, I would not have had the radiation. But it was a decision that I made and I can't waste my time thinking about it."

Study

"You better get yourself educated. My thing is that." Arlene advises women who have been diagnosed with breast cancer along these lines:

Start learning and finding out what resources are in your community. Who is the best guy to treat you? And if you can't find it in your community and if you have the financial resources to go someplace else, you can try it. If it makes you feel good.

\footnotetext{
${ }^{33}$ The edge of the tissue removed during surgery. A negative (or "clear") margin is a sign that no cancer was left behind. A positive margin indicates that cancer cells are found at the outer edge of tissue removed and is usually a sign that some cancer remains in the body. Website of the American Cancer Society, http://www.cancer.org/docroot/GRY/GRY_0.asp?dictionary=\&pagKey=M.
} 
After being diagnosed with breast cancer the second time, Arlene became even more serious about studying the disease and its effects. She wanted to find out what she could do not only to help herself but to help all of the women she heard about who were being diagnosed. Her desires for information and for impact were unexpectedly fulfilled while quietly sitting at home with her husband:

So one night I was watching television and I saw this woman on "Face the Nation" and her name was Eleanor Pred and she was from San Francisco. And I asked my husband, "Are you listening to what she is saying?" And she was talking about that she was a child of the 60's and she had been in the Peace Corps and just been diagnosed, a second diagnosis, of breast cancer and in her lung and she was just amazed at how many women were being diagnosed with breast cancer and no one was paying attention. I picked up the telephone, called 411, and spoke to her in San Francisco.

Arlene and Bob were invited to a meeting in San Francisco the following weekend. There were a lot of women sort of frustrated as I was with the numbers. Eleanor was my mentor. I told her I wanted to get involved: "How can I do it? I've never done political activism." And she said go to San Diego and start a newsletter, start your own groups; she said, "I can help."

Arlene began her involvement in the breast cancer movement as the Southern California representative of a statewide organization, $\mathrm{CABCO}$, which stands for California Breast Cancer Organization. She explained, "It would be an umbrella organization for all of the groups that wanted to join and that we would do political activism under that. Any issue in the political arena that came up, CABCO would take it." 
Soon Arlene collaborated with emerging women leaders in the breast cancer movement. She was involved in the Mautner Project ${ }^{34}$ from Philadelphia, and she worked with Susan Love, M.D., who was the "head of the breast center at UCLA." When these political activists found out that a statewide organization was already functioning and in existence, they used the existing network to form the National Breast Cancer Coalition (NBCC), "a national advocacy organization, which is headquartered in Washington, D.C." Arlene said that NBCC has been the mother of breast cancer political activism and nobody thought in 1990 that a group of women would go to Congress and tell the congressmen, you know, “This is what you have to do and, if you don't do it, you are not going to get reelected."

Arlene loved telling me this part of the story, about her participation in the movement. She became animated; her hands were moving and she was smiling and laughing. She appeared to like to tell the story of being on the ground floor of such an important effort for women. She pulled down her glasses for effect, and spoke loudly when she said, "and you are not going to get reelected" with a deserved pride in her voice. She was delivering not a threat to the legislators, but a promise. "You know, it has been amazing, amazing - the progress and the changes that have occurred since then."

I was sitting with a woman who has a national voice and presence in the breast cancer arena. I was very interested in finding out exactly what in her background had prepared her for this role. She replied to my query, "My job, I was an office manager. I had some idea of how to run something."

\footnotetext{
${ }^{34}$ Founded in 1990, The Mautner Project is the only national organization dedicated to lesbians with cancer, their partners and caregivers. Website of the Mautner Project, http://www.mautnerproject.org.
} 
Separation

Throughout the interview, Arlene referred often to her husband's support. She spoke of always being a "go-getter, and if somebody tells me I can't do that I say, 'How do you know I can't do that?" "Her biggest motivator was and is her husband. Even before she had breast cancer, she recalled he would say to her, "If you want to do it, do it." So there are no barriers as to what I want to do and what I do. He is always advising me and saying, 'Why not?"”

Arlene was on the cutting edge of women being public and open about having breast cancer. She was a participant in the political wave that brought breast cancer to the forefront of public and government attention. However, she began to have experiences in the breast cancer lobbying group that set her apart from many other women who were affected by disease and, also, at the same time she was separated from her former life. She had been a successful office manager and she was a go-getter. Breast cancer gave her a forum for putting her strong administrative and strong temperament to work on a larger scale.

Her efforts were also important in separating breast cancer research and funding and related political efforts, from normal legislative affairs, thereby creating a distinct and separate political movement, and funding strategy, for research and education. She explained:

Dr. Sue Love had a women's day at UCLA and invited me to speak. And I spoke on the political part of breast cancer. I did a lot of research on statistics and how the medical profession views women with breast cancer, etc. And at that 1992 meeting was [state] Assemblywoman Barbara Friedman. The next 
day the office of Barbara Friedman called and said, "We want a copy of your speech."

She asked them, "What are you going to do with it?" She learned "they were planning on writing legislation to tax cigarettes two cents." That was the first time Arlene worked with a legislator to assist in passage of a bill. She and other survivors were called to testify in Sacramento to "bring the human side in front of the legislators."

In 1993, the bill came to the floor and we thought it would never pass and the Governor will never sign it. Well, it passed, and in the language of the law it says that the money it raises will build the breast cancer Early Detection Program, which is a screening and education program for underserved women. It will also build a registry to improve data collection.

The bill also mandated there be "five breast cancer advocates in the advisory council." The advisory council was to take part in determining which programs would be funded. The criterion for a woman to sit on the advisory council is that she be a representative of an organization with a constituency like $\mathrm{CABCO}$. Arlene explained excitedly, "For us to have, for a group of women to have made that, it was, "Wow!"”

She let out a breath, with a sound like the whistle of a distant train and sat back and looked completely satisfied with the victory of which she had been a part. She was quiet for a few seconds. Lost in reverie, as was I.

I was thinking of the famous quote from Margaret Mead: "Never doubt that a small group of thoughtful, committed citizens can change the world. Indeed it is the only thing that ever has." It was as if the experience of breast cancer picked Arlene up and carried her through a journey, a quite different journey than she would have experienced otherwise. And 
within this journey Arlene separated from her former life and helped direct millions of dollars to worthy programs for helping to save other women's lives.

\section{Surrender/Reflection}

Arlene learned how to teach other women how to reflect upon breast cancer, to trust their intuition and to take charge of their own care, by doing just that for herself. She gave this example:

I started having trouble with Tamoxifen and I knew it was Tamoxifen. And then my oncologist said, "Tamoxifen doesn't do that." And then I started writing down all of my liver panel ${ }^{35}$ results. And then I decided I would go to one of the top oncologists, who was in San Francisco, and have him go over all of my liver panel results. So I went to see him and he read all of my papers and he said, "First of all you were over treated, second of all you should not have had radiation." So I stopped the Tamoxifen and my liver panels went back to normal.

I interjected that there are "a lot of women on Tamoxifen" (including me). And Arlene responded, "Tamoxifen is one of the best drugs we have." Then she added, "But if the patient has a problem and she had this intuition that there is something is going on, I think she should investigate it." I asked Arlene if she thought "breast cancer is teaching women to trust their intuition." She responded:

\footnotetext{
${ }^{35}$ A liver panel is a type of test that shows if the liver is functioning within a normal range.
} 
Oh, absolutely. Any disease, any life-threatening disease. Once you get hit in the head with a disease that can come back and kick you in the head, can come back and kill you, you start paying attention. First of all, the physician is not the one that has the disease. You are. And he is not going to fight for your life. He is going to do what the book says.

Arlene described one of the struggles the breast cancer advocate faces.

We have so many different cultures in this country that it is absolutely impossible to be culturally sensitive. First of all, you are not dealing with just one generation; you may be dealing with three generations, and within those three generations there are different ways of thinking.

She spoke to the current system that sometimes treats women who "don't have any funds as if they don't have any brains." She continued, "It doesn't matter if you don't have any money; you still can be a person with the responsibility for your health and the health of your children."

Arlene said that Hispanic women face additional challenges. "Their culture tends to put the woman last, and it is about time that they put themselves first." She continued, "Cervical cancer is very prominent in Hispanic women. That is their number one cancer. Why? Breast cancer is a disease of white women. Why? Are we genetically different? I don't know."36

\footnotetext{
${ }^{36}$ California data shows that white women have the highest incidence of both invasive and in situ breast cancer. The incidence rate is about 20 percent lower among black women, and more than 40 percent lower among Hispanic and Asian/Pacific Islander women. Website of the California Cancer Registry, http://www.ccrcal.org/Spotlight/spotquotes2.html.
} 


\section{Struggle/Strengthen}

Arlene understands breast cancer - not just her own, but the trends of the disease. She has given much thought to the "why me" of breast cancer. She said,

The greatest risk for breast cancer is being a woman. The second greatest risk is being an older woman. So you know you can't say Type A and Type B are different. It is such a complex disease. You have two women with the same exact diagnosis and their outcomes are totally different. So if all those diagnosed with infiltrating ductile carcinoma, Stage 2, you would think they would have the same outcome, but they don't.

She voiced concern that women are now being given the impression that mammograms alone will save their lives and said women need to remember that mammograms are "not treatments; they are a detection method." Arlene spoke faster and faster as our time was ending. I thought that she wanted to get some more important ideas into her interview. She stated, "We get caught up with the fact that we have been diagnosed with a life-threatening disease and we may die from it. But we don't think about the science and the studies." Arlene had a way of taking the scientific "mumbojumbo" and putting it so it can be understood.

But, you see, people forget that you can't get cancer from somebody else. It is your own gene [cells] gone bad. You could have been born with a screwed up gene that never develops into cancer. You could have been born with a screwed up gene that shows up when you are 36 . And in those 36 years something from the outside has been hitting you and has been changing those genes. And once they change, you know, your body is an amazing machine- 
it could be that your immune system kills them and they don't propagate. Or it could be that your immune system missed one and that one decided to find a home in the breast.

In describing her involvement in and her transformation relating to politics at the national level, Arlene explained that in "1993 there was $\$ 90$ million for research. Today, the National Cancer Institute has more than $\$ 700$ million." She is an observer for the Department of Defense Breast Cancer research program. She said at first the "scientists were up in arms saying, 'What do these women know about research? We don't want them there and they can't vote.' Now they really like us. They think we bring a human face to the table."

Additionally, she worked with California State Senator DeDe Alpert to "get a contribution line." She explained this is "where residents of California, when they pay their taxes, can donate money to this particular cause. If they owe money to the state they can add on to what they owe with a little note that this money has to go to breast cancer." This "line" passed in 1996 and brought in $\$ 250,000$ for research that year. "Now the line makes about $\$ 600,000$ a year."

As Arlene reviewed her political efforts at the national and state levels and a quarter century involvement with breast cancer research she remembered a time when she reached out to a young Hispanic woman. Arlene was about to begin her own radiation regime. A woman from the radiation center contacted Arlene and asked her if she would mind picking up a woman who didn't speak English and didn't have a ride to get her treatments. Arlene said "sure" and picked up the woman, who had "no money and three kids." Arlene took her five days a week for seven weeks of radiation. "I told her, 'I don't mind picking you up but after we get the radiation I don't want to go home. I want to go out and go shopping, or have 
dinner, or something." So they did these activities together. Over the course of the seven weeks she and this woman became close and Arlene realized this "woman didn't have a clue what was going on with her."

Spending time with that young woman helped Arlene get through her own radiation. More importantly, spending such time with a woman who was so vulnerable and who had so few resources helped build the understanding that Arlene has used to become a voice for all women with breast cancer, especially those who, like the woman she assisted in chemotherapy, desperately need assistance in understanding the disease and its treatment. Reflections on Arlene's Transformation

Arlene has become educated and very knowledgeable about breast cancer and has sought to educate others about this disease. Arlene has worked diligently so that all women, regardless of race, ethnicity or socioeconomic standing, can receive mammograms.

Arlene's transformation is work related. Before diagnosis, she worked as an office manager and she now sits on the board of state and national organizations directing millions of dollars to breast cancer research. This woman, who was born in Costa Rica 62 years ago, can pick up the telephone and speak to state senators or to a nationally renowned doctors and breast cancer researchers.

Arlene's calming voice brought comfort to me concerning my own fears of dying from this disease. I can still hear her saying to me, "Breast Cancer is an emotional emergency, not a medical emergency." As I replay her words in my mind, they bring me comfort. She has survived breast cancer for over 40 years. I pray 40 years from now that I am alive to say such words of comfort to other women. 
Krissy's Story-Introduction

Krissy was diagnosed at 40 years old and was 43 at the time of the interview. I had not seen Krissy for about three years before our interview. The last time I saw her, she was in mid-treatment for breast cancer and wore a wig that resembled her own hair. She said the wig was supposed to have a "Jennifer Anniston look." At first it did, but because she wore it for months during treatment it eventually got "fibery stiff and could kind of like ride out from my neck." As Krissy told me about the wig riding out, she reached back to her own neck and moved her "now" hair, blonde and shoulder length, and pulled down and I imagined that the movement of pulling down the wig had probably been performed by Krissy, subconsciously and consciously, thousands of times so that her hands may never forget the motion, not unlike the subconscious and conscious motion of moving a hand up to cover our eyes when we walk outside into the sun.

I've known Krissy since we both attended the same church several years ago. She always reminded me of Sandra Dee in the movie, "Gidget." In the movie, Gidget was perky and fun and knew just how to handle the boys. Even at 42, with time and all of the ravages of breast cancer, Krissy holds on to a guileless Gidget-like charm. Krissy is the young woman I wish I had been. She is wholesome, and doesn't swear or appear to think bad thoughts about herself or others. She is short and blonde and has a ready laugh. She has a timeless movie star-white smile and laughs with her whole body.

Krissy's only work experience was as a clerk in a bookstore while her husband was in college and as a part-time preschool teacher before her first child was born about 18 years ago. However, as her story shows she transformed herself into a commercial artist as a result of her recovery efforts. 
During our interview, when Krissy had something serious to say she leaned in for emphasis. She seemed to be watching and learning from everything. Krissy described herself as a "visual person"-_"one who learns from her eyes. She even blinked infrequently.

Krissy initially stated that she could not imagine having more than three minutes worth of information to share with me about herself. I assured her that was fine, just to begin at the beginning and we would end when she was done. After she had spoken for over 30 minutes (virtually uninterrupted) she threw her head back in laughter and said, "See, there is a lot to talk about. So much for my three-minute thing."

The following text quotes Krissy extensively, I use paraphrase for the following three purposes: (a) to provide information, (b) to make the presentation more succinct, and/or (c) to clarify transitions.

Surprise/Suspense

Krissy began by explaining her family's history with breast cancer. I was attending church with Krissy when her mother died. I remember Krissy's sadness. On the day of our interview, Krissy went even further back into her family's history with breast cancer.

When I was on my way to my tenth birthday party, we were going to see "Chitty, Chitty, Bang, Bang," and we got a telephone call that my grandmother, who was a nurse, had had a seizure on the hospital floor and it turned out that she had breast cancer that had metastasized to her brain.

She said her grandmother "grew up in a convent, because her mother had died when she was a young child and the story of that-they think it was breast cancer."

So this was a family with at least three generations of women with breast cancer, likely four. Since Krissy had a daughter now in second grade at the time of our interview, 
I'm sure she fears for her daughter, Megan, as I do for my own daughter, Laura. While only $5 \%$ to $10 \%$ of all breast cancer cases "result from inherited mutations in breast cancer susceptibility genes" 37 and "shared lifestyle factors may also contribute to the familial occurrence of breast cancer," in Krissy's family these phenomena appear to be real concerns. Krissy's mother survived more than 5 years after her initial diagnosis with breast cancer. Krissy recalled that she was with her mother at a family reunion in Colorado when her mother found a lump in her neck that signaled a reoccurrence of the disease that within a year would kill her.

Because of her family history, Krissy had been "looking over her shoulder" for years. She explained:

I have then this increased fear of breast cancer and I could just feel it in me. It was something that was just there all of the time and I didn't know what to do with it. I was in my early childbearing years, at this point, late 20 's early 30 's and I started going in for mammograms and once they found a calcification and that really threw me for a loop. Then I got pregnant with my third child and I didn't know I was pregnant and I felt this lumpy breast. That terrified me and so I went in and found that I was pregnant and that was why I had the lumpy breast.

Even with her family's history and after all her precautions, Krissy was nevertheless surprised to find the lump in her breast when she did. She had just been to the doctor for a mammogram, had been given a careful examination and nothing unusual was found. Just a few weeks later, when Krissy was on vacation with her own family she found a lump in her

\footnotetext{
${ }^{37}$ Quotes in this sentence are from "Breast Cancer Facts and Figures 2001-2002" [Electronic version], website of American Cancer Society, http:/www.cancer.org/downloads/STT/BrCaFF2001.pdf (p. 10 of that URL)
} 
breast. They continued their vacation and Krissy and her husband, John, attempted to think of ways that it could not be breast cancer. They were "off-roading" with their family at the time and tried to blame the lump in her breast on the fact that the seat belt had created a contusion or bruise. She laughed during the interview about how they tried to keep the diagnosis at bay during this vacation and the stories they came up with to explain away the unwanted mass growing in her breast.

As soon as they returned home, they went to the doctor together. The doctor, without a formal test and just by physical examination, told Krissy and John that she was sure it was cancer. Krissy spoke almost in a whisper and uncharacteristically slowly, "She [the doctor] looked at the X-rays and she felt the tumor and she said, 'I'm almost positive that this is a cancer.' And then she did the biopsy.",38

Study

Krissy was very familiar with breast cancer long before her diagnosis. In fact, Krissy's life had been a study of breast cancer. She had gone to her mother's chemotherapy appointments with her and gone through the life and eventual death of her mother from breast cancer. Krissy and her mother were "very close." So there was hardly anything Krissy didn't know about the disease, except maybe how, exactly how, to survive it herself.

Right after Krissy's mother died, and before Krissy was diagnosed, Krissy's first cousin, Lisa, was also diagnosed with breast cancer. Krissy responded to my question about the family relationship:

My mom's brother's daughter. So after my mom died she [Lisa] had married and had her first child and when she had her second child she was having

\footnotetext{
${ }^{38} \mathrm{Krissy}$ is the only one of the women in this work who received a diagnosis of cancer from a doctor just based on a physical exam. Her doctor must have been very, very sure to make such a dire prognosis so early.
} 
trouble nursing. And she felt a large lump in her left breast [as Krissy reached for her own left breast]. She told her OBGYN about it and kept saying you have a milk duct, you know, swollen, clogged, milk duct. She kept having troubles with it, and he kept saying, kept saying over and over again, "It is a swollen milk duct."

Finally, she was at the pediatrician's office and she complained about the lump again and how she was having trouble nursing. He checked it and told her she needed to get to a doctor right away. It was the size of a tennis ball at this point. [Krissy repeated in horror] It was the size of a tennis ball at this point.

And so she had cancer all through her body. New babies. And had to prepare to die. She was under some program that you make sure that you are doing the things that you need to do at the end of our life [I noticed that Krissy did not say at the end of her life, but at the end of "our life" I found that hard to hear and was deeply sad, but felt that any comment I would make would be inappropriate-or maybe I just didn't know what to say]].

\section{Separation}

Krissy underwent chemotherapy, and she described her husband's support when she lost her hair:

John was really good about this. After every change he always got me out in public. "Time to go out. We are going out to eat." So we went to the wine bar by the little Italian place by Harvest Ranch and we sat at the bar and there was a mirror across from the bar and I could see myself and I put on a little 
baseball cap. I was sitting there with my lemon water, looking at myself in the mirror and it was kind of depressing for me, and I was trying to be upbeat. So I just remember that was like a pinpoint moment for me. I felt separate fromat that point I felt separate from-normal life.

I asked her to elaborate. She continued:

Well, I will try. It is like you go from being a normal person, a normal part of society, to being different. You are like on the edge, you are physically changing. You might be dying. It is almost like a little bit like being a ghost, or something where you move over into that. Out of the mainstream and into that limbo land, or something. And sitting there seeing myself in the mirror like that, changing, not knowing where I was going, being separate. I was different now. I wasn't just one of the Mom's-I was a needy person.

Krissy elaborated on the separateness she was feeling from others on a deeper, more personal level.

And friends through all of this tend to-I think elevate you-and I felt they thought I was so wonderful and so spiritual and I'd learned so much about God. I was an example of experiencing God's peace and trusting God, and I felt that again was another way of feeling separate from everybody else. Because of the distance. There was always a part of me, even though I was feeling different. “Well, Yes. I'm experiencing God's peace and I have faith, and I'm just Krissy here."

Krissy and I began an interchange about the subject of how cancer had separated us (she referred to both herself and me) from others. My interjection was, "Yes, but what are 
our options?" She responded, “Right exactly! It isn't that I'm that brave and wonderful. It's just that I don't have many options here. It is so true." At that moment Krissy and I engaged in a laughter that is beyond the level of our relationship. We probably have not spent four hours together in the past four years and we were laughing like best friends. We both knew that having cancer had separated us from others and we both had received from others more awe and wonder than we deserved. We just really had no other options. We then almost simultaneously said, in almost the same words, "It's not that I'm such a wonderful person, it's just that the options are limited."

So I asked Krissy, “Did you ever feel like a leper?” She replied, I didn't feel like a leper, but I thought that sometimes people might think that I was unclean. And a leper could be a description of feeling isolated, outside, outside the main flow of society and what has gone on before.

\section{Surrender/Reflection}

Because Krissy had been through the lives and deaths of two close relatives with breast cancer, she was more prepared that any one should have to be for her treatments. Eventually she found out that she had metastasized breast cancer-one of her lymph nodes also showed cancer. She was not totally disappointed that the cancer had spread because she had feared that she would be under-treated. She feared a false negative (an erroneous diagnosis of no cancer) more than a false positive (an erroneous diagnosis of cancer). She had always believed that her mother was under-treated when she was diagnosed with a reoccurrence of cancer. Her mother was given medication but no chemotherapy or radiation right after she discovered the lump in her neck. Krissy said she and her mother believed that being under-treated initially caused her mother's cancer to advance to a point of no return. . 
Krissy was immediately ready to undergo chemotherapy. She was to be given the "red devil" of chemotherapy, Adriamycin. Because this was the same regimen her mother had received, Krissy said she knew that she would not only lose her hair but could also lose her toenails, eyelashes, eyebrows, and that she would be desperately sick.

Krissy also had to decide between having a lumpectomy or a mastectomy. [Some women don't have the option of lumpectomy, as occasionally the cancerous lump is located too close to the surface of the breast or is very large then a lumpectomy would leave a woman very disfigured.] For Krissy, the physical results from a lumpectomy would be satisfactory and not very disfiguring, but the question was whether or not this was a good move medically. Some of the data shows that women recover from breast cancer equally from a lumpectomy plus radiation of the affected breast, as compared to a mastectomy, but other data shows that women recover more often with a mastectomy. Krissy got second, third and fourth opinions, and she met with doctors in two cities.

Krissy enlisted her family to help make this decision. Her husband John, her father, her stepmother and her children were all given a voice in the decision as to whether to have a lumpectomy or a mastectomy.

And it was family time where everybody pulled together, and we were all out in the garden. And I remember my Dad really pulled in, and we prayed for God to just tell us what to do. It was so overwhelming. I got this telephone call from this woman cancer specialist from UCLA, I believe, and she happened to be a woman about my age and had children. She said, "I wouldn't mess with it, I would just get that breast off of there." 
Krissy was very clear about what her ultimate goal was. The mutilation of a mastectomy and the ordeal of chemotherapy were chosen to assist her in reaching her ultimate goal: "My whole goal is longevity. I want to raise my kids and take care of my kids."

Krissy's surrender to the drastic surgical treatment aligned with my own resolve about having a mastectomy. She sat up straight and looked me in the eye and said she went into the hospital to have the mastectomy "with great confidence."

Krissy then mentioned that she had "five surgeries in the last two and half years." She asked me if I remembered the feelings I had when I went in for my own surgeries. I quietly responded, with an almost inaudible and otherworldly voice as the impact of those recollections almost overpowered me, "Yes, I do."

She continued:

You remember, in the morning and you are going down there [to the operating room] and you have to kind of brace yourself to go into this kind of tunnel but I could do that. There was a kind of strength for me. So we took that baby off and I started chemotherapy right away.

I gasped out loud as she referred to her breast as "that baby." For Krissy, having four children and being the "Little House on the Prairie" kind of mom, babies hold a special meaning to Krissy. I have watched her watch her children. Her love for her three sons and her daughter fills whatever room she occupies with them. Krissy is the kind of mom we all wish we could have had. It would be difficult for Krissy to give up a baby. The only way to do this was to make it "that baby"-that baby that does not belong anymore. I realized anew how much she loves her children and giving up the part of her body that had helped her to 
"baby" her own babies was difficult. Krissy heard my gasp, but I covered it up with a laugh; she laughed, too. Perhaps neither of us wanted to talk about giving up our babies.

To change the subject I asked her about the type of chemotherapy she had and if she had chosen to have "the strong one" or if her oncologist had chosen it. She responded, "That was my oncologist's choice. I don't remember when I first met her. But I remember that feeling-going to an oncologist-my absolute worse nightmare." The last four words were spoken loud for Krissy, and she hit the palm of her left hand with her right in a four-part beat as she spoke, "My absolute worst nightmare."

Krissy then asked me, "And what do they call the radiology?" I responded in a frightened, almost inaudible, whisper, "Radiation oncologist.” She responded, "Yes, radiation oncology. Radiation oncologist." Saying those four words slowly and with a heaviness that does not usually accompany her communication. As she spoke the next sentence she moved both of her hands in front of her eyes palms inward, then she carefully moved her right hand right to the right and the left hand out to the left, "It is like passing through this veil of something into this place I tried so hard to never go."

She surrendered her will and her body to the chemo ward:

First of all, entering there was that disbelief and overwhelming fear, but at the same time God had given me peace through all of this and He was with me, and my husband was with me. So I put one foot in front of another and went and did what I needed to do. I was at peace and convicted. Yet, still overwhelmed and scared. But the feeling after going into the chemo lounge. ${ }^{39}$ It was a big chemo lounge, at least it seemed big to me.

\footnotetext{
${ }^{39}$ Typically, a room filled with recliner chairs; patients receive intravenous delivery of chemotherapy drugs, which can take several hours.
} 
As Krissy described the "big chemo lounge," I looked at her sitting on my couch, and for the first time I thought of Krissy as vulnerable and small. As she described the chemo lounge, she actually looked about six years old. She was sitting so that her feet were not touching the floor, but swinging free, like an elementary school girl in a desk she had not yet grown into. It feels as though none of us is ever big enough to take on chemo. It seems like there is too much chemo and too little us.

Krissy looked so small, vulnerable and overwhelmed, but somehow I needed to say something to break the sadness I was feeling. I pulled myself together and managed to choke out a short question, "Did you stay the night there?"

She responded, "I would go in for, I would probably be in for, about four hours. I don't hold onto a lot of the details because I kind of moved on."

Krissy's comment about "not holding onto the details" took me aback since by the time I interviewed Krissy I had interviewed all but one of the women for this study. And none of them dwelt on the chemotherapy experience. Each of them "moved on." The women did not want pity. Could this lack of feeling sorry for themselves, this lack of feeling pity for themselves or wanting pity from others, be one of the linchpins for transformation?

\section{Struggle/Strengthen}

Krissy said, "Let me tell you about how the art became part of me." At the time of the interview it seemed to me that this comment was like a wide right turn in the conversation, but more I thought about it, the more I saw how Krissy was explaining that surrender and reflection had put her more in touch with her creative side. Early in the interview Krissy had described herself as a "passive person." She "married really young" and

\footnotetext{
${ }^{40}$ The connection between illness, art and creativity is nicely explored and explained in Sandblom, P. (1999). Creativity and disease. How illness affects literature, art and music. New York, Marion Boyars Pub.
} 
received a lot of emotional support from both her husband and her father. Along with that support came a certain amount of influence and control from them. However, she described how that dynamic changed when she fell ill:

There is all of this support, but you are the one going through it. And so somehow you have to function on your own and I don't think I needed permission to make decisions as much as I had before. This has changed family dynamics. I feel like I have a lot more slack.

After surviving breast cancer, one of the ways Krissy had learned to function on her own was to give herself permission to be a successful artist. Krissy had always kept her passion for art under wraps and had not taken an art lesson since high school. Before breast cancer, she never considered taking lessons again and had not even remotely considered selling her art. This is at the heart of transformation for Krissy. She described how this happened:

I was going through chemo and my husband fixed up the garden for me as a kind of a healing place, and it really has been incredibly wonderful that way. He hired an art teacher to come into the yard, a contemporary art teacher. I felt kind of intimidated. And he bought me the easel and the supplies and everything and this guy came and I was supposed to paint. And it just felt really funny. But like we've talked about before there was something about, "Why the heck not? Just go, just do, and just be." You have to kind of grab onto that. You know what are you-you can't wait. So I just, “Why the heck not" and started growing from there. So I'm still pursuing art and I'll probably go to college and complete a degree in it. That is the goal I have. But in the 
meantime I'm enjoying it and I am growing as an artist and it is completing for me. It gives me an identity outside of my children and my family. And it is a place where I can see myself growing incredibly as years go by. It gives me a real future perspective on things.

I asked her to describe her work in more detail:

I'm doing an American flag on the side of a colonial home in Southern California. It is really big and it is supposed to look like the side of an old barn, so I've actually been learning faux techniques. I feel like wherever I go with the art God just opens doors. You know if I take a watercolor class, [then] I'm selling watercolors. If I do portraits, I've got people calling me to do portraits and sketches. If I paint then they are having me do these paints in their homes. I have this big commission for a big painting about this big [ 5 ' by 5'] of geraniums that is going into an Olivenhain home. So it is just I guess being open enough; I guess there is an openness or something being willing to share who I am more, what I'm doing and just do it. And not think I can't not holding back about it. I think I've lost that. Yes, it is just going. And that came since the cancer, that feeling of moving ahead.

Krissy has plans to have her art make enough money to put her four children through college. Art, and this new feeling of identity and new sense of strength, has been a gift to Krissy that was born in the midst of her struggle of surviving cancer.

\section{Reflections on Krissy's Transformation}

Krissy was diagnosed with breast cancer seven years after I was diagnosed. I can remember the day I heard she had breast cancer. I was devastated. And I'm embarrassed to 
say that I didn't want to call her. I knew the road she was about to travel and I did not want to explain to this dear woman what she was in for, even though she probably knew from her experiences with her mother. Krissy has always felt like a daughter-friend to me. She is so guileless and so kind. I just did not want this innocent to have to travel through the horror of chemotherapy and fear. On some level I love Krissy and it was wonderful to see how well she is doing on this side of beast cancer.

Krissy has taken a hit in life and has managed to keep her smile and her joy. The transformation for Krissy is her art. She never considered doing art before and probably would not have taken time out from her family to paint. But now she sees herself as a commercial artist, a transformed identity that came from the diagnosis of and recovery from breast cancer. 
Sherry's Story-Introduction

Sherry was diagnosed at 42 . She was 47 at the time of the interview. She was married at the time of her diagnosis and spoke warmly of Tom, her husband of over 15 years. She is one of two women in this study who had not had children. Sherry is a successful dress designer and her husband is in sales. Their home, where I interviewed Sherry, offers a noteworthy and out of the ordinary combination of their apparent different styles. Sherry has painted the kitchen a bright, designer yellow-orange, and has vivid deep blue glass objects in almost every room that catch and distribute energetic light that seemed to follow me as she gave me a tour of her home. Those bright colors noticeably contrasted with a large black leather sectional sofa parked in front of a huge wide-screen TV. This contrast had me wondering if her husband had selected the couch and she had selected the rest of the furnishings. If this was true, then their home appeared to be a combination of these two highly successful individuals' differences sitting comfortably side-by-side. Sherry shows emotion when she talks while moving her hands in rhythm to the story she is telling, rather like a conductor of her own story. Her hands, as well as her words and eyes, gracefully led me though her experience of surviving breast cancer.

Sherry was a total stranger to me; we met through an Internet referral. When I first entered she greeted me with a warm toe-to-cheek hug. When I left, we both hung onto each other for a few extra seconds. She thanked me for my time and interest in this important subject. I wasn't sure exactly what to say. I'd been quiet so long and was so interested in her that I was uncharacteristically speechless. She said, "There is nothing out there that tells the good stories of us survivors," and thanked me for doing the interview. She had taken nearly 
two hours with me and had shown me the rooms where she designs women's clothes and conducts her business.

Sherry told the first part of the story in two voices; the first voice sounded like that of a defenseless little girl, a little girl growing up in a world of unpredictable adults. The second voice, the strong voice, sounded like that of a woman who would not be manipulated. Sherry's voice varied as she told her story from the voice of a victim to the voice of a survivor - of a woman who has learned how to protect herself.

As the interview progressed the intensity between us grew; at the 20-minute mark we were both leaning closer to each other, seemingly at each sentence. We were like two schoolgirls joining forces against the school-yard bully. In fact, at that time my hand was draped over her green Adirondack chair, resting right behind her right hand. We were sitting on her quiet patio at the back of her house, her two large guard dogs next to her, neither of them comfortable while I was there. It occurred to me that since Sherry works at home, alone, she might not have many visitors during the day. These dogs were like friends to her. At one point Sherry leaned back in her green outdoor wooden chair. I noticed that the chair was lighter than, but the same shade of green, as her eyes. I thought of the importance of color and symmetry in this dress designer's world.

The following text quotes Sherry extensively, I use paraphrase for the following three purposes: (a) to provide information, (b) to make the presentation more succinct, and/or (c) to clarify transitions.

Surprise/Suspense

Sherry started this way: "I'd always been athletic, tried to eat right, took care of myself, so when I found a lump, my doctor-my OBGYN—she said it didn't look like 
anything, it didn't feel suspicious, I should not worry about it." Sherry had developed a very close relationship with her OBGYN because of the sensitivity and kindness the OBGYN had shown her when she had two emotionally and physically painful tubal pregnancies.

Although Sherry was told not to worry, her doctor wanted her to get a mammogram. In fact, her doctor kept sending her "little notes" to remind her to get the mammogram, but for about six months Sherry ignored them. ${ }^{41}$ Sherry's OBGYN "kept sending them in the mail; I thought this is the universe's way of saying, go get your mammogram. So finally I did." Another physician, Dr. M, took over, as described next. While telling the story of her initial exam for breast cancer by Dr. M, her green eyes grew wide and her left hand rested on her lap, while her right hand started moving in atypical nonsymmetrical movements.

For her mammogram, Sherry went to a major hospital, a research facility connected to a university close to her home. Sherry had a 9 a.m. appointment and after Dr. M did a physical exam, without introduction or asking for Sherry's consent “four or five more doctors, all young, all male, kept coming in to check the tumor." Then Dr. M. sent her "down the hall for a sonogram," and another wave of "all male, young men, like interns or whatever" entered uninvited and unannounced into the sonogram room. Sherry's voice drew down to whisper their unwanted request, "Can we check you?" She said she kept wondering why they were doing this to her. Then Sherry's voice changed and she used a more powerful and louder voice as if to address the intruders:

Who is he and how is he associated to me and where did he even come from? Isn't he seeing patients? You know, isn't he busy? You know, I know how

\footnotetext{
${ }^{41}$ Sherry's OBGYN is one of a handful of doctors who fair well in this study, in part because she went above and beyond standards of medical care to remind Sherry to get a mammogram.
} 
busy doctors are and it is hard to see a doctor, but these young men had time to come and see, and to check out this tumor and so, why?

Sherry came to the conclusion many of us would come to from all of this unsolicited attention: That the only reason so many doctors were interested in feeling "Mrs. Brown's lump" was because she had cancer. Without her permission, she had become a "teaching case."

Looking back at that experience, Sherry expressed surprise at her initial timidity and passivity in letting so many doctors treat her as if she was an object. She was unhappy that she allowed herself to be "manhandled" by all of "these horny doctors that just want to." She described being cold, feeling defenseless, and not knowing the diagnosis of this unwanted lump. At first she would ask these uninvited intruders if they thought her lump was cancer, and after repeatedly being ignored, or given platitudes, she just gave up and laid back on the table and allowed these invasions without comment.

Within a few hours it became clear why Dr. M. was rushing the normally longer process of diagnosis into one day. ${ }^{42}$ At noon the same day as her first appointment, Dr. M hurried to do an immediate needle location biopsy "during her lunch hour." Sherry described this procedure as "probably the most physically painful thing I've ever gone through in my whole entire life. She took three vials of fluid and without any anesthesia, and without any warning, ${ }^{43}$ out of my breast, out of the tumor, which now, looking back, I mean how dare she because she didn't even give me a choice."

\footnotetext{
${ }^{42}$ The process for delivering test results for breast cancer is often between three days and three weeks.

${ }^{43}$ Sherry is the only one is this study to describe being rushed through any procedure or treatment.
} 
Dr. M. told Sherry her tumor was too large for a lumpectomy. ${ }^{44}$ The larger the tumor the more likely a mastectomy and reconstruction would be needed. Dr. M said Sherry would need to have an immediate mastectomy. Then Dr. M. told her that she needed 1,000 women for a large research project that Dr. M. was heading up. Dr. M. told Sherry she could become part of the study if she had the immediate mastectomy. Sherry's diagnosis fit perfectly within the parameters of the study, namely, a woman with a 4-1/2 centimeter tumor who was a candidate for a mastectomy not a lumpectomy. The study involved introducing a new chemotherapy drug not yet accepted by the federal Food and Drug Administration. Sherry took over a month to let Dr. M. know that she would not be part of the study. It took a lot of courage for her to look at her doctor and to say "No," especially when she felt so vulnerable to breast cancer and when doctors are thought of as the holders of our passports back to health. She said, "I kept thinking I don't want to be experimented on with this new chemotherapy, because chemotherapy is so dangerous."

Study

Sherry began her study of this disease the night she found out she had breast cancer. That night "my husband and I went to the bookstores and I got every book written on breast cancer." Weeping and in metered words, she recalled:

I brought them all home, and I read everything that I could, I wanted to become -I became-an amateur oncologist. Because I wanted to ask the right questions, and I wanted to get the right treatment that was right for my particular situation. I didn't want any more trial study information. I didn't want anybody telling me the wrong information, And I think oncologists and

\footnotetext{
${ }^{44}$ For a woman to be a candidate for a lumpectomy she needs to have a small enough tumor that when it is removed enough breast tissue remains so as to have a breast that she would be pleased with.
} 
surgeons, they are business people, they want your business, so they are going to tell you that they are going to cure you, they are going to make you better, no matter what. 'cause that is their job and that is what they believe in. So I read as much as I could, from everything from diet to attitude, to medicine, to other people's stories. I just found a wealth of information out there, and that helped me through my treatments and my cure because I felt like and I still feel like I'm as smart as the disease, you know, or smarter than the disease I should say. So hopefully I'll be that for the next 50 years.

For the next five weeks Sherry did her homework. She interviewed doctors and "none of them mentioned the trial study and I didn't ask them."

She then leaned upward and for emphasis put both of her hands in the air, like waving for a lifeboat, before she said loudly, "Not one doctor mentioned that I needed a mastectomy!" She seemed embarrassed by the volume of her last words-loud enough for her neighbors to hear. She then whispered the next sentences, that all of the other doctors confirmed

my tumor was only $1-1 \frac{1}{2}$ centimeters, so they [Dr. M.] inflated my numbers to get me into the trial study, so if they had tried their chemotherapy drug on me it would probably, now looking back, thinking to myself, the initial chemotherapy treatment shrunk the tumor by $3 \frac{1}{2}$ centimeters, because it was initially 3 centimeters smaller than they had diagnosed it.

The dogs started to bark uncontrollably. They seemed to be Sherry's barometers. She was distressed, they were distressed. We probably both needed a small break from the tension and from her recollections of how she felt let down by a doctor who was supposed to 
help cure her. Sherry quieted the dogs, like a mother with anxious children, ushered them inside the house and closed the nearby sliding screen door.

When Sherry sat down again, we both paused for a minute. I let the beauty of the backyard enter my troubled mind. Sherry started breathing, big deep, cleansing, yoga breaths. This was a lot for us both to take in. The only enemy in cancer is supposed to be the disease.

Sherry returned to her story and described that the last meeting she had with Dr. M was heated. Dr. M. told Sherry if she would not agree to be a part of the trial study, then she would not treat her. Sherry replied to Dr. M., "What about me? What about Sherry?" Dr. M. replied, "You have to think of our sisters of tomorrow." At this point in the interview, Sherry spoke again in her strong voice and pointed her index finger at (an imaginary) Dr. M: "Right now I'm thinking about me and my family, you know. I want to live, I want them to live, too, but, you know, I want to be taken care of." Sherry chose a different doctor to perform her surgery.

When Sherry studied breast cancer she found that some Alternative Medicine ${ }^{45}$ resources recommend a very healthy diet for faster recovery from breast cancer. ${ }^{46}$ In the six weeks between her diagnosis and surgery, Sherry drastically changed her diet and that change in diet, she believed, changed the way the lump felt. ${ }^{47}$ Sherry described her lump

\footnotetext{
45 "Alternative therapy" is the use of an unproven therapy instead of standard (proven) therapy. Some alternative therapies have dangerous or even life-threatening side effects. With others, the main danger is that the patient may lose the opportunity to benefit from standard therapy. The American Cancer Society recommends that patients considering the use of any alternative or complementary therapy discuss this with their health care team. Website of the American Cancer Society, http://www.cancer.org/docroot/GRY/GRY_0.asp?dictionary=\&pagKey=A.

A more favorable look at alternative therapies can be found in almost any bookstore or library. See, e.g., Burton (1997), An Alternative Medicine Definitive Guide to Cancer (Future Medicine Publishing, Inc. Tiburon, CA)

${ }^{46}$ Many Alternative Medicine regimens feature food and dietary recommendations.

${ }^{47}$ Her description of the lump is unique from any of the other women in this study. All of the other women described their lumps as "stuck."
} 
initially as "stuck," but it changed as she changed her diet; she said it became "real hard, like an M \& M," but it had become more mobile. The American Cancer Society deems any treatment for cancer that is not surgery, radiation or chemotherapy "Alternative Medicine." Sherry added:

I changed my diet to vegetarian and I took wheat grass three times a day. I changed to totally organic and I cut out any sugar, anything that would feed the tumor. I did a lot of mental exercise to get myself prepared for the surgery, and the tumor seemed to be shrinking.

\section{Separation}

Her first chemotherapy treatment was right after New Year's, and soon thereafter she lost all of her hair (plus toenails, eyebrows, eyelashes) to "the big dog of chemotherapy Adriamycin." During the six months of treatment Sherry went with her husband on a business trip to New York. She made a deliberate choice to not wear a wig during treatment, and chose instead to wear hats. One night Sherry and her husband went to a play on Broadway, and because she was completely bald she simply put on a hat and was ready to go. With great peals of laughter Sherry related during our interview how easy it was to get ready to go out during chemotherapy. "My husband would say, 'Let's go out to dinner,' and badda-bing, badda-boom, little eyeliner, little eye shadow and some lipstick I was ready to go. I didn't have to curl my hair. I didn't have to shampoo." However, that night in New York, Sherry was treated to a type of painful behavior that exemplified what women often experience during the course of recovery from breast cancer, a reminder that she no longer fit in the mainstream of life: 
We [my husband and I] went to a play and the people behind me very rudely asked the usher if he could please ask me to remove my hat. I said to him [the usher], "You tell them I won't remove my hat. You tell them I have cancer." And I didn't take off my hat. I wasn't in their way; it was stadium style seats [so they could see fine].

Sherry felt separated not only from strangers but from her friends whom "she did not want to feel sorry for her."

Probably $75 \%$ of that was me, because I didn't want them or let them to feel sorry for me. I never really talked about it, what I was going through. And if they did feel sorry for me, they didn't show me. But the one thing that I do notice is that people whispering behind my back not so much lately, for the first two years or so, they would say [in a whispered voice] "Tom, how is she doing?" And things like that. And I said to my husband, "Don't they think I can hear them asking about me?" Ask me! Don't say it behind my back, and this I've heard from the other women, too, other breast cancer survivors that I've talked to; they hate it.

Sherry whispered as she reflected about those times when she would walk into a room and everyone would become quiet. Hearing the whispering that goes on behind her back, hearing her name mentioned, but only hearing some of the words spoken about her felt like a torture worse than the catty taunting of one's junior high school days. Whispering has a way of making us feel like we are in a group and at the same time not in the group, a separation that is most painful. 
The feeling of separation also came unwittingly from those who loved her, who treated her like she was fragile and terminal. This made her feel separate from those she loved and needed the most:

When I have a pain I'll tell my husband and he will tell me to call the doctor. Then I tell him, "You need to chill or I'm not going to tell you anything any more." Then later he will say, "How are you feeling?" And I'll say, "I'm feeling great." If I can forget about it, why can't they forget about it? It is like they are just waiting for the next bomb to drop.

\section{Surrender/Reflection}

Sherry told of a time, three years ago, right after she was diagnosed with breast cancer when she and her husband were at a party. Sherry, a self-proclaimed introvert, said she was "standing by herself " and a woman she hardly knew came over and "dropped a bomb" on her. The woman had just heard of Sherry's diagnosis. The woman cornered Sherry and told Sherry this story: "My husband's favorite secretary had a headache one afternoon and went home and died because the breast cancer was in her brain and they didn't find it, so it had metastasized to her brain."

It took this woman less than one minute to drop this bomb, but three years later Sherry is still dealing with the fallout. Sherry continues to be traumatized by this story; she still cannot take a nap if she has a headache. "I get a little pressure behind my eye, and I think, 'Oh! It's a tumor! I'm going to get it.' I get a little headache and I'm like, 'It's metastasized!"” 
She said she can't understand why people think "just because you had cancer you want to hear all of these horror stories and in detail." She wondered out loud why people don't know that "words stick." She said:

If I had a friend who was sick the last thing I would do is to tell them a story of how someone else who was had the same sickness had suffered. I would not tell them how he died, and how long it took and then how quick he went. And before he died after he got his leg, arm and ear amputated and then he had to hobble without a wheelchair and didn't have any insurance and lived on the streets and begged for money.

Sherry was not laughing. Sherry learned the hard way that many people don't seem to understand the effect of their words, Sherry explained. As soon as someone loads you up with a cancer story then they ask, "'Oh, is there something wrong? Sherry is in there bawling right now but I don't know why." "48 Sherry wondered if some people say hurtful things to those with cancer to distance themselves from thinking they might getting cancer themselves.

Because of her experiences, Sherry learned to treat people differently than before.

Sherry, like all cancer survivors, learned that there is much of her life that she can't control. She remained a positive and accepting person, and, at the same time, she had to learn to draw better boundaries between herself and others. Sherry was bruised by the comments of other

${ }^{48}$ O'Brien in Profit From Experience (1995) tells a story of how words can be weapons:

Something else also frequently happens in conversation: it becomes needless hurtful. Not long ago I was a bystander to such an exchange, one that, unfortunately, probably comes closer to being the rule than the exception in daily business conversation. It was over dinner. As is often the case, important business was being discussed. Then it happened. One of the parties to the discussion figuratively slipped a knife into the back of the other person. She asked a question - "Well, have you every worked retail?" the way a good trial attorney would have asked it, knowing full well what the answer was in advance. In other words, it wasn't an honest question. It was a trap, a dig. A few minutes later she did it again. For all practical purposes, not only did the value of that conversation come to an invisible, screeching halt, it became downright destructive. The air thickened with hurt feelings. Verbal swords were drawn, and the rest of the meal was taken up with thrusts and parries. (pp. 109-110) 
people, but she learned to use the lessons gained from these experiences to become less vulnerable to the unthinking comments of others. She has learned how to separate and reflect, and create boundaries with people. She described how she manages this:

I've always tried to be very polite and very, you know listen. But if somebody starts going there with me I either walk away or I just change the subject. I'll just interrupt them, because I don't want to hear it. So that goes back thinking more about me than thinking about them, because that is more like selfpreservation. You have to. I can't absorb all of that negative baloney.

\section{Struggle/Strengthen}

Sherry, like all of the women in this study, did not want to talk about how bad her reaction to chemotherapy was. Sherry was given the most toxic form of chemotherapy and was so sick by the final of six rounds of treatment she was admitted to the hospital. She didn't want pity so she didn't let any of her friends know how sick she was. Of the hour and a half that we spent together, no more than five minutes was spent on how sick the treatments made her. She described her experience with cancer as her "own personal 9/11.",49

Sherry explained that getting cancer is devastating; she talked about how getting cancer knocked her down to her own foundations. She spoke of knowing what is was like to lose everything. Sherry also spoke of the struggles of having a different physical reality, of having a different body after surgery. Then, she explained how she (with help from her husband) found a comfortable relationship with her "new" body:

I've always been conscious about my weight, my shape, and I just have been

fighting the weight because of age and the treatment and bla, bla, bla, laziness.

\footnotetext{
${ }^{49}$ The attack on the World Trade Center in New York City on September 11, 2001.
} 
So l've gone back to the gym, we have a nutritionist; we have somebody preparing meals for us. I've lost about 15 to 20 pounds so far. I'm going out, I'm a little bustier, and for my birthday, my husband, he must be bringing out my femininity, for my birthday he ordered from Victoria's Secret five boxes of bras and undies and the first box said, "I love you in black" and it is black bras and undies and black hose. And then the second box is "I love you in white" with white bras, undies and hose. So he is also bringing out my femininity and my sexuality so, dang it, I'm going to show it off. And I got my hair highlighted, and I'm feeling much better than wearing my big sweaters and leggings.

She glowed as she spoke of her husband giving her a series of intimate gifts, especially in light of her concerns about her "new body." Even though Sherry is aware of the loss she experienced with breast cancer, she is thankful for her husband's and her own continued good humor and good nature. She spoke of her humor as helping her through the treatment and recovery of breast cancer. At times, I found Sherry to be very funny:

We went skiing and I skied the best I'd ever skied and I partied all weekend and I was on chemotherapy and they were just amazed. And they asked, "Where are you finding the energy?" And I said, "The key to skiing, like swimming, is shaving the body." I said, "If you want to ski better shave your head - it really helps you to ski faster! It is a dynamic, there is not a hair keeping me back."

Sherry has been a successful dress designer for the past 15 years. Her career did not change through the survival of breast cancer. She worked out of her home and designed 
clothes that are sold in small boutiques across the U S. She hires "stay-at-home moms" to work in their homes sewing her designs. Most of her clothes have elastic waists and the material and colors that she designs are dramatic, flowing and look very comfortable. She said that business has been good. She works 12 -hour days and the only change she made in her schedule was that during chemotherapy she would "hit the wall" around three o'clock every afternoon and nap for about a half-hour. Even though her career did not change, the way she approached her designing did. She became more emotionally invested in having her clothes be "different," in making them stand out more than before. She took "more control of my business, not letting [the retailers] control what I do." And she found that the "colors are brighter, and I'm brighter, more cheery." She wanted to have a more shaped look to her clothing. She wants to help women feel, dress, and look more feminine. ${ }^{50}$

She said that women often wear "leggings, and big shirts make women look like pumpkins." Her designs now offer a more sexy approach for women: "For instance, I do a little sundress and I wasn't doing a lot of shape to them. They were more like cut straight, and now I wanted darts and I wanted them to have more of a tailored look so that it accentuates your figure." This change in her design may be part of the trade-off of surviving breast cancer. We lose parts of our bodies and we may gain something valuable in the trade. Sherry now feels that women should be wearing "little fitted tops and showing our breasts." Besides what she does for women in her dress designs, she also helps other women with breast cancer. Each year, with the help of her husband, Sherry runs the Survivors Tent ${ }^{51}$

\footnotetext{
${ }^{50}$ This was consistent with the data in front of my eyes. On the day of the interview she had on a bright, fresh looking, vivid lime green sleeveless shirt with denim Capri pants that had more bright colors of bric-a-brac at the hem. Both Sherry and her outfit were bright and cheery.

${ }^{51}$ I visit the tent each year when I run the race in San Diego. I've never seen Sherry, but I'll look for her and Tom now. The tent is about 15 by 15 feet and is a "party" in itself. Women who are survivors are invited to
} 
for Komen Race for the Cure in San Diego, California. She also works as a "Breast Buddy" through the Susan B. Komen Foundation, speaking to newly diagnosed women, explaining the journey on which they are about to embark.

Sherry summed up her new life, concluding that she had gained more than she lost, describing five ways that she described herself as being transformed:

1. She is no longer in "my shell," i.e., much more likely to speak her mind.

2. She "doesn't let others interrupt" her.

3. She is "stronger now."

4. She is "more self confident."

5. She has proved who she is to herself and to others.

\section{Reflections on Sherry's Transformation}

In my field notes from Sherry's interview I said, "She felt like a friend." And that is true. I compared my own story with Sherry's survival and thought of how we have both been blessed with supportive husbands. I thought of the blue and green brilliance of her home and the warmth of her backyard. I thought of how her hands and strong arms had led me through her story. I thanked her again for the gift of her valuable time. Somehow, I felt stronger and healthier after the interview. Listening to Sherry was healing for me.

To me, Sherry is a woman of contrasts. Even though she is a self-proclaimed introvert, and it is her choice to work alone long hours out of her home, she greeted me, a stranger, as warmly as a long-time friend. Her tools are scissors and pins, and yet she is as

enter and have special refreshments, have their portrait sketched, receive additional t-shirts, pens and other items. Every survivor leaves the tent with a smile and a plastic bag full of "gifts." I like going to the tent. I believe we have earned this special treatment. 
warm as sunshine. She is the only woman who asked to hear my story of survival before and after I listened to hers.

Sherry's transformation is work-related. Sherry had the same job before being diagnosed with breast cancer, but after her diagnosis she did that same job with an entirely new outlook. She designed clothing with a renewed interest in helping women to feel sexy. She was more interested in creating feminine designs for women, and more interested in wearing bright colors and feminine clothing herself. 
Samm's Story-Introduction

Samm was diagnosed at 46 and was 52 at the time of the interview. When I called Samantha about the interview, I told her that we needed one uninterrupted hour. Samantha said that could never happen at her office and asked if I could suggest a place to meet. I offered my home, which is about 25 minutes from her office, and she agreed. She asked for my first available appointment; she later said that it was a "miracle" that she had the two hours open she needed during her typically hectic workday.

When I first saw Samm, I thought of a character actor who would be hired for an Irish Spring soap commercial. She is blonde, about 5 ' 2 ," with a healthy, strong build; she has green-eyes and translucent skin. Later in the interview Samm told me that she was partly Native American; she said she knew it was hard to believe by looking at her.

Samm spoke with a measured business-like, but rapid-fire voice using inflections like a professional spokesperson or anchorwoman. She carefully and succinctly told the story of how her breast cancer was diagnosed. She paused from time to time, not to collect her thoughts, but to add desired effect.

The following text quotes Samm extensively, I use paraphrase for the following three purposes: (a) to provide information, (b) to make the presentation more succinct, and/or (c) to clarify transitions.

\section{Surprise/Suspense}

Samm said breast cancer "totally surprised" her because there are no incidences of cancer of any kind in my family. I was the very first in my family to have cancer that anybody knows of. We have a relatively 
small family; both of my parents are only children. But they know of no cancer with their aunts or uncles, they don't remember that occurring at all.

Samm's job was to manage, to present and to negotiate a positive public opinion for her employer, and she is a negotiator in her own life. When Samm was diagnosed in 1996 at age 45 with breast cancer, the first thing she did was to make a deal with God:

I told him that if he could get me through this, if I could survive this, I would do everything I could to educate women about breast cancer, about early detection, self-examination, and then I would raise as much money as I possibly could to find the cure. And that has been my quest for the past five years. I've had friends who tell me that breast cancer has changed my life; it has changed my life for the better.

Her cancer journey began when she went in "for a routine mammogram. Three days later I received a call from the mammography technician saying something didn't come out right." Two or three days after that Samm received a call from her family physician who wanted to schedule a biopsy. Samm was to have a needle location biopsy, and from this procedure she learned she had "a very high pain tolerance."

She said unequivocally and slowly, "I really don't like to hurt, but I tolerate more pain than I thought." When she spoke about her ability to tolerate pain, she turned to her left and looked me right in the eye. She then broke the tension of the moment with humor by saying that she was a "good little recovering Catholic girl" and was raised "not to complain."

A few days after the biopsy she came home during the middle of a hectic workday and saw a telephone message from a Dr. Mulvaney, whom she had never met. He had left a message on her machine "in this most wonderful voice"; he sounded like he was "straight 
over from Ireland." Dr. Mulvaney was working in the office of her regular family physician, who was on vacation. He had seen her test results and "took the liberty to contact" her. Dr. Mulvaney didn't want her to wait until her regular doctor returned to get the results. Dr. Mulvaney started out, "I am really sorry to tell you ...." Samm knew immediately "he wasn't going to say that everything on the test was negative." After she heard the diagnosis she, uncharacteristically, "could not speak." As Dr. Mulvaney continued talking he told her he had set up follow-up appointments for her. After a while the only voice she could find was that of her "good little recovering Catholic girl" and "I thanked him very much for calling and wished him a nice day." Samm laughed when she told me about this phone call but it was not the laugh we use when we think something is funny. It was a nervous laugh, the kind we utter when we are not sure what to do.

Up to this point in the interview, Samm had used a professional voice. But now I could hear fear and a tenderness that might be too vulnerable to use in her professional world. She continued:

My house was set up in such a way that I could literally walk in a circle through three rooms of the house. And that is what I did for the rest of the afternoon until my husband got home. I didn't want to call him. I called work and said that I was going to be stuck in this meeting a lot longer than I had anticipated and since it was near my home I was just going to go home.

I whispered to this suddenly vulnerable woman, "So you took this news by yourself?" and she said, "Yes." I then asked her, "So you were alone for three hours?" And she replied softly, "Yes." 
I wanted my husband to be the first to know and we decided not to tell anybody until we knew the course of treatment and knew how serious it was. And at this point I didn't know how serious it was. And I have to admit at that point I was concerned that maybe I was going to die. But I didn't feel that way for too long. And I can't tell you why, but I didn't feel that way for too long.

Samm worked through her fear of death, at least in the retelling of her story, in less than a sentence. And like the organized businesswoman she is, as soon as she was diagnosed, she went right into action. Samm and her husband decided not to tell her daughter, then 23 , about the diagnosis until they had more information. It sounded to me like Samm and her husband came up with a "business plan" to beat this disease, and part of it was to keep everyone on a need-to-know basis until all of the facts were available. Samm was eventually diagnosed with "inter ductal in situ, so it was very early detection, and they thought it would be confined to the breast, and ... in fact it was. ${ }^{52}$ But they didn't know until they got in there and took it out."

Because of such early detection and the small tumor size Samm was given the option to have a lumpectomy. Samm at first favorably considered the lumpectomy. Then she asked an important question of her doctors: "What will my breast will look like if I do decide to have a lumpectomy." She was told that the surgery could leave her "incredibly malformed." She "decided to have a mastectomy" and the surgeon was "very pleased with that decision." As it turned out, after they did the mastectomy, the lab results showed the cancer in her breast

\footnotetext{
${ }^{52}$ At this point I saw a big smile on her face - she actually beamed - I only saw this smile one other time in the interview.
} 
was more widespread than the mammograms showed. They found out after surgery. When I looked at the films it was like I had little grains of salt, grains of sand all through this breast [as she touched her left breast] and virtually nothing in the other breast. If I had not had a mastectomy they would have had to go in for further surgery.

Samm paused in our interview she seemed pleased with herself. She leaned back and was quiet. With the confidence of a negotiator who had just organized a satisfactory treaty she said, "So the decision was the correct decision." When she said this, she leaned back against the couch and paused again, then while reclining comfortably she put her right hand on her left breast.

Samm had a mastectomy of her left breast four and half years ago. She put her hand on the left side of her chest as we talked. Watching her comforting her body with her hand made me realize that I now often lay my hand on my chest for comfort. Samm's hand was finding home and loving what is and what isn't there.

\section{Study}

Like many successful businesspeople, Samm had connections. She said that other than her doctors, the only other resource she and her husband consulted was their neighbor and friend who is an oncologist in the Navy, Dr. Bob. In fact, they went to Dr. Bob to obtain a "second opinion" for each phase of her treatment. All through her story she referred to this pocket expert who lived next door and had a personal interest in her having quality care. Samm marveled at the "six degrees of separation"- Dr. Bob trained a few years before the oncologist she had been referred to by Dr. Mulvaney. Dr. Bob agreed Samm had been referred to an excellent oncologist. Throughout, Samm and her husband returned to this 
trusted neighbor who continued to offer information and support. At the time of our interview, Samm was about to reach her fifth anniversary since diagnosis of breast cancer and noted that her neighbor was "incredibly excited, as excited about it as I am." Separation

Samm's neighbor, Dr. Bob, wanted her to attend a support group "that was doing wonderful things." He was concerned that Samm had "not really dealt with the diagnosis of cancer." Samm laughed, the confident laugh of the knowing, and said, "I guess people expected me to be depressed, despondent. I don't know what they expected of me, but I know that is not what I expected of me. I wanted to get on with my life, but I wasn't in denial. I knew this was a major part of my life."

She did attend the support group, only once. She described her visit to this group as “depressing":

I'm sorry, I was way past where these woman were. I was in this group for two and one-half hours and there was a lot of men bashing and anger, and I guess I really never went through the anger part of it. Maybe because I was just so grateful things went so well.

Each time Samm said "I," she nodded her head forward for emphasis. Samm seemed to skip through the telling of this experience as though she wanted to move on to something else. The emphasis for Samm was the gratitude. She paused and opened her arms and seemed to welcome her health and good fortune. When Samm welcomed her own good fortune in surviving this disease I stopped and welcomed my own. Not everyone receives the diagnosis of breast cancer and finds herself grateful. But Samm separated herself from the women in 
the support group and perhaps a sizeable percentage of other women diagnosed with breast emphasizing her gratitude-for being alive and for her family.

When Samm spoke of her gratitude, I could not help thinking that she was the only woman in this study who never had radiation or chemotherapy. She had a mastectomy but no other treatment. So her total time of recovery was much less than all of the other women in the study who went through the poisoning of chemotherapy and the burning of radiation. I believe she is probably also grateful that she was cured without having to go through radiation or chemotherapy.

I asked why Samm and her husband kept the knowledge of her diagnosis from friends and family and I wondered why she kept herself separated from their potential assistance and support. It seemed inconsistent to me that they held this secret from everyone else, except Dr. Bob. She answered this way: "If someone was upset about [my disease] then I would feel the need to take care of them. Because I had to do that with my family." In the beginning of her journey, Samm separated herself from her family, other than her husband, so that she would not have to take care of them and herself at the same time. She then explained how her daughter happened to have a doctor appointment of her own a few doors away from Samm's surgeon and thereby found out that Samm had cancer:

The first appointment I had before we made the decision to have the mastectomy my husband and I were sitting in the waiting room waiting to see my surgeon and my daughter walked by and saw us. My daughter was in college, living at home and we were planning her wedding. We hadn't told her. She said by the time I told her, that she knew, when she saw us there, she knew something was wrong. 
When Samm and her daughter finally talked about Samm 's breast cancer, her daughter surprised Samm by asking, "Well, should I move up my wedding?" Samm acknowledged in the interview that her daughter reacted in a way that could be thought by many mothers as hurtful. However, Samm knew that her daughter realized for the first time "that her mother was mortal." Samm described their relationship then and now as excellent. The fear of separation by death may have brought the mother and daughter even closer. Samm's daughter is now expecting Samm's first grandchild, a son, on her fifth anniversary of surviving breast cancer and she smiled broadly when she talked about her daughter and her soon-to-be-born grandson.

No matter how hard Samm worked at staying healthy, mentally and physically, she could not promise her daughter that she would be able to attend her wedding in a few months, or even celebrate her daughter's next birthday. Samm watched her daughter realize "that mom may not be here" and found herself saying words about her future that she could not promise: "I'm going to be here when your kids graduate from high school. I'll be dancing at their wedding."

Samm explained separation yet another way. She was actually separated from her normal in-control persona. It happened at 5:30 one morning just before a breast cancer charity race. Samm was standing with a group of friends waiting for the race to begin. One of the men who was a family friend was listening to her explain how badly a breast cancer race had been planned in Washington, D.C., just a few months before. Samm explained that someone mishandled getting a permit allowing passage through a neighborhood and "probably 3,500 people had to be bussed from one point to another." The family friend 
listened to her and then said, "Well that is stupid. They probably didn't check it out right." Then he added, "They should get breast cancer."

At this point in the telling of her story Samm's eyes flashed. It was the highest level of emotion I would see in the interview. She looked angry. She leaned in toward me. I thought, "She doesn't back down from a fight." She continued:

That comment made me really angry, and I'm not a lashing-out show-myanger kind of person. I'll stew, but I usually don't show it. I lost it. I lost it. I put my hand out [Samm demonstrated this, like a police officer stopping traffic] and said, "No, No. You never ever say that, ever, and never in front of me and I don't care how upset you are about this group, nobody deserves breast cancer."

Samm spoke rapidly and her light skin was red with emotion. She was yelling at the man that morning that had made her "livid." She then said, "I was ready to chuck the whole thing and go home and that is not like me, but I was just, I could not believe he said that, and l'm still stinging from it as a result."

Samm was (and is) a professional spokesperson. She was paid to keep her cool in heated situations. She was paid to not show emotion in tough situations. This situation caused a separation between Samm and her work persona. "I wanted to tell him, you don't know what it is like. You should walk in my shoes. You should carry my one breast..." I then whispered to her, "Or perhaps he should carry your empty breast?" Samm said, "Exactly," then paused. We just looked at each other for a while. There was a silence, a pleasant silence you usually earn in a long-term relationship. 
Surrender/Reflection

From her story it appeared that Samm has always been purposeful. One does not get to her level in business without having clear goals that are backed up with hard, purposeful work. She faced breast cancer as she did business undertaking -with purposeful goals and reflection.

You get your diagnosis, you have your surgery and your treatment, and then there is the next phase of your life, which is a totally different phase than you had before cancer. You are definitely a different person. If you are not a different person - this is my personal opinion-then you are in denial of what you have gone through. Because you can't not be changed by this experience.

Samm's purpose involved getting through this disease by "helping other people. That helped my healing, the emotional healing."

Samm was not one to require much privacy. She tended to live her life in a fish bowl. Her personality and her job exposed her to public scrutiny. For Samm, breast cancer has become "a very public matter. And I've worked really hard. I'm very public about my breast cancer. Everybody at work-everybody-knows."

Samm had no idea how public her contributions were about to become. In 1998, Samm was running in the annual San Diego Race for the Cure with thousands of other participants. It rained that morning. I was at the race that day and I could picture in my mind men and women slipping on the wet, muddy pavement and all of us looking like homeless wet dogs. I agreed with Samm's summation of that day, "It was a horrible, horrible event." Samm continued: 
My friends and I started out together. You always start out together, but I'm a rather fast walker so usually after maybe a mile or so I try to hold back, but I'll say, "Hey, I'll meet you guys at the finish line" and I take off. Well at the finish line, a San Diego Union Tribune photographer took a picture of me "high-fiving" the cheerleaders that were there. I was just drenched and it made the front page of the paper the next day.

Samm was not totally surprised to see her picture in the paper the next day and even though they had asked her age at the race she did not expect them to print that (it appeared in the caption to her picture). Samm, although a public figure as the spokesperson for one of the major businesses in San Diego, was now additionally known as a 53-year old woman who had breast cancer. "But that was sort of like, almost like my coming out if you will. Now everybody knows." In short, Samm, who is used to sharing information on a professional level had surrendered all privacy in connection with the breast cancer cause.

Samm and her husband, through participation in the Race for the Cure and other events such as the Avon Three Day Walk, ${ }^{53}$ have raised "over $\$ 50,000$ for the cure." Samm and her husband get sponsors for their participation in such fundraising events. Some of the people with whom she works set a goal to raise money for the cure "and a group at work had a raffle. They wanted to raise $\$ 1,000$ for me, for the Avon event. They raised over $\$ 3,000$." She smiled and was obviously pleased then told how she thanked the people at her work for their kindness and they thanked her back by saying, "We are doing it for the cause but we are doing it because you are doing it." Samm said the kindness of others in supporting her efforts to raise money for the cure for breast cancer has been affirming. "I'm doing the right thing."

\footnotetext{
53 The Avon Breast Cancer 3-Day is one of several fundraising efforts of the Avon Breast Cancer Crusade, an initiative of the Avon Products, Inc. begun in 1993. (Website, October 6, 2002; www.bethepeople.com)
} 


\section{Struggle/Strengthen}

Immediately after being diagnosed Samm became active and political about breast cancer. Right after surgery, she knew she wanted to help people through the disease. She considered going to the American Cancer Society or the Reach to Recovery ${ }^{54}$ programs, but then reconsidered. She wanted to have a "closer connection" with survivors. She wanted friends and family to know that if they "knew someone who needed help and if they were comfortable with me, that I would talk with their friends, or I would talk with them." She wanted to make her contribution "personal."

I get a lot of people coming to me and saying, "My friend, Suzy, was just diagnosed and I don't know what to say. I don't know what to do," or "She is going in for surgery next week, what is the best thing I could do for her, what is the best thing I could do for her family." Or husbands will call me, and husbands will also call my husband asking, "What will we do?"

I will do everything I can to raise as much money as I possibly can to find the cure. And that has been my quest for the past five years. I've had friends who tell me that breast cancer has changed my life. It has changed my life for the better. Because now, not that I wasn't focused on my life because I was, but now I have this mission in my life.

Samm's father "had always felt that I should do something in the political arena and now he knows I am doing this and this is the best thing for me to do. Making the difference, making change, you know, that kind of thing." So Samm is fulfilling not only her own

\footnotetext{
${ }^{54}$ A program of the American Cancer Society designed specifically for breast cancer patients. Website of the American Cancer Society, http://www.cancer.org/docroot/SHR/content/SHR_2.1_x_Reach_to_Recovery.asp?sitearea=SHR
} 
"avocation" but may also be fulfilling, at least in part, her father's lifelong dream for her to be political.

Susan B. Komen Foundation ${ }^{55}$ asked me to be their honorary survivor, so I was out with the media on the speaking circuit so to speak, on the interview circuit, and realized then, and Joe Bauer" said to me, "I think you've found your calling," in this little interview that we had. And Joe is a very spiritual man, and seems to have a sense for that kind of thing, and I had always believed that. This is now my cause, my mission in life. And I love talking about it and if anytime someone wants someone to speak about breast cancer and the need for, especially for our underserved women to have access to mammograms, to have education in languages, in the cultural way in which they can best understand it and to be sure that young women know how important this is, l'm there, and I've chose to spread the word.

I asked Samm how she finds the time to be so active in the promotion of breast cancer awareness. She laughingly replied:

You know what I do? I just do. You just work it in. Like it's like the time is there. When you said, "These are the dates I have open"-my calendar is very seldom open-this is like a two-hour deal for me, to drive up here, and then go back. I very seldom have a two-hour window, but I did. So I was supposed

\footnotetext{
${ }^{55}$ Susan B. Komen died of breast cancer in her thirties. Her sister, Nancy Brinker, started the Susan B. Komen Foundation that is dedicated to education and research about causes, treatment, and the search for a cure. The Komen Foundation sponsors, among other events, The Race for the Cure, held in tens of cities across the United States and even in some foreign cities (www.komen.org).
}

${ }^{56}$ A long-time San Diego radio personality. 
to talk to you. And if I get a call to do a radio or a TV interview, it's never a problem, and my calendar is always open....

This is what I'm supposed to be. So now I'm a little more involved with both Komen and with ACS [American Cancer Society]. I'm part of what they call their "relay-for- life advocate." I meet with the legislators, talk to them about cancer issues. The last time we talked about the tobacco tax, important issues, but I really want to talk about breast cancer. I'm a spokesperson for them on breast cancer issues. I sit on the Komen board, and am one of their advocates and do interviews and so forth for them.

I then asked about the future and without hesitation she replied:

And I'm going to be 53 this year. I hope to retire in 29 months, 8 days and who knows how many hours, but about that time. And this is what I plan to do. I plan to get more involved in the legislative part. I want to be more of an advocate for underserved women.

Reflections on Samm's Transformation

Samm explained how healthy and healing this interview had been for her: "Usually I have a two-minute sound bite, if I'm lucky to get a two-minute sound bite, to talk about my background. But this has been fabulous for me."

Samm touched her left breast a few times. And in the other interviews, I never had to ask the women which was affected. The women all reached to that breast early in the conversations. This reaching was interesting. The women, without apparently noticing it, just left their hand on their chest for minutes at a time. This is a difficult touch to describe, and it may be impossible to understand for those who have never had a part of their body removed 
or who have not been attacked by a part of their body. It is a different touch. Each of the women would not stroke but lay their hand on their once affected breast. It was not like the stroking a favorite pet, or of an ardent lover, but a comfortable laying on of the hands. It was rather like the way a proud father would touch his child's shoulder after a successful piano recital or basketball game, or like a good mother touching her defenseless baby's ice cream covered face.

It reminds me of times my husband and I dine out. My husband is a non-flashy romantic and one of the ways he demonstrates his quiet romantic side is that he almost always sits on the same side of the table with me. And often, about mid-way through the meal, I find that either my hand is resting on his leg or his is on mine. Neither of us is conscious of how our hands get there. This is like the touching of the women to their breasts. Touching a favorite place, touching a place with history and passion. Touching a place you are proud of. Loving what is and isn't there in the same way. The touch and the laying on of the hands was the same for the women who had their breasts removed in a mastectomy as with those whom had a portion of their breast removed in a lumpectomy.

The self-touch of these women appeared to be a mixture of many emotions: tenderness was obvious, a type of pride and a type of long-term connection, an unconditional, but painful love of the parts of us that have in some ways betrayed us. Like the ambivalent way one may love an alcoholic child. During the interviews I often found myself touching my chest. In 1999 I had a double mastectomy so I don't play favorites any more. I center my hand on my chest, under my chin, flat out like a traffic cop holding back traffic at a broken signal. My hand is facing inward toward my heart. My hand is there to stop any 
further attacks, the inward invasion. In my mind I whisper to any random cancers to go to sleep, to stop, to die, and to blow through my body without harm.

Samm has become a whirlwind in the breast cancer movement. It is remarkable that this busy woman appears to love to find the time in a very busy schedule to donate her talents to organizations and individuals to promote the cure for breast cancer. Her transformation surrounds Samm. She found in her journey through breast cancer a cause, an avocation, a way to use her many talents to accomplish goals that will help thousands. Her transformation continues to unfold because she plans to work full time for "the cause" after she retires. She has become a fighter for the cause. She has raised $\$ 50,000$, and I predict that is only the beginning. Samm is "making the difference, making change" for the women who have been or will be diagnosed with this disease. 
Judy's Story-Introduction

Judy was diagnosed at 52 and was 60 at the time of the interview. When I first walked into Judy's quiet and secluded condominium, I was struck by the symmetry of each piece of furniture as well as the knick-knacks that were carefully dusted and circumspectly placed on her polished, matching maple furniture. Her home was a study of order and practicality. She had soft music in the background and was drinking a vanilla flavored coffee. My senses were pulled into the slow-paced rhythm of her home life by the smell of the coffee and the slow beat of the music. It occurred to me that Judy not only liked order and predictability, she probably worked very hard to create it. Based on the order I was seeing in her home, I wondered if the diagnosis of breast cancer and all of the unpredictability that comes in the door with breast cancer might have been particularly challenging for her.

The following text quotes Judy extensively, I use paraphrase for the following three purposes: (a) to provide information, (b) to make the presentation more succinct, and/or (c) to clarify transitions.

Surprise/Suspense

It was consistent that Judy, whose job involved managing detail, would remember the exact date when she was diagnosed with breast cancer: December 2, 1992. She was trained as a nurse and, at the time of diagnosis, worked in an advanced position as a medical administrator. She was enjoying "the peak of her professional career," was enrolled in a doctoral program and was married with two teenagers.

"For quite awhile" before diagnosis she experienced pain in her left breast. The medical professionals with whom she worked told her not to worry and repeatedly told her, "You don't get pain with breast cancer." Besides, her last routine mammogram was negative. 
After a few months of continued pain, Judy demanded an out-of-cycle mammogram "and they did detect something." The new mammogram showed something on it that the previous ones did not. After explaining to me the difficulty of just getting this mammogram authorized at the hospital where she worked, Judy leaned back on her floral couch and said, "So I had been diligent in having mammograms." She looked straight up at me and I noticed for the first time that the color of her eyes was an arresting Paul-Newman blue. Looking steadily at me she said, like a teacher to an elementary pupil, that she had since learned "the mammogram is not a good indicator, particularly since you can actually have [cancer] eight years before it is detected on the mammogram." Judy had followed the best medical wisdom, worked in a hospital, and found herself on the other side of a medical chart.

Judy explained that based upon the results of the mammogram the doctors scheduled a biopsy. Before the biopsy she was really kind of "numb - it just really didn't register." She felt "this couldn't really be happening to me." Within two hours of the biopsy, Judy was told she had breast cancer. "It kind of took my breath away. I felt that my body had just let me down, because I thought intellectually I had everything under control, and I could control my body as well. Since then I've learned that really isn't true." As soon as Judy received the diagnosis she "began searching frantically for options."

When they started to present the options to me that were available for me, I was so angry because I had been a nurse and a nurse educator for all of this time, for 20 years. I had never worked oncology per se, but the options were just the same ones as they were in 1962 . I could have a mastectomy, radiation and chemotherapy.

She then took a long deliberate breath and said, 'I told my husband I was not having a 
mastectomy." Judy was convinced then that, no matter what, she would not have a mastectomy. "And it took three different physicians to find one who told me I didn't have to have that done because the tumor wasn't that big and it was under the breast and it wasn't that disfiguring." Judy could accept some of the unacceptable, the diagnosis of breast cancer, and she could accept the miserable and hoary treatments, but she could not, and would not, accept a mastectomy.

Before 1992, diagnosed women were usually just given a mastectomy. After 1992, the option of having a lumpectomy instead of a mastectomy was "being presented to women." Judy concluded she was an excellent candidate for a lumpectomy-a potentially less disfiguring treatment- because the tumor was located in an easy to reach place within the breast and the tumor was very small. Because of her medical education and background, Judy knew how find, to obtain, or to demand, if necessary, the best possible care. "Initially I had been turned over to a Resident and when I found out he was a Resident, I was very angry because I was not going to be seen by a Resident, and I was not going to be experimented on."

After surgery Judy went to the doctor to find out the results of the lumpectomy and of the nodal dissections. ${ }^{57}$ The doctor saw her just as she entered the long medical hallway heading toward his office. He yelled loudly to her, 'I've got good news and I've got bad news." His good news was that the tumor was small. The bad news was that it was poorly

\footnotetext{
${ }^{57}$ A nodal dissection is where part of the lymph system (usually under the arm) is removed in order to examine some of the lymph nodes. This is often done often at the time of a lumpectomy or a mastectomy to determine if the cancer has spread from the breast to the lymph system.
} 
defined ${ }^{58}$ and that 11 of 22 lymph nodes were malignant. A "poorly-defined" tumor is an indication that the tumor is spreading in all directions.

When Judy explained the doctor's hallway pronouncement to me she spoke loudly. She cupped her hands to her mouth, as though using a megaphone. Her eyes looked cold and angry to me. It was clear that she was still angry that the physician would treat her with so little decorum. After meeting her, I know she would behave in a proper and dignified manner with any patients with whom she came in contact. This doctor's casual, public and insensitive treatment of her must have been particularly unsettling to Judy. It appeared that, almost a decade later, Judy could not believe that the doctor would be so crass as to yell her unfavorable diagnosis down the hallway.

While the doctor was speaking to her in the hallway, one of her ex-students was "listening in the distance." This further infringed on her privacy and made her feel a loss of control. "I was devastated that this was happening to me and to have the news presented in the hallway." At this, Judy, normally a regal-looking woman, bent her head as if to demonstrate the shame she had felt then. Then Judy in a split second moved from sad to angry and said, "I was just livid about everything." At this point, Judy's voice was loud and serious, so much so that her husband, Dan, whom I didn't know was home, came from the back of their condominium to be sure that I was not upsetting Judy. I felt his gaze upon me. I smiled weakly.

\footnotetext{
${ }^{58}$ A "well-defined" tumor often is in situ or living in a sack that is a boundary for the spread of cancer. "Poorly defined" definitely fell into the "bad news" category.
} 
Study

After quickly introducing me to her husband, Judy continued and said that she and her doctor began considering her options. "He decided that my prognosis wasn't very good." Judy and her doctor carefully weighed all available strategies that might increase her chances for survival. The doctor told Judy she could go to into the standard regimen of chemotherapy and radiation or she could opt to become part of a "clinical trial."

As for the clinical trial, Judy knew she would not get to choose which regimen ${ }^{59}$ she would be a part of, "but one of the choices was to get quadruple doses of a chemotherapy agent or I could have stem cell, ${ }^{60}$ which wasn't a good option because he said I probably wouldn't live through it."

After much discussion, Judy and her doctor came to the conclusion that Judy's "prognosis wasn't very good anyway so why go the traditional way if the higher doses of chemotherapy might work." So Judy opted for the clinical trial and "by the luck of the draw" did "get into the group which got the quadruple doses [of chemotherapy]." Judy said the treatments were "overwhelming." When Judy said "overwhelming" I believed her. She looked at me and I could imagine her drowning in an angry sea. Like most of the women in the study, not too many details were given to Judy about the horrible effects of chemotherapy prior to her treatment. I can't imagine quadruple doses; I could not imagine how out of control and sick she must have been.

\footnotetext{
${ }^{59}$ In a clinical trial the participants do not get to choose if they are in the control group or not.

${ }^{60}$ Stem cell and stem cell transplant: A variation on bone marrow transplantation in which immature blood cells called "stem cells" are taken from the patient's blood and later, in the lab, stimulated with growth factors to produce more stem cells which are returned to the patient by transfusion. Website of the American Cancer Society, http://www.cancer.org/docroot/GRY/GRY_0.asp?dictionary+\&pagKey=S.
} 
Judy acknowledged that many women who are diagnosed with breast cancer not only find solace in support groups but they gather helpful information from them. She attended a support group for a while with seven other women. Judy said that she was continuously "searching frantically for options." She said she "tried a couple of [other] support groups" and was "very depressed." The support groups did not offer the solace she sought, so, after carefully studying her options, she decided she would benefit from visiting a psychiatrist. "I was smart enough to do that." Judy, skilled at finding and assessing medical options, found out that her work "could not give me disability compensation for cancer, but they could for depression, so I could get leave for depression but not for cancer." So that is what she did. She went to a psychiatrist to get that diagnosis.

Judy knew that she was facing "four and one half months" of chemotherapy and that it was going to "compromise her immune system." Judy walked into her first chemotherapy treatment with her eyes wide open to the possibility of becoming as ill as she had seen others become, or even more so.

Separation

Judy immediately began to separate herself from the rest of the world. She took steps in keeping with the thorough, careful woman and medical professional she is.

I quarantined myself, nobody gave me any instructions, but I decided I needed to stay away from people. So when I went to the hospital [for treatments or blood work] I wore a mask. Nobody told me to do that. When I went to the lab I made sure I went early in the morning before sick people showed up; nobody told me to do that. And I sent my husband to the pharmacy because there were 
sick people there. I just did all of these things that I thought made sense to me, but nobody was coordinating-nobody was.

Judy told of losing her hair and having her white blood count ${ }^{61}$ get dangerously low, so low in fact that her doctor recommended that her husband give her injections twice a day to boost her white blood count, which "had dropped to 200, which was just almost nothing."

Judy's health spiraled downward, and the doctors who were administering chemotherapy informed her that her "white count was so low that I would probably hemorrhage to death over the weekend and that I needed to come in for a transfusion." She said it was difficult to hear that she needed a transfusion and because of their failure in planning she was not given the option of having blood donated for her. She mouthed the following sentence carefully and threw her hands into the air, "I guess they figured that if I got AIDS I would probably live longer from that than I would from the cancer, so that didn't matter."

Judy finished her last chemotherapy treatment alone and separate from her former well-ordered, productive, controlled life. She said, "I just wanted to end it all." She looked defeated and said, "Here is this bald lady bawling" (referring to this last day of chemotherapy and being alone). I asked to confirm this, "Were you by yourself?" and she answered, "Yes." Judy has had to live with the knowledge that the quadruple doses of chemotherapy didn't help any of the women in the clinical trial to survive longer. ${ }^{62}$ "The results for the clinical trial were that the higher does of chemotherapy didn't make any difference."

\footnotetext{
${ }^{61}$ Before administering chemotherapy doctors usually order a blood test to determine if the patient can tolerate continued medical treatment. The lower the white blood count the less likely the patient can continue chemotherapy.

${ }^{62}$ The purpose of this study was to try to determine if quadruple doses of chemotherapy would improve longevity for the participants. The study proved that the group that received quadruple doses did not live longer than the group that received regular doses of chemotherapy.
} 
Judy's father and grandfather were physicians. Judy herself had spent two decades following and promoting the Western way of practicing medicine. She had been offered in 1992 exactly the same protocols to fight cancer that were available in the 1960 's when she had taken her nurses' training. Practical and forthright, Judy became disillusioned with the "status quo" of American medicine. She reflected, "While I was going under all of this I was trying to research alternative methods and it was a whole different arena." Judy was about to depart "totally out of the [Western medical] framework."

Interestingly, Judy described how cancer patients separate themselves from the rest of the general population:

When you meet someone who has had cancer you just kind of cut through to the chase. And you bypass, it doesn't matter who you are or what you are in your life, in terms of what you do. It is not important anymore. And you are with someone who is a fighter and someone who is trying to survive.

Yes, what you do is, now all of these layers that people have in terms of who they are what they think they are and how important they are doesn't matter any more. Because they are in a life-and-death situation. And so you are searching to grab onto a soul or a person who can share with you what you are experiencing and to give you the strength and not to take away from what you are trying to do. And to understand the fight and the struggle and the desire to survive.

Judy also described a more chronic type of separation: "We are never rid of cancer, it is always working in the shadows, and it is always a fear. I don't think a day goes by, at least 
with me, that it doesn't cross your mind, it's always a possibility, it is always around the corner."

\section{Surrender/Reflection}

In addition to surrendering her belief that she could control her body, Judy was about to surrender herself to an entirely new type of medical care, the type she might have laughed at just a few months before. In fact she laughed in our interview as she recalled:

I've been burned [chemotherapy], I've been fried [radiation], so they said this [alternative] treatment might make me tired, and I thought that is OK, sure. But it makes sense to me because it was a treatment that would boost my immune system. And I thought, "Well, that is the first time I've heard anything in this whole course that makes sense to me."

The new medical procedure entailed the following:

Checking your blood daily and checking to see how your immune system is functioning and they provide you with a serum customized to you that will boost your immune system. All of the items they use they know about in the treatment of cancer in the US. They use this system in veterinary medicine in terms of treating feline leukemia and are having great success with it.

Judy said that this type of alternative medicine is only offered outside of the United States (Bahamas, Europe and Japan). ${ }^{63}$ Methodical Judy did not throw caution to the wind; she obtained the names of former and current patients and talked to them:

I spent probably a week calling, all over the world, actually. I called Europe, Canada, I called Australia, and I called people here in the U.S. and I heard the

\footnotetext{
${ }^{63}$ Most alternative medicine clinics and hospitals are located outside of the US because they use techniques and substances that are not approved by the American Medical Association or by the Federal Drug Administration.
} 
most incredible stories I've ever heard in my life. So I thought, "Why not try it?"

She explained the purpose of this type of alternative medicine:

They kill cancer cells. If you go with anything else in your mind you will be very disappointed. And if they can kill them faster than you make them, then you win; and if they can't, then you lose.

The doctors in the Bahamas asked her to bring her medical records. Judy found this to be a daunting task. She said her stateside doctors "put every obstacle in the way that they could to keep from me from getting my own medical records." She persevered and eventually got her records. On the airplane on the way to the Bahamas she started carefully reading her own medical records. She read the last entry, written by her oncologist, "Patient is making arrangements to go to the Bahamas for treatment. It is obvious that she has not come to terms with her diagnosis as of yet." She continued:

Nobody here was supportive, even my peers when I went to school or faculty meetings. They would make comments like, "Well, Judy if you feel that is going to work then you need to do it." It was so condescending. ${ }^{64}$

At the time of the interview Judy was about to return to the Bahamas for another treatment. She has been going once or twice a year "since 1993." After she returned home from her first trip to the Bahamas she "fired [my] old oncologist" and interviewed three others. "I was looking for somebody who can deal with what I'm doing." Her current oncologist "smiles and says 'keep on doing whatever you are doing."' But Judy says this

\footnotetext{
${ }^{64}$ And an additional type of separation.
} 
about doctors and the Bahamas: "Down there [the Bahamas], I've met people from all walks of life. If you want to know where doctors go when they have cancer, this is where they go." Judy's regimen for healing appears extreme, but it is impossible to argue with its success. When she leaves the Bahamas, she brings home a supply of a medical "cocktail" which she gives to herself by injection. This cocktail is specifically designed for Judy so she can keep killing any new cancer cells in her body. "I give myself injections, up to twelve shots a day." She explained how giving herself shots so many times a day led to some interesting experiences.

Sometimes I'll do it in the car, at a stoplight. One time I was going somewhere with my daughter, going to a bridal shower and we were on the highway and it was time for me to take a shot. We were pulled off onto the off ramp and I was giving myself the shot in the abdomen and it was still frozen and I could not take it out. My daughter turned her head and saw that parked behind us was a Highway Patrol. Fortunately, he didn't get out of the car, he just rolled down the window and asked if everything was OK. We nodded our heads up and down. Isn't it fun embarrassing your children?

Also, Judy has learned how to take better care of herself, to "shield" herself: I tried to protect myself from things that would distract myself from the inner battle that is going on. And I realized that when all of this happened that I was going to have a second chance. I wasn't going to worry about all of the things I used to want to be and do. And it didn't matter as much as my family and to have them around me. One of the great things that happened to me was to learn how to accept. I never could accept things; for somebody to give me 
something or to do something for me was very hard for me to do. So it has been sort of a humbling experience, it has been an equalizer, yes.

\section{Struggle/Strengthen}

Judy got lighter and more humorous as the interview went on. She smiled and said she doesn't know why she has survived. "But obviously I have, since I've not had a reoccurrence." She remarked: "Of the seven women in the support group I belonged to, I had the worst prognosis and they are all gone but two of us." She then said, "In the study [with the quadruple chemotherapy treatments], $70 \%$ of the women who had the same prognosis that I did were dead at the end of five years." She is obviously glad to be alive. She said, "I'm so thrilled."

She made these pronouncements in her matter-of-fact style, looking directly into my eyes. She looked so strong and healthy, so bright and clever. Her blue eyes were dancing. I felt ashen, intimidated and small. I felt like she had found the key to not having another battle with cancer and that somehow I had spent ten years looking in all the wrong places.

She said "a lot of things have transpired" for her and added:

I used to be pretty wrapped up by the values coming from putting a lot of emphasis on achievement-achievement in terms of monetary types of things. Things. And I've become more inward and those things don't seem to matter any more.

Judy described how the time in the Bahamas has proven to bring more than just physical healing. "I call it my time out of time." She said, "People can't understand what it is like to walk into a cancer clinic and see the patients laughing, smiling and encouraging each other, sharing not just at a superficial level, but sharing intimately, at a deeper level." Judy 
said the experience in the Bahamas has taught her how to "identify a spiritual side I didn't know I have."

Judy described how other ways of thinking have changed. "I was very frightened. I was all alone in a country with a lot of black people. I had never been around black people." Right after she arrived she was walking down the street alone.

There was this great big black man coming towards me. And you know how we are here; we don't look at anybody. But this man looked at me and just grinned and he said, "Good mornin', darling." I just stopped in my tracks and thought, "Oh, my God, that just feels so good."

Judy then laughed a different laugh, lighter than any in the interview thus far. I was wondering if this is the laugh she usually reserves for her time-out-of-time in the Bahamas. Just thinking of the healing atmosphere of her times in the Bahamas seemed to bring out a warmer side of Judy. She said part of the treatment "is the land itself." Judy then summed up her evolution from Western medicine to her experience in the Bahamas, "It is really simple; just listen to your body-it will tell you what to do."

Judy said, "The first three years I could not think of tomorrow or next week or six months. It took me six months to take my life back because I could not. [I] didn't know where to go. I got so much negative input from people; there were no answers."

Because Judy had not taken a day sick off from her work when being a medical administrator she was owed almost "three years of sick pay." She tried to go back to her old job. "I'd go back for a week and I knew that I could not, and didn't want to go back." She then started her own business five years ago administering testing for nursing assistants. She 
is highly successful and has a staff of 22 people. "I work part-time, I work out of my home, on my own schedule. I am an entrepreneur."

\section{Reflections on Judy's Transformation}

Judy was the only woman in the study to have a perception that breast cancer has been over-feminized, or perhaps was the only one who chose to comment on this topic. She said she hated the Komen Race for the Cure and thought that money could be better spent. All of the others thought the event was "fabulous." Judy would probably agree with author Barbara Ehrenreich (Harpers, 2001) that breast cancer is now being "suffocated by the pink sticky sentiment" (p. 43) of a women's disease. Ehrenreich lamented that "a mammogram [can] lead to a cult of pink kitsch" (p. 45). Ehrenreich aptly denounces "Shop for the Cure" and the "little pink teddy bears" that are associated with recovery for breast cancer. This disease is a woman killer and she objects to it being treated as the "most popular girl at the corporate charity prom" (p. 45).

Judy's transformation is at least twofold. She was not a likely candidate for Alternative Medicine, as both her father and grandfather were physicians. Breast cancer gave Judy the impetus to explore medical treatment that she would never have considered before. She spoke of developing an entirely different life when she is in the Bahamas, a life that would not have been considered without breast cancer.

The second transformation for Judy is work related. Before breast cancer she worked in a high stress job in a hospital. She now works out of her home in a business she created. The experience of breast cancer helped to give Judy the desire to become an entrepreneur. 
My Story-Introduction

I was first diagnosed with breast cancer on the left breast when I was 42 . I was diagnosed with breast cancer on the right breast when I was 48 . When I was 49 the doctors discovered that the cancer in my left breast was still there. I am 53 at the time of publication. Surprise/Suspense

I have always had a lot of energy. I was running out the door of our home on a warm day in July, 1992 when the doctor's office called to say that my mammogram of the day before had not come out quite right. I was annoyed because I assumed they had made a mistake. I was not frightened-I was only 42 years old. I told the woman I did not have time for at least a week to come in for another mammogram. She told me that I needed to come in for a second set of mammograms the next day.

My life was pretty chaotic and messy at that time. I was married, with a blended family. Our children ranged in ages from 22 to 16 . To our horror our son, $\mathrm{Jim},{ }^{65}$ had started using drugs. Instead of my husband and me working together to help our son get over addiction issues, we fought like hornets. My husband, Jim, (same name) was adamant that I was too soft, and I found him to have ice in his veins. It is interesting to me now that I was angrier with my husband than I was with our son. As I reflect, I realize it was easier to be mad at my husband. My anger at least got a response from my husband. Our son just ignored my warnings, advice, anger and tears - nothing seemed to penetrate this son's drugged-out stare.

\footnotetext{
${ }^{65}$ Our son asked to have his name used in this work. He has experienced a transformation in his own right. At the writing of this work he has been clean and sober for six years. He is another example of how crisis revealed character. Today he blesses our family with his kindness, humor and joy.
} 
At the time of my initial diagnosis another one of our children was going to college 200 miles away. My husband was thrilled to have our house become quieter, and I was devastated that this child was leaving. I felt the light was leaving me. Once again my husband and I were at odds over something.

I did not know it then but I was about to find out that I was at also odds with my own body. When they took the second set of mammograms they said they saw "calcifications" on my left breast. These calcifications looked on the mammogram like tiny grains of white sand. Our family physician said to wait six months and then take another set of mammograms. I was certain I did not have cancer, so I took his advice. However, two weeks later one of our children fell ill and as I was putting on my shoes to take this child to the doctor I had a very strong feeling of urgency that I should arrange an appointment with a surgeon immediately to obtain a biopsy. This thought did not originate inside of me. I was not thinking about the mammograms before the thought came to mind. I felt like God was talking to me. I was surprised by this realization. I do not remember a time before or since that I received such a clear "from-out-of-the-blue" message to take action. A needle location biopsy was scheduled.

I will describe this medical procedure in detail. The nurse gave me a hospital gown and took me into a small room with a mammogram machine. It was about three feet from the floor; this was unusual because other mammogram machines I had seen were about 5 feet from the floor. The reason this machine was close to the ground was about to become painfully clear. The nurse sat me in a black, five-wheeled doctor's examination chair and moved me to the machine. She put my left breast into the machine and I held my breath to prepare for the 30 or 40 seconds that it takes to get a mammogram. Boy, did I underestimate this process. While my breast was in the machine she injected a painkiller into my left breast 
(Not sure it worked and the shot was extremely painful). She also inserted a large gauge needle into my breast. Next, a doctor I had never seen before, and was never introduced to, entered and manipulated the needle. The doctor and the nurse started talking to each other (not to me) about the positioning of the needle. I was in constant pain and to even move my head up or down made the pain unbearable. The nurse and the doctor then walked behind a shield and took x-rays. They then released the intense pressure on my breast (though it remained captured in the machine) and left the needle in my breast. Then the doctor and the nurse left carrying X-rays. I sat in the cold room, alone and terrified, for about 15 minutes with the huge needle sticking out of my breast praying (out loud, I think) for the procedure to be over.

The doctor and nurse returned and began the process again. My breast was squeezed again and the doctor moved the needle slightly inward; the nurse and doctor would then get behind the shield, take another $\mathrm{x}$-ray and then disappear again. This process of moving the needle, taking an $\mathrm{x}$-ray, was repeated no less than 15 times and took more than an hour and a half. There was no explanation of what they were doing; it may have been obvious to them, but I felt too small and afraid to ask. They were trying to pinpoint the exact location of the "calcification" before surgery so they could be sure to remove the "infected" tissue. Each time they moved the needle, each time they left me alone, I cried. Before the process was over I fainted and they had to revive me with smelling salts. After I fainted the nurse went and got my somber-faced husband. Jim's face matched my own ashen face. We were both too scared to touch each other. I was painfully aware of the darning needle sticking out of my bloodied left breast. 
After the procedure I had to wait almost an hour, alone again, for surgery. The needle location biopsy procedure started at 9 a.m. and I did not go into surgery until after noon; all of that time the large needle protruded about 3 inches out of my breast. I was too terrified to move for fear I'd lose their pinpoint location. I actually was too afraid to even look down at my own breast. I looked straight ahead and was frozen with fears of dying.

When any of the women of this study referred to the needle location procedure I asked few, if any, questions; I didn't want to look into their story very deeply. I just wanted to pass by as quickly as possible. None of them lingered to relive that experience either. ${ }^{66}$ The biopsy was positive. I had breast cancer. We were referred immediately to an oncologist. Further surgery was scheduled and that surgery revealed that the cancer had already spread to several lymph nodes.

Study

At age 42 I had a whopping 11 units of college. I did not feel very competent to study anything, and even though this disease frightened me, I was afraid to look it up on the Internet. I listened and asked questions of my doctors, but I did not have the courage to read a book about breast cancer.

Right after the biopsy results, Jim went downstairs in our home office and he came up with a milky white face. I asked him what was wrong and he told me he had been researching breast cancer on the Internet. I told him not to tell me what he found. That night I woke up in the middle of the night to find Jim standing over me, praying. Tears were running down his face. We were beginning to find ourselves on the same side of a problem. I felt then as I do now that Jim is completely committed to my well-being.

\footnotetext{
${ }^{66} \mathrm{I} \mathrm{had}$ another needle location procedure in 1998 on my right breast. This experience, although painful, was conducted in a far more patient-friendly way.
} 
To study this disease I just wanted to "catch" information on breast cancer from upbeat articles I found in the newspaper and in magazines. I wanted to have my doctors tell me enough to make me feel like I was going to live forever. I did a dance with learning about breast cancer, the same dance I had always used in school-up to that time I was not a very serious student. I brought those old patterns of schooling to the study of this disease. I thought what I knew about cancer could hurt me, although my study was about to take an unusual path.

At the time of diagnosis, I was continually disappointed by family problems. In desperation I started attending Al-Anon ${ }^{67}$ meetings (and thereafter did so at least one night a week for three years). From Al-Anon I learned to ask myself these three questions: Did I cause it? Can I control it? Can I cure it? In Al-Anon I learned that if the answer to any of these questions was No, then it was not my problem to solve and I needed to humbly accept my inability to change the situation.

Al-Anon helped me greatly, not only with our family problems but also with my illness. I learned how to find peace in my home and in my own body. I learned I could not control my body or the family, but I could control my anger and my actions. I continued to go to school and I pursued my A.A. degree at National University. So my path of study was in Al-Anon, learning how to control what I could and to accept what I could not.

\section{Separation}

My history with breast cancer has been a long and winding road. In 1992, I was diagnosed with breast cancer on my left breast. I had a lumpectomy, chemotherapy and

\footnotetext{
${ }^{67}$ An organization to help families and friends of alcoholics (and other substance abusers) recover from the effects of living with that problem. The approach is adapted from Alcoholics Anonymous and is based upon the Twelve Steps, Twelve Traditions and Twelve Concepts of Service. Website of Al-Anon/Alateen, http://alanon.alateern.org.
} 
radiation. I continued with my education and finished my B.A. and was mid-way through my Master's when in 1998 a mammogram on the right side showed an abnormality. Another lumpectomy on my right breast detected cancer. This cancer was "In situ" and therefore had not spread, but we decided to have radiation on the right side to be careful. I took my comprehensive exams in my Master's program after completing my final weeks of radiation. I enrolled in a doctorate program and then a year later in 1999, Dr. Johnson, a radiologist at Mercy Hospital in San Diego, noticed from my latest routine mammogram that the original cancer on the left breast seemed to be spreading. A biopsy was performed. I had breast cancer for the third time.

I decided to have a double mastectomy. At that point I never wanted another mammogram again in my life. In ten years I had had over 50 mammograms. Frankly, my breasts were not bodacious and they were beginning to look pretty beat up from the surgeries. The doctors said my decision to have a double mastectomy was over-kill, though I frankly regretted that I didn't have them both removed in 1992. I would have saved myself chemotherapy, over 80 treatments of radiation and several surgeries. I've never regretted the decision in 1999 to have the mastectomy, not once.

At the mastectomy, they could not get an I.V. in me in the operating room and the nurse and two doctors were literally sweating over me trying to get a needle in my recalcitrant veins. I sang hymns while they toiled over my left, then right, arm and then back again to my left. My arms were black and blue for days after the surgery but I was completely calm and resigned, waiting for them to put me to sleep to take off both of my breasts. I was ready to separate from them. After they got the I.V. going, and just before I went into the deep sleep of the drugs, they put both of my arms out at my sides and strapped 
them down. I was being separated from my breasts and, on some level I also separated from myself watching it happen.

Additionally, breast cancer has often separated me from peace of mind. Now, if my foot hurts my first thought is cancer has spread to my bones. If I get a headache, I feel it has spread to my brain and God forbid that a new mole appear on my chest or neck area-that can send me into a two-day sleepless tailspin. Before I was so unaware of so many of the changes in my body; now I feel hyper aware. I have been separated from the peace that comes from not knowing.

Finally, the most painful form of separation for me was in the subtle ways that others treat me or I perceive they are treating me. A few weeks after my first surgery in 1992 our youngest nephew was born. I went to see him and realized that my brother-in-law and sisterin-law might not want to me to cuddle their baby. I sat in that hospital room and thought I had better not assume they wanted me to do so. My left breast was still bandaged and I thought I was a leper. In a recent conversation with them, I realized they had never thought I should not touch the baby. The separation I felt that day was internally generated-though just as powerful as if they had held their baby away from me and asked me to wear a scarlet letter.

Surrender/Reflection

The experience of cancer taught me I no longer could live in a dream world thinking that we are all safe. As Sherry said in her interview, she wasn't surprised by September 11; she had already been attacked by breast cancer. She knew what it was to be brought down.

In 1992, doctors used what they called the "Oreo" method of treatment for me: Three rounds of chemotherapy, seven weeks (six times a week) of radiation, then three more rounds 
of chemotherapy. I started losing my hair after the first three chemotherapy sessions, not all at once, and not all of it. My hair became so thin it was impossible to conceal that I was on chemo. I went to college at nights; school was a bright spot in my life and lifted my spirits. School was something I could control.

However, sometimes I would wake up in the morning despondent, sure that I was going to die. Early each day Jim and I would take a walk. I usually feel good out-of-doors, but soon after I started radiation I found myself wanting to kill myself. What is interesting to me now about that time in my life, was not just that I wanted to kill myself but how I wanted to do so. I wanted to throw myself over the cliffs near our home. I would find a real pull from the cliff. When Jim and I would walk within 100 yards of the cliffs I would ask him to hold my hand and not let me go until the cliffs were out of sight. At first Jim thought I was kidding, and there was a part of me, at first, that thought that I was kidding, too. But as time went on I became more and more obsessed with wanting to throw myself over the cliffs. One day after a walk my husband started to take my fixation seriously. The minute we returned from a walk we called my oncologist and he immediately got on the line. He told me that I was having a chemical reaction; he told me that radiation could have the same effect on the brain that depression does. He told me this was serious. I asked him what he thought I should do. He offered to prescribe an anti-depressant. I got quiet, and told him I'd call back. I sat and prayed and reflected about my depression for hours. After reflection, I decided I was going to handle this myself. I didn't want any more medications polluting my already weakened body. I decided I was done with the fixation of throwing myself over the cliff. I need to separate myself from my desire to die, and I did. 
My journey with breast cancer included exploration and implementation of several forms of alternative medicine. This surrendering began in 1993 after I completed all the conventional treatments (surgery, chemotherapy, and radiation) that American medicine had to offer. Proponents of conventional medicine did not have any other advice or help for me. It seemed their strategy was to wait around to see if the cancer would recur. I believed that the immune system had to be compromised for cancer to take hold, and I knew that what we eat does impact the immune system. I was also aware that all of the treatments offered through conventional American medicine such as surgery, chemotherapy and radiation had seriously weakened me. With this in mind, I asked my oncologist what I should be eating, and he merely said, "I like Italian food." Soon thereafter I surrendered my body to the unfamiliar world of non-traditional methods of healing, beyond eating Italian food.

Jim and I began the search into alternative medicine by going on an all-day bus tour to Mexican hospitals and clinics specializing in cancer treatments. We learned that there were over 30 such hospitals and clinics near the border. We visited eight of them. We were so impressed with all of them; we practically flipped a coin to decide which one I would go to. We decided on Hospital Santa Monica in Rosarito Beach, Baja California, which had an American Chief of Staff, Dr. Donsbaugh. I signed up for three weeks of treatments to begin immediately. I brought my schoolbooks and did homework between treatments. In Mexico I had chelation therapy ${ }^{68}$ and Selenium shots. ${ }^{69}$ Most of the other patients were worse off than

\footnotetext{
${ }^{68}$ Chelation therapy is the "giving of intravenous solution containing selected vitamins, minerals, heparin (a blood thinner), and EDTA (a synthetic amino acid that bind up or "chelates" heavy metals). A patient circulation is greatly improved and toxicity load is reduced. The solution acts as a magnet, pulling positively charged calcium and other metal ions out of the cells of the arterial walls" (Diamond, Cowden \& Goldberg, 1997, p. 129).

${ }^{69}$ The importance of Selenium is stated this way in one source: "All Schachter Center cancer patients receive relatively high doses of selenium (400 to $1,000 \mathrm{mcg}$ daily, in divided doses), as research has shown that this
} 
me. Some of the patients had jaundice so bad that their eyes were a bright orange-yellow. I was not put off by the sounds and smells of their sickness; I was too familiar with my own. I prayed and sang to the other patients, and to myself when everyone else was too sick to listen. I asked God to heal us all. ${ }^{70}$

Eventually, I also surrendered to the fact that my fate was out of my hands. I could pray, eat vegetables, think good thoughts and enjoy my life, but I could not control whether cancer would return. This was humbling to me. And in this humility, this acceptance that I might die no matter how hard I tried to live and to live well, brought to me a time of reflection. I reflected on what I wanted my life to look like. Did I want to stay home? Did I want to work? Did I want to make peace with those around me? Did I want to teach the world to read (as I had dreamed as a child)?

This time of reflection brought me back to how important education was becoming to me. I decided I needed to eventually get my doctorate. I decided that I had energy and commitment to offer and I wanted to teach college. I still wanted to teach the world to read. Struggle/Strengthen

For me, breast cancer and school are interrelated, because with the struggle of surviving breast cancer I developed the strength, focus and determination to get to the doctorate level. The ordeal of surviving breast cancer and the joy of pursuing my education have been interrelated throughout both journeys. Without the lessons learned from my

mineral clearly is involved in cancer prevention and treatment. According to Dr. Schachter, 'Selenium is the single most important mineral for fighting cancer"” (Diamond, Cowden \& Goldberg, 1997, p. 368).

\footnotetext{
${ }^{70}$ I especially remember a 30-year-old woman, Mary, who was dying of cancer. After misdiagnosing her for years, conventional American medicine had left Mary no options and the clinic in Mexico had offered to have her stay free of charge for two weeks to see if they could help. I can still see their three-year-old son, Nathaniel, and her husband, who appeared to me to be already in mourning like. It was hard to feel anything but blessed when I held Mary's translucent hand or looked at tow-headed Nathaniel.
} 
diagnosis and treatment, I would not have had the desire and determination to continue up each successive step of the educational ladder. And the focus I had to maintain in order to climb those educational steps assisted me in handling the emotional anguish of a lifethreatening disease.

Some of my earliest memories are of feeling like the only kid in the class to "not get it." The fear became even more real to me when I was in junior high school in the early 1960 's. At that time the school labeled me as not being "college material," so instead I was taught how to keep a set of books, take Gregg shorthand at 80 words per minute and type at about $45 \mathrm{wpm}$. My first job out of high school was in a factory, not unlike the place where my own father had worked for a quarter of a century. I wore a white lab coat and peered though a microscope to weld interconnects that were very small pieces of the "Mariner Mars Project." I felt discouraged about my opportunities in life, although somehow I picked up five units of college at Los Angeles City College.

I always had a job and I always worked hard. For almost a decade, I was a headhunter ${ }^{71}$ and then became the Director of Personnel for Jazzercise. While there, I acquired another six units of college credit in Executive Compensation at University of California at San Diego. At Jazzercise I gained the impression I might be smart enough to get an Associate of Arts degree and I learned that some of the women I worked with were going to college at National University. In my dealings and work-related discussions with these women I found that I was able to keep up. I began to wonder if I might make it at National. The same month I started at National University to get my A.A. degree I was diagnosed with breast cancer.

\footnotetext{
${ }^{71} \mathrm{~A}$ "headhunter" is someone who places others in jobs. The position is usually straight commission paid by the new employer. A more acceptable title is "Executive Search."
} 


\section{Reflections}

My transformation was relational and educational. Breast cancer led me to learn more about myself and to try new things. I found strength and the ability to calm myself by going to Al-Anon meetings, something I didn't consider until after I was diagnosed with breast cancer. I also found the strength in the struggle of breast cancer to continue my education. Like Krissy, I would ask myself, "Why the heck not?" Each success I had in treatment spurred me on to seek another success at school. Additionally, I found that as I became concerned about my health taking a step backwards, I found that attending school kept my energy going forward and counterbalanced dark thoughts. I have been transformed in my abilities to tackle some of my earliest insecurities concerning my capabilities. I can't remember a time before cancer when I didn't struggle with thoughts of being inadequate and stupid. I'm often surprised by the gift of confidence that surviving this disease has brought me.

Relationally, I have learned to respect the differences between my husband and myself. We now tackle problems together. We have faced many difficulties since the first diagnosis of breast cancer and we have been able to apply the wellspring of information we learned surviving breast cancer to these new problems. We are better communicators. When things are tough, I am more likely to listen and to be gentle and at the same time I feel I receive that type of respect from Jim. Before we would criticize the different ways we handled problems; now we are more likely to listen and learn from the other.

With the fear and dread of this disease there has also been a revelation and a celebration for a newfound spirit from which I draw greater levels of kindness, confidence and joy. 


\title{
CHAPTER IV
}

\author{
DISCUSSION \& IMPLICATIONS \\ "You Know, I'm Not Missing Anything. I'm probably Gaining Something \\ Out of This Whole Experience Because These Are New Experiences that \\ I Thought Would Never Be Possible."
}

Overview

This study involved interviews of seven women who self-identified as having a transformational experience in surviving breast cancer. The results from the previous section demonstrate the unique ways the women encountered their recoveries and resulting transformations.

Each story in this study connected to the others in individual, yet related, ways. Like the analogy used by DePree (1992) in Leadership Jazz, each woman during and after recovery took a stronger role playing the lead in her own life, and learned to be deliberate when she decided to let another lead. Each enjoyed the times they could join with others, but they now more often joined with others out of choice, not out of custom or blind need. As a result of surviving breast cancer, these women described a new and stronger identity within their lives (Collins, in press; Hirshberg \& Barasch, 1995). For example, Krissy discovered her desire to be an artist and Sherry incorporated more feminine features into her clothing line. Jorie and Judy decided to change drastically the stress levels in their work lives. Arlene, Samm and Dani became politically active.

When combined the stories of these women formed a type of jazz band. They described unique experiences relate to the diagnosis and treatment of breast cancer, and at the 
same time their stories carried similar rhythms or themes. The combined voices were those of women of differing ages, of differing backgrounds, with differing diagnoses and treatments, and their voices came together to offer hope and transformation to the millions who have been, and who will be, diagnosed with breast cancer.

Analysis of the journeys resulted in the development of five themes. These themes, in turn, provided the bases of a five-stage model regarding their transformational experiences. The model was presented graphically and is included in this work. A step-by-step explanation follows of how the themes were identified, how these themes became regarded as stages, and how the stages were developed into a model.

\section{The Five Themes Identified}

Similarities appeared within the topics and events discussed by the women of this study (using the transcriptions and the field notes). These similarities hinted at several broad themes. Using Polkinghorne's (1995) analysis of narratives, the themes became clearer. It also became apparent that the women had each experienced discernible progressions of similar, though unique, experiences. I found repeating patterns and identified underlying trends in the stories of the women. The women had described the often-unseen forces and progressions that had surrounded them through their remarkable recoveries and resulting transformations. Some of the most constant themes and progressions were identified categorized as themes.

I looked for practical and useful ways to explain their varied stories. I continued to look for simplicity in and among the complexities of these women and the events they chose to describe. I read and reread the stories dozens of times. I took a week sojourn alone and 
carried the transcripts and field notes with me. I slept with them on my bed. I even dreamt about the women and their stories.

Toward the end of that week, the first theme, Surprise/Suspense, became apparent. The second theme, Study, quickly followed. The third theme, Separation, started to emerge when rereading Krissy's story. She explained a number of ways she felt separated from her former life. She eloquently described how she felt people attributed new and amazing qualities to her because she was enduring chemotherapy and this awe of her felt (to her) like a separation. Krissy repeatedly used the word "separated" to explain how she felt different this side of cancer.

As I considered Krissy's feelings of separation, I looked again at the other stories and I found that each woman had experienced in her own way at least one kind of separation, such as from her previous way of life, from former expectations, from parts of her body, and, in Dani's case, from her fiancé.

Next, as I reread the stories I found that each of the women had a time of surrender that was closely followed by a time of reflection. Thus, the fourth theme of Surrender/Reflection took form. These two experiences were combined into one stage because they were inextricably linked in the stories. There was a balance that the women maintained between surrender and reflection. For example, each woman surrendered to a treatment and then had a time of reflection. This pattern sometimes repeated itself. For instance, each woman had to choose either lumpectomy or mastectomy. Each needed to decide how much of her body she was willing to surrender in order to improve her chance to live. Thus, Samm was clear that mastectomy was exactly the right choice for her, while Judy was not open to that option. 
Giving up parts of our bodies is not done lightly, and having such a profound experience provides fertile ground for discovery that we are more than our bodies and that we have possibilities that extend beyond our breasts. The decisions to have a lumpectomy or a mastectomy came to these women after deep reflection. The women redefined themselves out of necessity. It is important to note that the word surrender for this model is not a type of blindly giving up. "Surrender" in this work means an informed and gentle yielding to what is reality $\rightarrow$ a reality that cannot be changed. Surrender is not tight-fisted and forced; it is open handed and peaceful.

The fifth theme, Struggle/Strengthen, eventually emerged as I became aware that this theme was also a matter of balance, a type of trade-off. Their struggles and the lessons learned in those struggles became wellsprings of strength, as though the experience of cancer was like a gym where they worked out and became stronger. As they tackled new tasks they used the success of surviving cancer as a catalyst to become stronger. I thought of my own story, and I knew that as I struggled to survive this disease, I simultaneously watched myself survive this disease. Jorie reminded both of us during the interview that this was a good reason for self-admiration. She looked me in the eye and said to me, "I admire you. I admire anybody that has gone through a life-changing experience."

Indeed, the successes I had in surviving this disease became platforms for my next undertaking. When I finished chemotherapy and radiation in 1993, I was convinced that I could do anything —even get a college degree. This determination was born out of my struggle to survive. Each of these women had to deal with a life that had been forever changed by the diagnosis of a life-threatening disease. Each struggled with the fear of having 
her life shortened by cancer. And at the same time, each was strengthened by the battle and each found wider possibilities for her life.

\section{The Five Themes Became Stages}

The women in this study addressed salient issues of how humans handle personal crises. The five themes identified in the experiences and events described by the women began to appear as progressive stages. The descriptions of the topics and events described by the women had general similarities of experience. I considered whether or not my own journey through this disease fit within the stages. At that point I began to wonder if there might be a model. I was familiar with Hagberg's (1994) model for power, and I drew what I remembered of it. ${ }^{72}$

My own experience conformed to the themes described by the women. After identifying the five themes as progressive stages, I considered that a visual representation could be useful in understanding the experiences of the women of this study. I knew that the women in a broad sense were describing transformation and a type of newfound wisdom in the diagnosis and recovery of breast cancer. I turned to the Bible to consider ancient words about wisdom and found that wisdom is described as a woman.

\section{The Five Stages Became the Sophia Model}

The name for the model, Sophia, is found in the Torah, part of the Bible's Old Testament. In Proverbs 4:6-9, wisdom is referred to as "she." According to Johnson (1992): Another, even more explicit way of speaking about the mystery of God in female symbol is the biblical figure of Wisdom. This is the most developed personification of God's presence and activity in the Hebrew Scriptures, much

\footnotetext{
${ }^{72}$ Hagberg's work is explored a few pages hence.
} 
more acutely limned than Spirit, Torah, or word. The term itself is of feminine grammatical gender: bokmah in Hebrew, Sophia in Greek, and sapientia in Latin. (p. 87)

The women of this study connected to a deeper wisdom in their lives. This type of wisdom is described as follows:

Do not forsake wisdom, and she will protect you;

Love her, and she will watch over you.

Wisdom is supreme; therefore get wisdom.

Though it cost all you have, get understanding.

Esteem her, and she will exalt you;

Embrace her, and she will honor you.

She will set a garland of grace on your head

And present you with a crown of splendor.

(Holy Bible: Proverbs, 4:6-9)

In developing the model, I drew a line between the stages to identify whether the women described positive experiences (the line would go upward) or negative experiences (the line would go downward; see Appendix F). The first curve, which moves downward, depicts the negative feelings that the women described at, and immediately after, Surprise/Suspense. The icon for the first stage is a woman looking surprised, eyes wide open in apparent shock. The women described more positive moods and experiences during and after the Study stage. The icon for the second stage is a woman sitting at a desk with a computer. Study occurred in various ways, such as reading, or seeking expert advice. After Study, the line (or path) moves upward. The women described a series of more positive 
experiences as they went through the succeeding stages. So for the rest of the model, the line is ascending.

The icon for the third stage, Separation, presents three woman. The woman on the left represents the ways of thinking before diagnosis and treatment for breast cancer; the woman on the right is designed to represent potential future worries and fears. The woman in the middle is satisfied knowing that her past and her future are not as important as the present; her pose represents the ability to see the mistakes of the past, to sense an unclear future and to be grateful for this day. She is able to enjoy the moment.

The fourth icon represents Surrender/Reflection and shows a woman in a yoga position on her mat. Her face is calm and peaceful. The fifth icon shows a woman foreheadto-forehead with a bull, and displays determination and strength, emblematic of the Struggle/Strengthen stage.

I wanted to use icons, or figures, to represent the different stages of the Sophia model because I had found the representations that Hagberg $^{73}$ used assisted me to understand her model. I had also found that when I used her model for teaching, my students invariably found her graphic representations of the Stages of Power also helped them to understand her work.

I spent hours with a professional graphic artist explaining to him the transformation stages and the ways I saw, or felt, the women of this study projected as they explained their journeys through the five stages. For instance, in the Separation stage, we talked about how the women had actually three different experiences. In this stage they were turning away from the woman they had been, they were currently carefully looking at their current

\footnotetext{
${ }^{73}$ Hagberg's works is discussed a few pages.
} 
circumstances, and they were hyper-aware that the future would hold another realization or separation from their current situation. In short, they knew they were facing, and could watch themselves progress through, a dramatic time of change. They were in a time of transition. I wanted an icon to show this awareness in the midst of change. In the Surrender/Reflection stage, none of the women actually sat in a yoga pose, as the representation is shown on the model, but it appeared to me that they took on a calmer demeanor as they relayed this part of the story.

As part of my further development of the model, I considered other works that offered themes, or stages, which had proven to be a guide for hope to others. For a superb example, I studied the five stages of grief ${ }^{74}$ depicted by Elizabeth Kubler-Ross (1969). Her stages provided me, as well as countless others, strength and hope in the past. She elucidated the stages or progressions that many people experience as they grieve from a loss and developed her model to assist those who are dying, in part by explaining they are progressing through predictable stages. She feared that the medical profession had lost its heart in dealing with the terminally ill. Her book, On death and dying was based on the stories of men and women who were in the process of dying. The model emerged as she focused

\footnotetext{
74 The five stages of grief as defined by Kubler-Ross are: Denial/isolation, anger, bargaining, depression and acceptance.

1. Denial/Isolation. At first, we tend to deny the loss has taken place, and may withdraw from our usual social contacts. This stage may last a few moments, or longer.

2. Anger. The grieving person may then be furious at the person who inflicted the hurt (even if she is dead) or at the world for letting it happen. She may be angry with herself for letting the event take place, even if realistically nothing could have stopped it.

3. Bargaining. Now the grieving person may make bargains with God, asking, "If I do this, will you take away the loss?"

4. Depression. The person feels numb, although anger and sadness may remain underneath.

5. Acceptance. This is when the anger, sadness and mourning have tapered off. The person simply accepts the reality of the loss.
} 
on the patient as a human being, to include him in dialogues, to learn from him the strengths and weakness of our hospital management of the patient. We have asked him to be our teacher so that we may learn more about the final stages of life with all its anxieties, fears, and hopes. (p. i)

Kubler-Ross presented data and stages, but no (graphic) model. However, I was aware from a review of leadership literature that Hagberg (1994) had constructed a series of stages and that her stages were represented in a graphic model. In her work, Real Power, six stages of power ${ }^{75}$ were identified. Hagberg's model offered a graphic representation for individuals to assess their current stage of power. The model also offered suggestions for ways to move up the progressive stages of power. She posited that these stages were progressive, identifiable and distinct from each other. I used Hagberg's stages to identify and analyze personal power.

Similarly, the Sophia model offers benchmarks so that women can gauge and observe that the place where one begins in this disease is not where she ends. The model may offer at least a glimmer of hope in a woman's life at a time when a glimmer of hope is needed (and hard to find). Women may be able to see that the possibility exists that the end of breast cancer is not always death, or despair. At least for the women in this study on which this model is based, more meaningful, more interesting and intentional lives have resulted. The model demonstrates for the newly diagnosed that there are stepping-stones placed by the women who have been diagnosed before them that will assist them on their journeys to recovery and perhaps to transformation.

\footnotetext{
${ }^{75}$ Hagberg's stages are: Powerlessness, power by association, power by symbols, power by reflection, power by purpose, power by gestalt.
} 
The following is offered as a more in-depth review of the stages. A quote from one of the women of this study begins each section.

Details of Stage One-Surprise/Suspense: "This can't be happening to me"

Surprise is defined in Webster's Dictionary as “ To come upon suddenly or unexpectedly; take unawares, to attack without warning" (Webster's, 1987, p. 602). Suspense is defined as "a state of uncertainty" (p. 603). The women in this study experienced surprise and suspense in different ways.

Dani was 20 years old when she first noticed a BB-sized lump in her breast. She was a Division I varsity athlete. ${ }^{76}$ The doctors assured her she was too young to have cancer. Jorie found a lump on her breast while on her honeymoon, underwent a lumpectomy and several weeks of radiation, only to find within the next year a second lump that was aggressively malignant. Arlene had a 14-year gap between her first and second battle with this disease. Krissy's family history of breast cancer put her on guard to watch for the disease, only to discover a lump in her breast while on a family vacation far from home and shortly after a successful mammogram and physical exam. She was surprised even though Krissy's mother, grandmother and possibly her great grandmother all had breast cancer. Krissy had lived in hope that this disease would not take hold in her own body and life. Sherry, 42 years old, athletic, was not only surprised to find out she had breast cancer, but she was surprised to find herself being treated with all the compassion of that given to a lab rat. A parade of resident doctors treated her as a nameless, faceless object of only medical interest or curiosity. Sherry also spoke of having her physician misrepresent the size of her

\footnotetext{
${ }^{76}$ Division I level athletics is the most competitive level of college sports. This means that Dani was in top physical condition. She was playing basketball, a highly physical and demanding sport, against other "best of the best" female college athletes.
} 
tumor in an attempt to rush her into a clinical study. Samm, 46 years old, was totally surprised; there was no family history of cancer on either side or any other warnings. Judy was faithful in getting mammograms, and the most recent mammogram had showed her breast to be completely normal. Even while her mammograms continued to show normal tissue she experience pain in her left breast. She was first told it could not be breast cancer because breast cancer does not reveal itself by pain. An out-of-cycle mammogram detected the abnormality and Judy was then told in a public hallway for all to hear she had breast cancer. As for me, I exercised and ate well and had had normal mammograms in the past. I was totally unprepared for the "white dots" on my regular mammogram.

Wadler (1992) explained the circumstances of finding a lump in her breast. Wadler writes for the New York Times and for other publications. The afterward of her book, My Breast, is written by Dr. Susan Love, a surgeon mentioned in the beginning of this study and in Arlene's story. Wadler's story is in many ways similar to the stories of the women of this work.

Then, as I'm showering, I feel it: a large, egg-shaped swelling on the upper, inner part of my left breast. I have always wondered how women who discover lumps find them, but there is no missing this; it seems to be, as I move my hand around it, the size of an egg, slightly raised, sore to the touch. (p. 12)

Surprise/Suspense is the stage where the women in the study began to realize that their lives were about to change drastically. None of them talked about knowing at this stage that their life was going to improve, or that breast cancer was going to offer to them an opportunity to construct a transformed self. In fact, they all (as would be expected) spoke of 
fear and dread. They all agreed, as Sherry explained, that in this first stage "everything happens very quickly." For all of the women but one this stage progressed rather quickly. For Sherry it was just a matter of days between surprise and suspense, but for Samm it was three weeks. Dani is the outlier in the timing of this stage because it took almost a year for her to be able to get a physician to take her seriously enough to perform a biopsy. So she was in suspense that entire year.

Details of Stage Two-Study: "I want to get smarter than cancer."

Each of the women followed different paths of study. Dani conferred with eight specialists immediately, then actively sought the best medical advice available, at the national level, from physicians such as M. D. Anderson in Houston, in fact, she sought out two opinions there (and they even contradicted each other). Jorie's husband did the studying for them both and accompanied her on all medical appointments in a collaborative effort. Arlene sought to help herself by connecting to medical and political activists working for breast cancer research, and she helped others as she learned. Arlene and Dani spoke of studying their own laboratory reports, and Arlene traveled to San Francisco to obtain a second opinion concerning one of them.

Krissy was very familiar with breast cancer because of her family's history. Even with that, she obtained several medical opinions on her choices of treatment, and then involved her whole family in a debate of the alternatives. Sherry and her husband bought all the books they could find and read them the whole night through. Sherry and her husband also interviewed several doctors. Samm had a nearby expert—her neighbor who is an oncologist — who was consulted every step of the way. Judy found her way into a clinical trial involving quadruple doses of chemotherapy agents, and after barely surviving that she 
began to study and participate in alternative medicine regimens. As for me, my husband studied the disease, attended the consultations and took careful notes. We conferred after each appointment and went over (and over again) what the doctors had said. In addition, I became familiar with principles of Al-Anon (initially for a completely different reason than the disease) and used those principles in my recovery from breast cancer. Like Judy, I studied alternative medicine and decided not to sit around and wait to see if Western medicine had cured me. I opted for a three-week stay in a Mexican hospital, far from home in many ways.

Details of Stage Three-Separation: "I felt that I had just lost my old life."

There were many forms of separation described by the women. However, the three that follow were most prevalent. First, the women described how they felt they were separated from the rest of the world. Cancer brought the fear of death into their lives, and they felt separated from those who did not have or understand this fear. Second, surgeries for this disease separated them from parts of their bodies. Third, breast cancer sometimes separated them from previous relationships. (This also was a highly individualized stage.) Some poignant experiences, like the one that follows next with Dani, can fit all three forms of separation at the same time.

Dani suffered a sudden termination of her engagement to a man she once thought was "Mr. Right," shortly after she had a reoccurrence and just before they were set to go on a trip around-the-world. Arlene's separation was expressed more politically in her successful efforts, combined with the efforts of others, to have breast cancer treated as a separately studied and, most importantly, funded disease. This was a separation from Arlene's former life because she was now awakened into political activism, a totally new endeavor for her. 
Jorie felt her friends were treating her differently because they looked at her as though she magically had gained newfound wisdom from surviving breast cancer. Krissy stated it most eloquently when she wistfully commented that the breast cancer patient is separated from normal life. Sherry recalled how she felt separated when strangers treated her rudely during the period she was bald from chemotherapy. Ironically, she also noted how the solicitousness of friends could be trying and stressful, thus causing an ambivalence or uneasiness, at least for a time, in spending time with them.

Samm tried to connect with support groups and felt separated even from fellow breast cancer patients because of the anger she found in those groups. She also had to separate herself from the way she described her normal in-control persona. Judy also separated herself from sick people in waiting rooms, in laboratories, and at pharmacies. She separated from Western medicine and had to endure condescending remarks about her decision to seek alternative medicine regimens, not only from her doctors but also from co-workers and friends.

My experience was in parallel to the women, in some ways I felt like I "died to myself." I had always been blessed with a lot of energy and drive. However by enduring ten surgeries, chemotherapy and radiation I had to separate from the idea (at least for a time) that I was always going to have boundless energy. I also felt separated from others during those many times I felt like a leper. I have felt that sometimes others have wanted to avoid me because I was damaged goods - the cancer leper.

The awareness of our mortality separates those who have been diagnosed with a terminal disease from the rest of the population. Many people walk around thinking they are assured a long life, and each woman of this study knew she might die soon. After cancer 
diagnosis, our mortality stares us in the face each time we look in the mirror. Getting dressed and putting on a bra reminds us that we can't pretend with ourselves or our loved ones that we are invincible. A large portion of the world seemingly walks around convinced that death is a long way off-we survivors are not so sure.

The women in the study found themselves separated from their former bodies. All of the women of this study had parts of their bodies removed. Three had lumpectomies; four of them (plus me) had mastectomies. Arlene and I had a double mastectomy. It is hard to describe to those who have intact bodies what it is like to give up a part of our own bodies. We reminded ourselves that it is for the good of our whole body that we must give up parts of ourselves. We told ourselves that we wanted to live, and this was a small part of us to give up to make this happen. We had to talk ourselves into giving up all or parts of our breasts so that we could continue to live. For me, having a double mastectomy felt almost like a religious act, a sacrifice. I had to let parts of me die so that the larger part could survive. Wadler (1992) experienced separation from parts of her body in a different way. Wadler explained a conversation she had with her doctor after the diagnosis of breast cancer where they discussed breast surgery options. The doctor had just suggested to Wadler that she allow the doctor to make her breasts as small as possible to "reduce the amount of potentially dangerous breast tissue" (p. 104). Wadler responded to the doctor, "I've got a certain kind of body, I don't want to be Wadler the Pear-Shaped Girl. I have broad shoulders; I have a big chest; I have a big ass. What I mean is I want to keep things in proportion" (p. 104). Wadler continued telling how the doctor then said the "medical considerations have to come first." Wadler stated, "He seems to be suggesting that having had a diagnosis of cancer, 
I'm not entitled to the same degree of vanity as other women" (p. 104). This is described as her desire to not separate from her image of her former self.

All of the women in the study spoke of some people who were very supportive of the physical issues that surround breast cancer and the treatment, and all of the women talked of people who made them feel worse about themselves. Sherry told a story of how a woman left her with this message:

"You look so good. You have cancer and you look so good," like, "I can't believe that you have cancer and you look that good." Like I should be, like, the color of, like, jaundice.

The patronizing comments from, as well as the expectations of, others that we do, or should, look "really sick" caused further separation. These were hurtful nuisances that the women mentioned and something I often experienced as I went through treatments for this disease. When anyone tells me now that I look tired, I hear "sick," and I get angry or want to flee. This is a form of separation for me.

Details of Stage Four-Surrender/Reflection: "You have to accept your body all over again."

Surrender for this study is not about blindly giving up, but of accepting our boundaries and getting ready to receive. In this stage the women began to take a longer view of their lives and what they wanted to accomplish. As with the other stages, the women's experiences were unique. Dani surrendered herself to grueling and untested chemotherapy. Jorie's surrender involved acceptance of her altered physical appearance. Arlene reflected on how she wanted her dress designs to look, and she gave up her old designs. 
Krissy had to choose between a lumpectomy and a mastectomy, and has endured multiple surgeries in surrendering her breast. Her surrender is also found in her "giving up" even the memories of those events. In her words, she just "moved on." Krissy said she could hardly remember parts of the treatment process. Sherry was victimized by at least one acquaintance telling her a thoughtless "cancer story." After reflection Sherry gave up old patterns of socializing (pleasing and being polite) and now manages social interactions so as to insulate herself from those hurts by moving away—suddenly and rudely if necessaryfrom people who want to tell her "the bad stories" of others with cancer.

Samm had to learn to live with the somewhat accidental surrender of her private life to the media exposure surrounding her participation in the "Race for the Cure." She became active in that effort and has raised over $\$ 50,000$ for it. Judy surrendered to the fact that Western medicine, the medicine of her father, of her grandfather and of her own career, was leaving much undone to heal her and others. As for me, I had to conquer the depression that accompanied radiation therapy. My choices were to take more medication or try some other approach. After prayer and deep reflection, I vowed to overcome depression without still more drugs (I was already in chemotherapy). I also reflected on the benefits and promise of alternative medicine and while in the Mexican hospital surrendered myself to the sights, sounds and smells of the other patients, many of them very, very sick. I accepted that my fate was out of my hands.

Details of Stage Five-Struggle/Strengthen: "You are with someone who is a fighter." The participants of this study found that the struggle to survive breast cancer had given them an overall and newfound strength. They saw new accomplishments as they went through the difficult medical regimens, and they were proud of themselves. This spurred 
them on to greater accomplishments. In this stage, each rose above her former self and learned more about who she was. Power came from the knowledge of a successful struggle against breast cancer.

Dani's struggles occurred on many fronts, including blood transfusions, pain, fear, loss of "Mr. Right," and learning to date as a woman with one breast. Her "sales babe" persona was adapted to a new enterprise, that of working with cancer patients and cancer survivors to assist their journeys. Dani founded three support groups, helped create a "Cancer Park" near downtown San Diego, and now works in an oncology office.

Jorie's struggle brought her joy and a celebration of life. She transformed her work and enjoys a part-time, more relaxed method of earning a living. Arlene's struggle gained traction at the national and state levels of politics concerning funding and especially inception of the line-item check-off donation on the California state income tax return relating to breast cancer. She also assisted Hispanic women to obtain breast cancer screening and any treatments they needed.

Krissy's struggle and strength came in the form of "Why the heck not?" She was struggling through the ravages of chemotherapy when she decided to take herself seriously as an artist, and then later as a commercial artist. Sherry endured the agony of a needle location procedure, then as part of her recovery completely re-thought and re-designed her line of women's clothes. She also gained satisfaction by being a coordinator for the "Race for the Cure." Judy put herself in a clinical trial, survived quadruple-strength doses of chemotherapy, changed her way of thinking about medicine and found a lighter life in her long trips to the Bahamas for treatments. She turned her back on her job as a medical 
administrator, found she was an entrepreneur and created a successful business in the medical field.

As for me, my struggle with recovery was mirrored by my inner struggle to change my self-image regarding my potential as a student. Success in my medical arena instilled confidence for the next academic step.

Reactions from the Women of this Study to The Five Themes and to the Sophia Model

A letter (see Appendix C) was sent to the women of this study asking for their reactions to the five themes and to the Sophia Model. One of the women called immediately and said, "the stages work perfectly, [fit] exactly my experience." She added, the faces on the model were "perhaps a bit trite" and she wondered out loud if the faces were respectful enough to the experience of breast cancer.

Another said, "I recognize myself with Surprise, Study and Strength." As to Surrender/Reflection she said, "I reflected on wanting to see my grandchildren grow up, I wanted to enjoy them longer." She did not resonate with the theme, Separation. "No, I don't think so-I would say [there was] more intimacy with my husband, more wanting to be with others." She continued, "I did sometimes feel afraid of losing my life at an earlier age, but as time goes by, I feel better and look forward to a brand new day instead of a 'last day."'

Another woman responded, "Wow! This is right on! I've heard of people dealing with the grieving process after diagnosis and treatment, but that always seemed such a sad description. The Sophia model better describes what I went through, and continue to go through. Thanks so much for your wonderful insight!"

Another woman said, "I identify with these stages." She suggested a few words be added to the themes, "Nervous" to Surprise/Suspense and "Gathering Information" to Study. 
These comments added reliability to the themes and to the Sophia Model.

Interestingly, the women responded to the model in individual and unique ways, that were just as varied as their reactions were to the diagnosis, treatment and recovery of breast cancer, as set forth in the main body of this work.

\section{Subsequent Stages}

Hagberg (1994), after proposing her six stages for power, stated:

I have a strong suspicion that there is a Stage Seven in this model of personal power. I have deliberately chosen not to describe the stage, probably because I had enough trouble describing people at Stage Six. My sense is that it would be called something like Power by Transcendence and that the crisis to overcome in order to reach it would be the crisis of being human. (p. 148)

Likewise, I want to leave room that the Sophia model may, with study by future scholars, contain one or more additional stages. Hence, the model is open-ended on the graphic.

\section{Conclusions}

Each of the women in this study experienced a transformed life as the result of surviving breast cancer. Five of the women (Jorie, Arlene, Krissy, Judy and Sherry) experienced a work-related transformation. Dani experienced both a personal and a professional transformation. Judy experienced a personal transformation regarding her views on medicine. I experienced a personal transformation on relational and educational levels. We all demonstrated that crisis can reveal character. 
Heifitz (1994) made a distinction between two different types of problems that we face, adaptive and technical. A technical problem is one that can be solved routinely. Examples of technical problems would be to set a broken arm, or to buy a house. Technical problems may involve complexity but a prototype has already been established, and by following a set of pre-established procedures the technical problem can be solved. However, an adaptive problem is defined this way:

Adapting to human challenges requires that we go beyond the requirements of simply surviving. In human societies, adaptive work consists of efforts to close the gap between reality and a host of values not restricted to survival. We perceive problems whenever circumstances do not conform to the way we think things ought to be. Thus, adaptive work involves not only the assessment of reality but also the clarification of values. (Heifitz, 1994, p. 33)

Each of the women in this study faced an adaptive challenge in recovering from this disease. They desired to survive and as they did so they brought into their lives formerly unthought of transformational possibilities. They wanted their remaining years to be better and more meaningful. Each demonstrated personal leadership and growth, including acceptance of what is and what isn't. These were presented in the interviews, and manifested in diverse ways, including through expressions in art, in fashion, in career changes, in entrepreneurship, in education, and involvement in breast cancer-related causes.

Although the experiences of each woman were unique, some broad categories of remarkable similarities were hidden in plain sight, as follows: (a) all avoided self pity; (b) as their recoveries progressed they took up more authority in their medical care; (c) most of the 
women spoke of a stronger connection with other women, especially other survivors; and (d) they all learned they were fighters. These similarities are discussed here briefly.

No self-pity. Each woman spoke about what it was like to lose part of her breast, or all of one or both breasts. Each addressed having to learn how to accept her post-treatment body. None of the women seemed to be embarrassed to discuss what they had lost. To the contrary, they spoke boldly about the partial or complete loss of their breasts. I found the women had pragmatic reactions to their new bodies, and their experiences aligned with my own. I would rather live with manufactured breasts than not live at all.

The women of this study showed gratitude for surviving this disease, and they were grateful for the lessons learned in the process. The women of this study all spoke more of gratitude than self-pity. As Dani said, "Pity is good for a weekend."

More authority in medical care. In the past, women had a very different experience with breast cancer than the women of this study have had. "Thirty years ago, when the disease went hidden behind euphemism and prostheses, medicine was a solid patriarchy, women's bodies its passive objects of labor" (Ehrenreich, 2001, p. 47).

Dani described how, before her diagnosis, she apologized to her doctor for being a "hypochondriac" as she pleaded for a biopsy. As her medical situation worsened, she took charge of her care. She traveled to cancer centers, researched clinical trials, and turned down a bone marrow transplant that was thought to be a state-of-the-art cure at the time and was endorsed by a senior oncologist of impeccable credentials. Judy was disappointed that since the 1950's there had been no significant Western medical advancement in treatment for cancer. She turned her back on conventional medicine and decided to become involved in sophisticated alternative medicine. Sherry at first allowed unnamed and unknown doctors to 
come in and "feel her lump." Later, she declined her doctor's insistence she become part of a clinical trial and decided to do what was best for her. I decided that eating Italian food was not going to boost my immune system, so I explored Alternative Medicine and spent three weeks in a Mexican hospital.

Stronger connections with other women. Arlene, Sherry, Samm and Dani have connected with local, state and national organizations to find the cure for breast cancer. These women donate countless hours to these organizations, and work side-by-side with other women (many of whom are survivors of breast cancer). Without being asked, all of the women (but one) spoke of talking to at least one other cancer survivor and encouraging those women through the adaptive process of cancer recovery.

Even though Dani and Sherry were the only women in this study who felt that support groups were helpful to them, support groups have been helpful to thousands of others. The other women in the study talked with less enthusiasm than Dani about attending support groups, and at the same time most of the women spoke of having renewed connections with women through the process of recovery. Ehrenreich (2001) reminds us that a few years ago support groups were discouraged:

The women's health movement, in which I was an activist in the seventies and eighties, legitimized self-help and mutual support and encouraged women to network directly, sharing their stories, questioning the doctors, banding together. It is hard now to recall how revolutionary these activities once seemed, and probably few participants in breast cancer chat rooms and message boards realize that when post-mastectomy patients first proposed meeting in support groups in the mid-1970's, the American Cancer Society 
responded with a firm and father "no." Now no one leaves the hospital without a brochure directing her to local support groups and at least in my case, a follow-up call from a social worker to see whether I am safely ensconced in one. (Ehrenreich, p. 47)

"You are with someone who is a fighter." Lastly, the women of this study learned that they were fighters. They learned how to tackle a tough problem head-on. They watched themselves as they battled through diagnosis, treatment and recovery and they now know that they know how to fight. They have gained the confidence that comes from winning. The knowledge of their successful battles against breast cancer helps them to know they are prepared to win some of the other battles of life and can inspire the thousands and thousands of others who will be forced to take the same journey.

\section{Explanation of Tables/Appendices}

Attachments include tables highlighting the experiences of the women. Table 1 shows the Ages and Dates the women were diagnosed. Table 2 presents the Family Factors that the women discussed in their interviews. Table 3 describes the Methods of Diagnosis. Table 4 sets forth the Methods of Treatment. Lastly, Table 5 lists Other Factors.

Attachments include two letters to the participants. The first was sent to the participants asking them to go over their transcript for accuracy. The second letter was sent to have them provide feedback concerning the five stages and the model.

Additional attachments offer of advice from the women of the study to four different audiences: (a) to newly diagnosed women, (b) those that love them, (c) people who work or socialize with diagnosed women, and (d) the doctors who treat them. 


\section{Limitations}

The limitations of this study relate to the participants, study design, especially autoethnographic, geography and a paradox within the work itself.

Participants. First and foremost, not everyone diagnosed with breast cancer lives to tell her story; those tragic outcomes are not included in this work. Further, approximately $3 \%{ }^{77}$ of breast cancers occur in men. This study was not designed to address issues surrounding breast cancer in men. Second, not all women who are diagnosed with breast cancer self-identify as having a transformational experience. There is a wide range of potential experiences. These could include, but are not limited to: (a) finding the diagnosis of breast cancer to be an inconvenience; (b) finding the diagnosis of breast cancer to lead to prolonged or chronic depression; and (c) having the diagnosis of breast cancer lead to death.

Of the participants in this study, one is a Hispanic American born in Costa Rica, one is part Native American, and the rest are White-Non-Hispanic. The educational level of the participants was not a focus of this study and was not addressed in the interview process. There was a range of ages at the point of interview, from 41 to 62 . However, there was a wider range of ages at time of diagnosis from 29 to 52 . A limitation may be in not having enough diversity in the sample.

All of the women appeared to me to be upper-middle class and were not faced with, not did they speak of issues of, not having adequate medical insurance or funds for care. ${ }^{78}$

\footnotetext{
${ }^{77}$ The American Cancer Society estimated that in 2002 some 1,500 new cases of invasive breast cancer would be diagnosed among men in the United States. Breast cancer is about 100 times more common among women. American Cancer Society, website http://www.cancer.org/docroot/CRI/content/CRI 2_4_1X What are the Keystatistics_for_male_breast_cancer_28.asp?sitearea $=$ \&level $=$.
}

${ }^{78}$ Although Dani ended up $\$ 70,000$ in debt, she was nevertheless able to obtain care and treatment. 
The fact that many diagnosed women do not have adequate medical insurance or other resources could be a topic for future studies.

Another limitation of this study is that all participants, except Dani, were married at the time of diagnosis and spoke of supportive husbands. This study may not address the specific concerns for unmarried women or those who have unsupportive husbands.

Study Design. This is a very small sample $(\mathrm{n}=7)$ from a very large population (two million women who are breast cancer survivors). These seven women may not provide a large enough sample to draw conclusions for the larger population.

This study is qualitative in nature and provides rich, deep data, but may not speak to the broader issues that might confront women who are not transformed by the experience of breast cancer. Because I was looking for women who self-identified as having a transformational experience, I excluded all others at the design level. This is a limitation.

Specific limitations to the autoethnographic design of this study are present. Because I am a fellow survivor there is a high probability that I had an insider's advantage (Sherif, 2001). Additionally, because I am a survivor the women may have felt more free to share their underlying stories of transformation. However, a trade-off may have occurred. At the same time that I had an "insiders advantage," I may have been too close to the subject matter for objectivity. Indeed, my doctoral Committee Chairperson voiced the concern at my proposal defense that I might not be disinterested enough to be able to analyze the data. Accordingly, I was encouraged to keep track of my own reactions and responses to the women of the study. My responses are often recorded in the telling of the stories of these women to address that concern. 
As an insider I may not have thought to ask questions that would have made the study more valuable. I may have made assumptions that someone unfamiliar with breast cancer would not have made. I may have overlooked areas of importance to this study because of my familiarity with the diagnosis, treatment and recovery from breast cancer.

Geographic. All of the women for this study live within San Diego County, California. Each of these women live in affluent areas of this county and most of these women would be considered at least middle class to upper middle class. ${ }^{79}$ Other than those differences these women have very similar experiences in culture and health care availability. All had strong support networks at the time of diagnosis and through recovery. To determine the experience with breast cancer of women in subordinated groups is important work to be done in future research.

Paradox. The first paradox of this work is that women demonstrated ways that they were transformed through the survival of this disease. And at the same time each of the women in the study would agree with Sherry, "I would not wish this disease on my worst enemy."

Another paradox is, as Arlene said, "Breast cancer puts you in connection with mortality and makes you realize that there is a beginning and an end, but if you think about it, this is the truth for anyone living today."

\footnotetext{
${ }^{79}$ Unlike many other cancers, women with more formal education and higher incomes have a higher risk of developing breast cancer than poorer, less educated women. Such measures of socioeconomic status ("SES") are probably indirectly related to cancer risk, and represent a constellation of behavioral and lifestyle choices that are yet to be fully understood. For example, data of invasive breast cancer incidence rates among women age 15 and older in Los Angeles County, comparing rates in the lowest SES group (least educated and poorest) to the highest (best educated and highest income) for women in the four major race/ethnic groups in California was gathered. In each race/ethnic group, women in the highest SES group have rates that are about 40 to 60 percent higher than in the lowest SES group. California Cancer Registry, website http://www.ccrcal.org/Spotlight/spotquotes2.html.
} 
The last paradox is central to this work. The women of this study described how the unwanted crisis of being diagnosed with breast cancer and surviving the treatments for this disease brought profound positive personal change and transformation. 


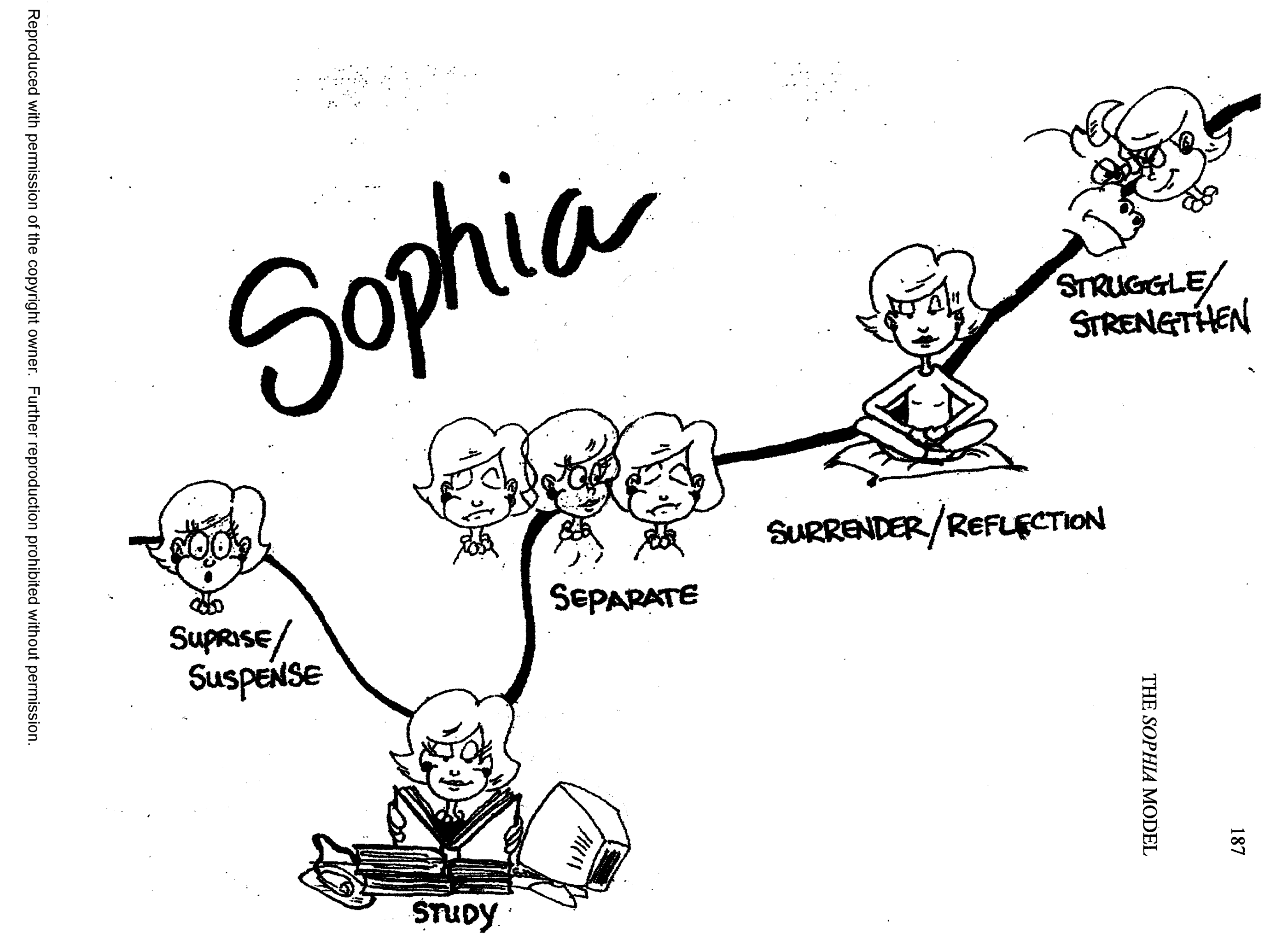




\section{REFERENCES}

Abu-Lughod, L. (1993). Writing women's worlds - Bedouin stories. Berkeley, CA:

University of California Press.

Al-Anon/Alateen. Retrieved February 1, 2003. website: http://www.al-anaon.alateen.org.

American Cancer Society. Retrieved October 10, 2001, through October 13, 2002, from: http://www.americancancersociety.org.

American Medical Association. Retrieved October 10, 2001, through October 13, 2002, from: http://ama.-assn.org/ama/pub/category.

Barnes, H. (1997). The story I tell myself: A venture in existentialist autobiography. Chicago: The University of Chicago Press.

Behar, R. (1993). Translated woman: Crossing the border with Esperanza's story. Boston: Beacon Press.

Behar, R. (1996). The vulnerable observer: Anthropology that breaks your heart. Boston: Beacon Press.

Bennis, W. (1996, January). The leaders as a storyteller. Harvard Business Review, 3-6.

Berkin, C. \& Horowitz, L. (Eds.). (1998). Women's voices - women's lives. Boston, MA: Northeastern University Press.

Bridges, W. (1980). Transitions: Making sense of life's changes. Reading, MA: AddisonWesley.

Bruner, J. (1986). Actual minds, possible worlds. Cambridge, MA: Harvard University Press.

Burns, J. (1978). Leadership. New York: Harpers Publishers. 
California Cancer Registry. Retrieved October 10, 2002 through February 2, 2003, from: http://www.ccrcal.org.

Cancernet. Retrieved January 31, 2003, from: http;//www.cancertnet.co.uk.

Chopra, D. (1997). Ageless body, timeless mind: The quantum alternative to growing old. New York: Random House.

Collingwood, H. (Ed.). (2001, December). Personal histories: Leaders remember the moments and people that shaped them. Harvard Business Review, 27-38.

Collins, J. (2001). Level 5 leadership: The triumph of humility and fierce resolve. Harvard Business Review, 67-76.

Collins, J. \& Porras, J. (1994). Built to last. New York: Harper Collins Publishing.

Collins, K. M. (in press). Ability Profiling and School Failure: One Child's Struggle to Be Seen as Competent. Lawrence Erlbaum Associates.

Collins, K. (Speaker). (2002). How can narrative forms of inquiry contribute to educational research? (Videoconference "Narrative inquiry and educational research"). Location of origin: Vanderbilt University, 2/19/02.

Davies, C. A. (1999). Reflexive ethnography. London \& New York: Routledge.

Denzin, N. K. (1989). Interpretative interactionism. Newbury Park, CA: Sage.

DePree, M. (1992). Leadership jazz. New York: Dell Publishing.

Diamond, W., Cowden, W., \& Goldberg. B. (1997). Alternative medicine definitive guide to cancer. Tiburon, CA: Future Medicine Publishing.

Dietrich, D. \& Shabad, P. (1989). The problem of loss and mourning: psychoanalytic perspectives. Madison, CT: International Universities Press, Inc. 
Donmoyer. R. (1990). Generalizability and the single-case study. In E. Eisner \& A. Peshkin (Eds.), Qualitative inquiry in education: The continuing debate (pp. 175-200). New York: Teachers College Press.

Eckmann, J. (1995). Breast cancer: Strategies for husbands to support their wives. San Diego: Nehemiah Publishing House.

Ehrenreich, B. (2001, November). Welcome to cancerland: A mammogram leads to a cult of pink kitsch. Harper's Magazine, 303, 43-53.

Ellis, C. \& Bochner, A. (2000). Autoethnography, personal narrative, reflexivity. In N.

Denzin \& Y. Lincoln (Eds.), Handbook for qualitative research (2 ${ }^{\text {nd }}$ Ed., pp. 733768). Thousand Oaks, CA: Sage Publications.

Frankl, V. (1984). Man's search for meaning (Beacon Press, Trans.). New York: Washington Square Press. (Original work published 1946).

Gardner, H. (1995) Leading minds: anatomy of leadership. New York: Harper Collins Publishers.

Gardner, J. (1990). On leadership. New York: Simon \& Schuster, Inc.

Gilligan, C. (1982). In a different voice: Psychological theory and women's development. Cambridge, MA: Harvard University Press.

Glesne, C. (1999). Becoming qualitative researchers: An introduction. New York: Addison Wesley Longman, Inc.

Gordon, Mary. (2002, January). Women of God. Atlantic Monthly, 58-91.

Gorman, C. (2002, February 18). The new thinking on breast cancer: The smartest drugs, the gentlest treatments, and the latest on mammograms. Time, 159, 50-58. 
Goodson, I. F. (1998). Storying the self: Life politics and the study of the teacher's life and work. In W. F. Pinar, (Ed.), Curriculum toward new identities. New York: Garland Publishing, Inc.

Gravel, A. (1995). The interplay of autobiography and ethnography: A rhetorical approach to autoethnography in women's writing. (Doctoral dissertation, Pennsylvania State University, 1995). UMI Dissertation Services.

Hagberg, J. (1994). Real power. Salem, WI: Sheffield Publishing Company.

Hagberg, J. (1995). Wrestling with your angels: A spiritual journey to good writing. Holbrook, MA: Adams Media Corporation.

Heifitz, R. (1994). Leadership without easy answers. Cambridge, MA: Harvard University Press.

Hirshberg, C. \& Barasch, M. (1995). Remarkable recovery. New York: Riverhead Books. Holy Bible, New International Version, (1984). Grand Rapids, MI: Zondervan Publishing. Jaworski, J. (1996). Synchronicity the inner path of leadership. San Francisco: BerrettKoehler Publishers.

Jackson, E. M. (1983). Coping with the crises in your life. New York: Aronson Publishing. Jacobowitz, R. (1993). 150 Most-asked questions about menopause. New York: Hearst Books.

Jacobowitz, R. (1993). 150 Most-asked questions about osteoporosis. New York: Hearst Books.

Johnson, E. (1992). She who is: The mystery of god in feminist theological discourse. New York: The Crossroad Publishing Company. 
Kotter, J. (1998). Why transformational efforts fail. In J. Collins \& J. Porran (Eds.). Harvard Business Review on Change (pp. 1-20). Cambridge, MA: Harvard University Press.

Lather, P. (1991). Getting smart: Feminist research and pedagogy within the postmodern. New York: Routledge.

Lather, P.\& Smithies, C. (1997). Troubling the angles: Women living with HIV/AIDS. Boulder, CO. Westview Press.

Lerum, K. (2001). Subjects of desire: Academic armor, intimate ethnography, and the production of critical knowledge. Qualitative Inquiry, 7, 466-483.

LeShan, L. (1994). Cancer as a turning point: A Handbook for people with cancer, their families, and health professionals. New York: Penguin.

Lincoln, Y. \& Guba, E. (1985). Naturalistic inquiry. Beverly Hills, CA: Sage Publications.

Locke, L. \& Spirduso, W. (2002). Proposals that work. Thousand Oaks, CA: Sage Publications.

Love. S. (1995). Dr. Susan Love's Breast Book. Los Angeles: Perseus Publishing.

Luria, A.R. (1968/1987). The mind of a mnemonist: A little book about a vast memory. Cambridge, MA: Harvard University Press.

McDougal, L. (1989). The research paper. Evanston, IL: McDougal, Little \& Company. Merriam, S. (1998). Qualitative research and case study applications in education. San Francisco: Jossey-Bass.

Miller W. \& Crabtree, B. (2000). Clinical Research. In. N. Denzin \& Y. Lincoln (Eds). Handbook for qualitative research $\left(2^{\text {nd }}\right.$ Ed., pp. 607-631). 
Mink, O. (Ed.). (1993) Change at work: A comprehensive management process for transforming organizations. San Francisco: Jossey Bass.

Montada, L. (Ed). (1992). Life crisis and experiences of loss in adulthood. Hillsdale, NJ: Lawrence Erlbaum Associates, Inc.

Moran, L. (1987). The anatomy of courage: The classic study of the soldier's struggle against fear. Garden City Park, New York: Avery Publishing Group, Inc.

Northouse, P. (2001). Leadership theory and practice. Thousand Oaks, CA: Sage Publications.

O'Brien, M. (1995). Profit from experience: How to make the most of the learning and your life. Austin, TX: Bard \& Stephen.

O'Toole, J. (1995). Leading change. San Francisco: Jossey-Bass.

Parker, P. (1996, Winter). Leading from within. Noetic Sciences Review, 69-74.

Patton, M. Q. (1997). Utilization-focused evaluation: The new century text. Thousand Oaks, CA. Sage.

Pert, C. (1997). Molecules of emotion: Why you feel the way you feel. New York: Simon \& Schuster.

Pierce, J. \& Newstrom, J. (1995). Leaders and the leadership process. Chicago: Austen Press.

Polkinghorne. D. (1988). Narrative knowing and the human sciences. Albany: SUNY Press.

Polkinghorne, D. (1991). Narrative and self-concept. Journal of Narrative and Life History, 1(2\&3), 135-153. 
Polkinghorne, D. (1995). Narrative configuration in qualitative analysis. Qualitative Studies in Education, 8 (1), 5-23.

Quinn, R. (1996). Deep change: Discovering the leader within. San Francisco: JosseyBass.

Remen, R. N. (1996). Kitchen table wisdom. Stories that heal. New York: Riverhead Books.

Ross, E. (1969). On death and dying. New York: Macmillian Publishing Company.

Rost, J. (1993). Leadership for the twenty-first century. Westport, CT: Praeger Publishing.

Rowe, P. (2002, November, 3) Chemicals, breast cancer: a strong link? San Diego Union Tribune.

Rubin, H. \& Rubin, I. (1995). Qualitative interviewing: The art of hearing data. Thousand Oaks, CA: Sage Publications.

Sandblom, P. (1999). Creativity and disease: How illness affects literature, art, and music. New York: Marion Boyars.

Sherif, B. (2001). The ambiguity of boundaries in the fieldwork experience: Establishing rapport and negotiating insider/outsider status. Qualitative Inquiry, 7, 436-447.

Spradley, J. (1979). The ethnographic interview. New York: Harcourt Brace Jovanovich College Publishers.

The Susan G. Komen Breast Cancer Foundation. Retrieved October 1, 2002 through October 20, 2002, from: http://www.komen.org.

Sykes, D. J. (1998). Family involvement in early childhood interagency collaborative efforts: Nine case studies. Unpublished dissertation, Ohio State University, Columbus.

Tirgan Oncology Associates. Retrieved October 1, 2002 through October 20, 2002, from: http://www.tirgan.com 
Van Mannen, J. (1998). Tales of the field on writing ethnography. Chicago: University of Chicago Press.

Van Manen, M. (1990). Researching lived experience. New York: The State University of New York.

Wadler, J. (1992). My breast. New York: Simon \& Schuster, Inc.

Wagner-Martin, L. (1994). Telling women's lives: The new biography. New Brunswick, NJ: Rutgers University Press.

Webster's new-world dictionary (3rd ed.). (1987). New York: Warner Communications.

Wolcott, H. (1990). Writing up qualitative research. Newbury Park, CA: Sage Publications. 
APPENDIX A

CONSENT FORM 


\section{University of San Diego, School of Education}

\section{Informed Consent Form}

Helen Eckmann, a doctoral student in the School of Education at the University of San Diego, is conducting a lived experience interview as part of the course requirements completion of her dissertation.

1. The interview will serve as a study of women who have been diagnosed and treated for breast cancer. The purpose of this research is to gain further insight into the experiences of these women and the impact this disease has had upon their lives.

2. Mild fatigue and the remembering of difficult times may be the results related to my participation in the interview process.

3. The interview will be audiotaped and transcribed for analysis. I understand that my identity will remain confidential, if I so desire. I also understand that I will be given transcripts of the audiotape to review and edit.

4. I can benefit from the opportunity to talk about my experience as a breast cancer survivor and to discuss both the negatives and the positives I have encountered while surviving.

5. My participation in this study is entirely voluntary and I understand I may refuse to participate or withdraw at any time without penalty. There are no expenses associated with this study for me to incur.

6. Helen Eckmann has explained the research project to me and answered my questions. I understand that if I have further questions, I may contact Helen Eckmann at any time at (858) 259-9230 or (858) 481-0848, or at eckmannh@aol.com by email.

7. There are no other agreements, written or verbal, related to this study beyond that expressed in this consent form.

8. I understand that I will participate in a forty-five to sixty-minute interview. Follow-up interviews may be scheduled in the future to obtain additional data and clarify details obtained during the initial interview.

9. My identity will be will remain confidential should I so desire and I will be assigned (or may ask to assign) a pseudonym in the transcription of the interview.

I, the undersigned, understand the above explanations and on that basis, consent to voluntary participation in this research.

Signature of Participant

Signature of Researcher
Date and Location

Date

Signature of Witness

Date 
APPENDIX B

LETTER TO PARTICIPANTS TO VERIFY TRANSCRIPTS 


\author{
Helen Eckmann \\ 421 Oceanview Avenue \\ Del Mar, CA 92014 \\ $858259-9230$ \\ eckmannh@aol.com
}

October 13,2002

\title{
Dear XXXX:
}

On XXXXX, you met with me and granted me an interview for my dissertation on breast cancer survivors. The topic is:

\section{"You are with someone who is a fighter"}

I am sending a copy of your transcript to you. Please look this over and see if I have misunderstood any of your words. You may keep this copy. I'm sending it to you so that you can let me know if I mixed up any of your words. If I did mix up something important an envelope (and postage) has been provided for you to return this to me so that you can correct them. I would need corrections and changes in the next 20 days in order to adjust the story before publication.

Once again, I want to thank you for your kindness in being part of this study. It has been pure joy for me to work on this project. Your story was rich and interesting and added greatly to the work. I interviewed a total of seven women and your story has been added to theirs to weave a tale about surviving breast cancer. One of the themes is that we are all different. Your story helps in many ways.

Once this is all completed and approved I'll give you a copy of the whole project if you like. Just let me know. Thank you again.

Blessings,

\section{Helen Eckmann}


APPENDIX C

LETTER TO PARTICIPANTS TO VERIFY

THEMES/MODEL 
February 3,2003

Dear Participant:

First, I want to thank you again for agreeing to be interviewed and to be a part of my doctoral dissertation at the University of San Diego. Because I am a survivor myself, this project has been a joy from start to finish. It is nearing completion. The title of the work is: "You are with someone who is a fighter."

I interviewed seven women for this study. I performed levels of analysis on the interviews. The first level was to interpret your individual stories of survival. The second level of analysis was to look at al of your stories and to find how your stories intersected (or didn't intersect) with each other. I looked for themes that all of you experienced through recovery of breast cancer. When this second level of analysis was completed I saw what looked to me live five major stages that each of you (and me, when I analyzed my own experience) experienced on the way to recovery.

I would appreciate it if you would once again consider your experience surviving this disease and look at the attached model. Please look to see if your experience connects to these broad themes. As you recall, each of you was asked a very broad opening question, and the interviews proceeded along the lines and in the directions each of you thought important. The questions I asked during the interviews essentially came from the directions your comments were taking us. There were no "set" questions, other than the grand-tour opening question. Even with this wide-open approach, and the equally wide variation in the topics each of you emphasized, it was significant that your disparate experiences had, in my view, these five themes in common.

The first theme was Surprise/Suspense. I noted from the interviews the participant spoke of being surprised by the diagnosis, even if there was a family history of breast cancer. This surprise was preceded by a period of suspense, varying from a few hours to weeks and even months, between the time a symptom was noted and a firm diagnosis.

The second theme was Study. I noted from the interviews the participant "studied" the disease, though often in differing ways. "Study" ranged from buying books to consulting with various doctors and clinics, and for some involved exploration of clinical trials.

The third theme was Separation. I noted from the interviews the participants described "separation" in various ways, such as separation from normal life, from parts of our bodies incident to surgery, and from relationships. Some spoke of feeling separated from normal friendly relationships, or an altering of those relationships.

The fourth theme was Surrender/Reflection. I noted from the interviews the participants faced acceptance of difficult surgical and medical choices and surrender to those procedures. 
Reflective thought was involved in those decisions. Acceptance of an altered physical appearance was often mentioned.

The final theme was Struggle/Strengthen. The interviews presented vivid descriptions of struggles with sickness, with anxieties, with changes and also, almost in the same breath, equally dramatic comments of how those struggles resulted in a strengthening of character, of resolve or of determination.

I sought a practical and useful way to present these themes, and the result is the enclosed graphic, or model, entitled "Sophia," from the Greek word for wisdom.

I would appreciate any comments you have about these themes and about the enclosed graphic by February 18,2003. I am very interested in learning if you found these themes to agree with your experience and also where you believe they do not. Enclosed please find a self-addressed, stamped envelope for your convenience in reply. You may also call your comments or e-mail them, as above.

Thank you again for your cooperation.

Very truly yours,

Helen L. Eckmann

Encls. (graphic and SASE) 
APPENDIX D

\section{KRISSY WITH HER ART}




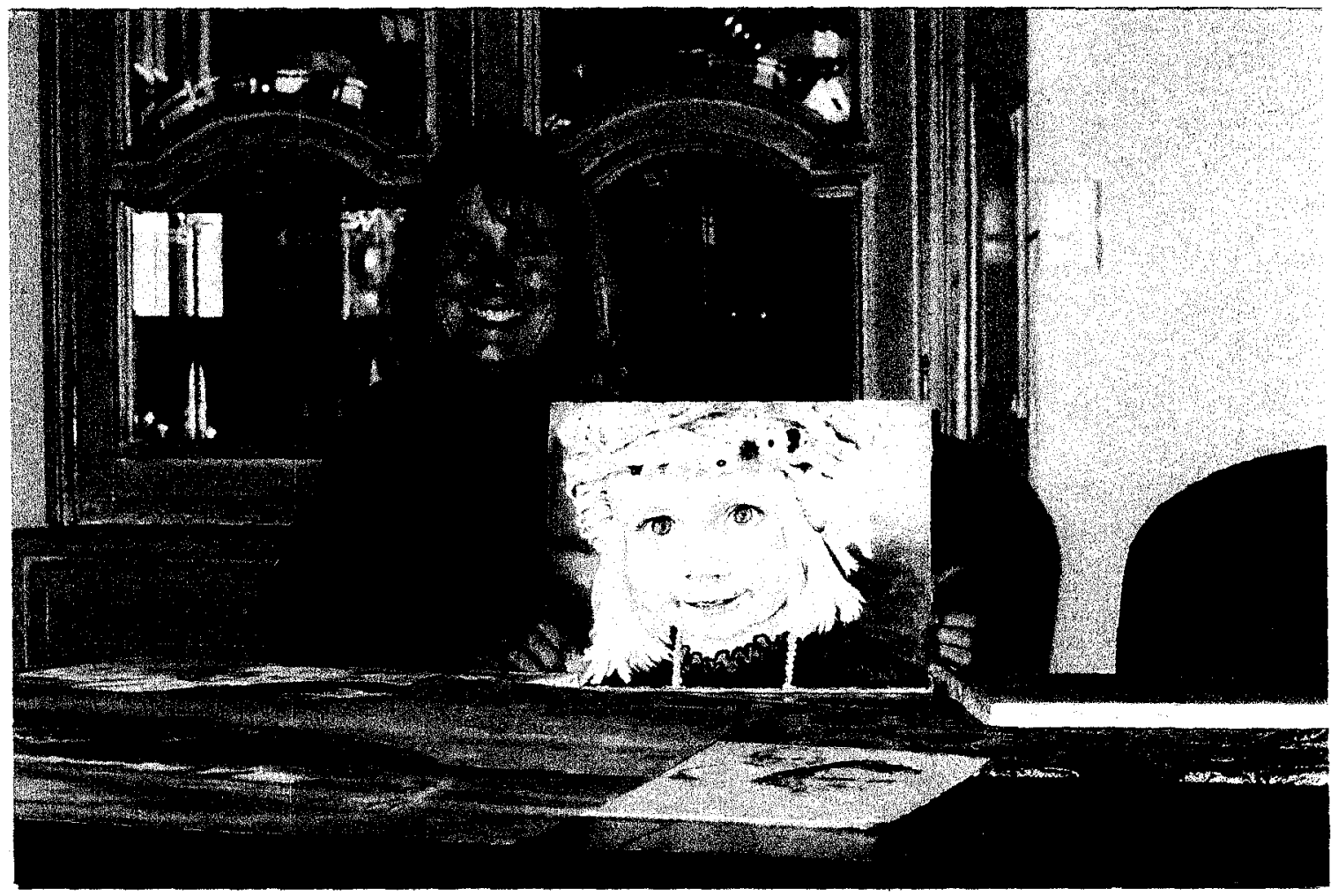


APPENDIX E

TABLES 
Table 1

Table of Ages and Dates at Diagnosis

\begin{tabular}{llllllll}
\hline & Dani & Jorie & Arlene & Krissy & Sherry & Samm & Judy \\
\cline { 2 - 7 } & 29 & 36 & $36 / 60^{*}$ & 40 & 42 & 46 & 52 \\
$\begin{array}{l}\text { Age at } \\
\text { diagnosis }\end{array}$ & 42 & 41 & 62 & 43 & 47 & 52 & 60 \\
$\begin{array}{l}\text { Age at } \\
\text { interview }\end{array}$ & 1987 & 1996 & $1976 / 1990$ & 1999 & 1998 & 1996 & 1992 \\
$\begin{array}{l}\text { Year } \\
\text { diagnosed }\end{array}$ & & & & & & \\
\hline
\end{tabular}

*Arlene was diagnosed twice with breast cancer 
Table 2

Family Factors

\begin{tabular}{llllllll}
\hline & Dani & Jorie & Arlene & Krissy & Sherry & Samm & Judy \\
\cline { 2 - 7 } $\begin{array}{l}\text { Family } \\
\text { history of } \\
\text { breast } \\
\text { cancer? }\end{array}$ & No & No & No & Yes & No & No & No \\
\cline { 2 - 7 } $\begin{array}{l}\text { Number } \\
\text { of } \\
\text { children }\end{array}$ & 0 & 1 & 2 & 4 & 0 & 1 & 2 \\
\cline { 2 - 7 } $\begin{array}{l}\text { Married at } \\
\text { time of } \\
\text { diagnosis? }\end{array}$ & No & $\begin{array}{l}\text { newly } \\
\text { married }\end{array}$ & Yes & Yes & Yes & Yes & Yes \\
\hline
\end{tabular}


Table 3

Methods of Diagnosis/Node Involvement

\begin{tabular}{|c|c|c|c|c|c|c|c|}
\hline & Dani & Jorie & Arlene & Krissy & Sherry & Samm & Judy \\
\hline $\begin{array}{l}\text { Did she find a } \\
\text { lump? }\end{array}$ & Yes & Yes & No & Yes & Yes & No & No \\
\hline $\begin{array}{l}\text { Did } \\
\text { mammography } \\
\text { detect initial } \\
\text { event? }\end{array}$ & No & No & Yes & No & No & Yes & Yes \\
\hline $\begin{array}{l}\text { Did she } \\
\text { experience } \\
\text { pain in her } \\
\text { breast? }\end{array}$ & No & No & Yes & Yes & No & No & Yes \\
\hline $\begin{array}{l}\text { Did she have a } \\
\text { needle biopsy? }\end{array}$ & Yes & Yes & Yes & Yes & Yes & Yes & Yes \\
\hline $\begin{array}{l}\text { Number of } \\
\text { nodes } \\
\text { with cancer. }\end{array}$ & $\begin{array}{l}\text { Yes, but } \\
\text { not } \\
\text { given }\end{array}$ & $\begin{array}{l}3 \text { or } 4 \\
\text { of } 14\end{array}$ & $\begin{array}{l}\text { Not } \\
\text { given }\end{array}$ & One & $\begin{array}{l}\text { Not } \\
\text { given }\end{array}$ & None & 11 of 22 \\
\hline
\end{tabular}


Table 4

Methods of Treatment

\begin{tabular}{|c|c|c|c|c|c|c|c|}
\hline & Dani & Jorie & Arlene & Krissy & Sherry & Samm & Judy \\
\hline $\begin{array}{l}\text { Clinical } \\
\text { trial? }\end{array}$ & $\begin{array}{l}\text { No, but } \\
\text { asked to } \\
\text { be }\end{array}$ & No & Yes & No & $\begin{array}{l}\text { No, } \\
\text { but } \\
\text { asked } \\
\text { to be }\end{array}$ & No & Yes \\
\hline Lumpectomy? & $\begin{array}{l}\text { Yes, but it } \\
\text { failed }\end{array}$ & Yes & No & No & Yes & No & Yes \\
\hline Mastectomy? & Yes & No & Yes & Yes & No & Yes & No \\
\hline Radiation? & Yes & Yes & Yes & Yes & Yes & No & Yes \\
\hline Chemotherapy? & $\begin{array}{l}\text { Quadruple } \\
\text { doses }\end{array}$ & Yes & Yes & Yes & Yes & No & $\begin{array}{l}\text { Quadruple } \\
\text { doses as } \\
\text { part of a } \\
\text { clinical } \\
\text { trial }\end{array}$ \\
\hline
\end{tabular}


Table 5

Other Factors

\begin{tabular}{|c|c|c|c|c|c|c|c|}
\hline & Dani & Jorie & Arlene & Krissy & Sherry & Samm & Judy \\
\hline $\begin{array}{l}\text { Wear a } \\
\text { wig? }\end{array}$ & No & No & No & Yes & No, hats & No & Yes \\
\hline $\begin{array}{l}\text { Support } \\
\text { group } \\
\text { experience? }\end{array}$ & $\begin{array}{l}\text { Yes, } \\
\text { helpful, } \\
\text { Started } \\
\text { her own }\end{array}$ & No & $\begin{array}{l}\text { Went, } \\
\text { but not } \\
\text { helpful }\end{array}$ & No & Yes & $\begin{array}{l}\text { Went, } \\
\text { but not } \\
\text { helpful }\end{array}$ & $\begin{array}{l}\text { Went, } \\
\text { helpful. }\end{array}$ \\
\hline $\begin{array}{l}\text { Alternative } \\
\text { medicine? }\end{array}$ & No & $\begin{array}{l}\text { No, but } \\
\text { do eat } \\
\text { better }\end{array}$ & No & $\begin{array}{l}\text { No, but } \\
\text { do eat } \\
\text { better }\end{array}$ & $\begin{array}{l}\text { No, but } \\
\text { do eat } \\
\text { better }\end{array}$ & $\begin{array}{l}\text { No, but } \\
\text { do eat } \\
\text { better. }\end{array}$ & Yes \\
\hline $\begin{array}{l}\text { Doctor } \\
\text { experiences? }\end{array}$ & Mixed & $\begin{array}{l}\text { Favor- } \\
\text { able }\end{array}$ & $\begin{array}{l}\text { Favor- } \\
\text { able }\end{array}$ & $\begin{array}{l}\text { Favor- } \\
\text { able }\end{array}$ & Mixed & $\begin{array}{l}\text { "We all } \\
\text { love our } \\
\text { doctors" }\end{array}$ & $\begin{array}{l}\text { Mixed, } \\
\text { but } \\
\text { mostly } \\
\text { negative }\end{array}$ \\
\hline $\begin{array}{l}\text { Political } \\
\text { now? }\end{array}$ & Yes & No & Yes & No & Yes & Yes & No \\
\hline
\end{tabular}


APPENDIX F

ADVICE FROM THE WOMEN 


\section{Advice from the Women of this Study \\ To Newly Diagnosed Women}

Do:

1. Remember your doctors are there to help you decide what is best for you to do to heal yourself.

2. Think of breast cancer is more of an emotional emergency than a medical emergency. Be sure that you take time to make any important decisions.

3. Remember your reaction to the treatments may be completely different than someone else. Some people have few side effects from chemotherapy, others get quite sick. Your response will be as individual as you are.

4. Think about the people who make you feel better about yourself, tell them, and include them in more plans for your week.

5. Try a support group and if it helps go back and if it doesn't, don't.

6. Take a nap, enjoy the sunset, pet your pet, smile at strangers.

7. Gently remind yourself that this too will pass.

Don't

1. Let anyone make you feel guilty for having breast cancer.

2. Be polite and let other people tell you "cancer stories" about people you don't know. Stop them immediately and tell them that telling you this story is not helping you. They won't get it - tell them again to stop. If they persist turn around and walk away. Tell someone that loves you to keep that person a million miles away from you for a long time (maybe forever).

3. Let your doctors rush you into anything. You always have time for a second opinion.

4. Try to help your family or others. You are the one with the medical situation. Let them take care of themselves for a while.

5. Feel like you need to do as much as you did before (unless you want to do more).

6. Worry about how you look, other people are too wrapped up thinking about how they look to notice you.

7. Spend time with people who bring you down (even if they are family). 
Advice from the women of this study

To someone who loves someone who has just been diagnosed with breast cancer

1. First we thank you for reading this. The fact that you are reading this demonstrates that you will be able to help.

2. Remember a newly diagnosed person often feels guilty for getting this disease. Do your best to remind her she didn't make herself sick.

3. Support her in whatever decision she makes. If she decides to take dancing lessons, go with her. If she does not want to participate in a particular medical treatment discuss it with her - but don't infantize her by acting like you know better for her than she does.

4. Remember that each woman's experience through this disease is individual. Some will want to tell her families right away, others will want to keep the information quiet for as long as possible. Some women will be more angry while others will be more melancholy, or others may find humor at new unexpected and interesting times.

5. Never tell her that she looks tired - never!

6. Take her out to dinner. Tell her you like her smile.

7. Keep people away who bother her. Don't make her explain why.

8. Offer to pick up her clothes at the dry cleaners, go to the grocery store. Drop off a good book to read. If she has children offer to pick them up from school. Drop off dinner once a month. Go with her to doctor appointments.

9. Pray for her. 


\section{Advice from the Women of this Study}

To Someone Who Works with or Socializes with a Woman Who is Newly Diagnosed with Breast Cancer

1. Never tell her a story about anyone else you know who has cancer.

2. Never tell her a story about anyone else you know who has cancer.

3. Don't let anyone in your presence tell her a story about someone else's battle with cancer. (She will find the stories that will help her on her own).

4. If you feel that you must put her in contact with another breast cancer survivor then ask her if she would like to have the number of another survivor. If she calls then it will be helpful, if not, it won't.

5. If she is participating in an event where you can sponsor her - please do - this is a real encouragement.

6. Cards and letter are often appropriate and helpful (Be careful of \#1 and \#2 above).

7. Ask her what you could do to make it more convenient or comfortable for her to accomplish her tasks 
Advice from the Women of this Study

\section{To the Doctors that Treat Women with Breast Cancer}

1. Let us know as soon as humanly possible what the results from our tests are.

2. Give us all of the information we need in order to make good decisions for ourselves.

3. Explain all of our options until we understand them completely.

4. Treat our breasts as important, but not more important than our lives.

5. Know that our tears and frustration are often connected to our strength.

6. Never take away our hope.

7. Please find the cure for this disease. 